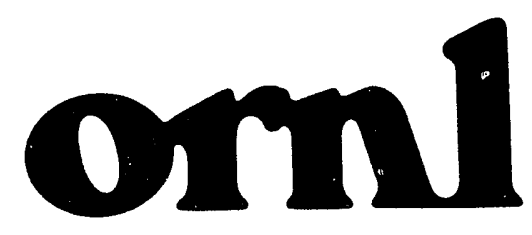

OAK RIDGE NATIONAL LABORATORY
MARTIN MARIETTA

ORNL/TM-11923

\title{
Validation of a PC Based Program for Single Stage Absorption Heat Pump
}

\author{
A. Zaltash \\ M. R. Ally
}


This report has been reproduced directly from the best available copy.

Available to DOE and DOE contractors from the Office of Scientific and Technical Information, P.O. Box 62, Oak Ridge, TN 37831; prices avaliable from (615) 576-8401, FTS 626-8401.

Available to the public from the National Technical Information Service, U.S. Department of Commerce, 5285 Port Royal Rd., Springfield, VA 22161.

This report was prepared as an account of work sponsol _. by an agency of the United States Government. Neither the United States Government nor any agency thereof, nor any of their employees, makes any warranty, ex|;iess or implied, or assumes any legal liability or responsibility for the accuracy, completeness, or usefulness of any information, apparatus, product, or process disclosed, or represents that its use would not infringe privately owned rights. Reference herein to any specific commercial product, process, or service by trade naine, trademark, manufacturer, or otherwise, does not necessarily constitute or imply its endorsement, recommendation, or favoring by the United States Government or any agency thereof. The views and opinions of authors expressed herein do not necessarily state or reflect those of the United States Government or any agency thereof. 


\title{
VALIDATION OF A PC BASED PROGRAM FOR SINGLE STAGE ABSORPTION HEAT PUMP
}

\author{
A. Zaltash \\ Energy Division \\ Oak Ridge National Laboratory \\ and \\ M. R. Ally \\ Energy Division \\ Oak Ridge National Laboratory
}

Final Report - September 1991

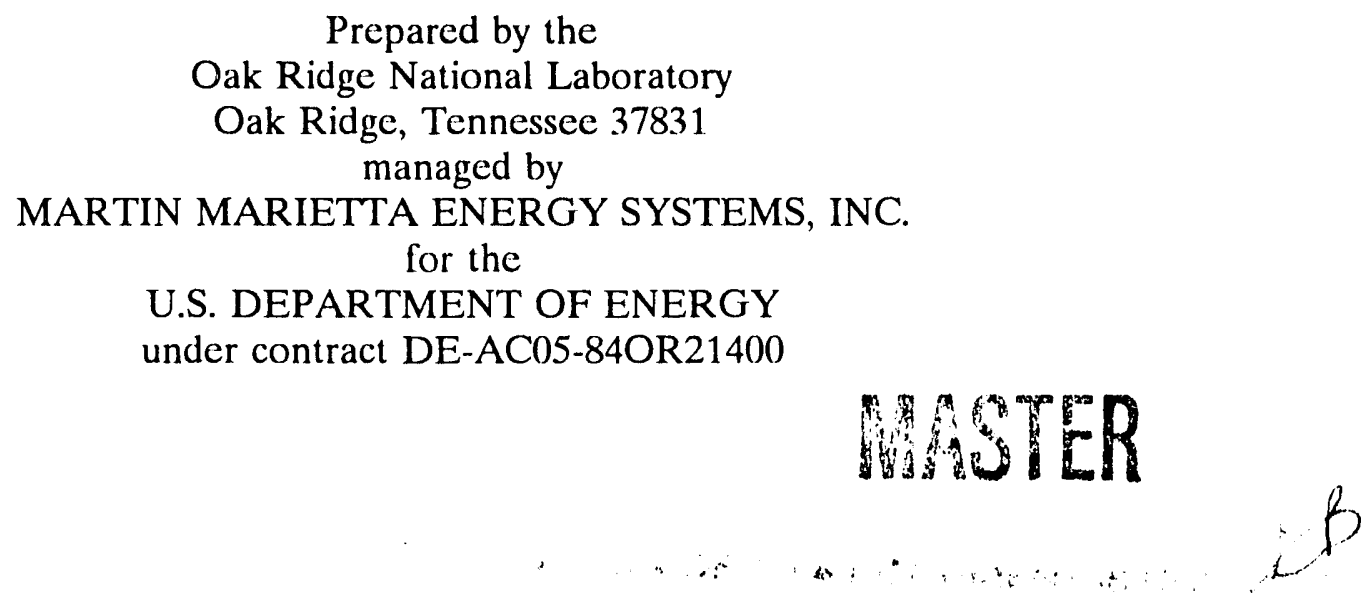




\section{TABLE OF CONTENTS}

LIST OF TABLES $\ldots \ldots \ldots \ldots \ldots \ldots \ldots \ldots \ldots \ldots \ldots \ldots \ldots \ldots \ldots \ldots \ldots$

LIST OF FIGURES $\ldots \ldots \ldots \ldots \ldots \ldots \ldots \ldots \ldots \ldots \ldots \ldots \ldots \ldots \ldots \ldots$

NOMENCLATURE $\ldots \ldots \ldots \ldots \ldots \ldots \ldots \ldots \ldots \ldots \ldots \ldots \ldots \ldots \ldots \ldots$ vi

PREFACE $\ldots \ldots \ldots \ldots \ldots \ldots \ldots \ldots \ldots \ldots \ldots \ldots \ldots \ldots \ldots \ldots \ldots \ldots \ldots \ldots$

ABSTRACT $\ldots \ldots \ldots \ldots \ldots \ldots \ldots \ldots \ldots \ldots \ldots \ldots \ldots \ldots \ldots \ldots \ldots \ldots \ldots \ldots$

EXECUTTVE SUMMARY $\ldots \ldots \ldots \ldots \ldots \ldots \ldots \ldots \ldots \ldots \ldots \ldots \ldots \ldots \ldots$

1. INTRODUCTION $\ldots \ldots \ldots \ldots \ldots \ldots \ldots \ldots \ldots \ldots \ldots \ldots \ldots \ldots \ldots \ldots$

2. DESCRIPTION OF THE COMPUTER CODE $\ldots \ldots \ldots \ldots \ldots \ldots \ldots \ldots \ldots$

3. CYCLE ANALYSIS ON THE LIQUID-VAPOR ABSORPTION HEAT PUMP $\ldots \ldots \ldots 2$

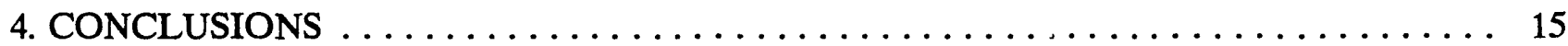

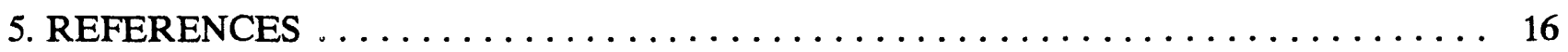

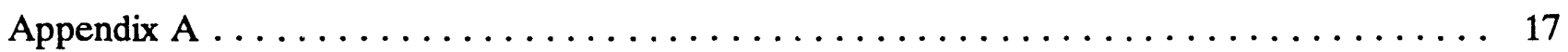

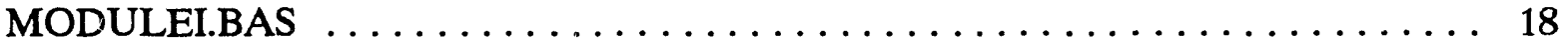

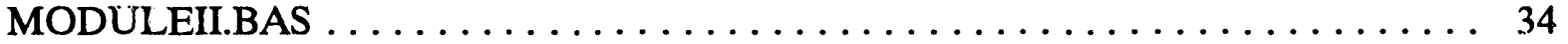

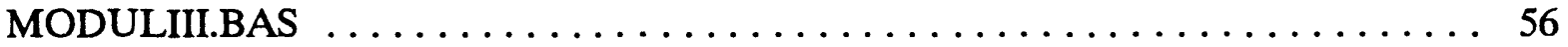

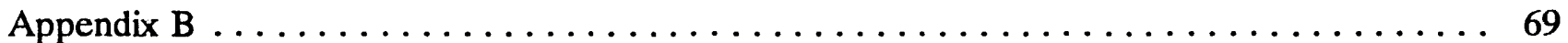




\section{LIST OF TABLES}

Table 1. Operating parameters in the TA mode for $70 \mathrm{wt} \% \mathrm{LiBr} /$ water system from HEATPUMP program $\ldots \ldots \ldots \ldots \ldots \ldots \ldots \ldots \ldots \ldots \ldots \ldots \ldots \ldots \ldots$

Table 2. Operating parameters in the TA mode for $70 \mathrm{wt} \% \mathrm{LiBr} /$ water system from

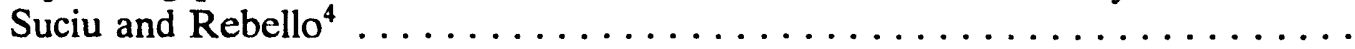

Table 3. Operating parameters in the TA mode for $90 \mathrm{wt} \%(\mathrm{Li}, \mathrm{K}, \mathrm{Na}) \mathrm{NO}_{3} /$ water system from HEATPUMP program $\ldots \ldots \ldots \ldots \ldots \ldots \ldots \ldots$

Table 4. Operating parameters in the TA mode for $90 \mathrm{wt} \%(\mathrm{Li}, \mathrm{K}, \mathrm{Na}) \mathrm{NO}_{3} /$ water system from Davidson and Erickson ${ }^{1} \ldots \ldots \ldots \ldots \ldots \ldots \ldots \ldots \ldots \ldots$

Table 5. Operating parameters in the HA mode for $52.8 \mathrm{wt} \% \mathrm{LiBr} /$ water system from HEATPUMP program $\ldots \ldots \ldots \ldots \ldots \ldots \ldots \ldots \ldots \ldots \ldots \ldots \ldots \ldots \ldots \ldots$

Table 6. Operating parameters in the $\mathrm{HA}$ mode for $52.8 \mathrm{wt} \% \mathrm{LiBr} /$ water system from Davidson and Erickson ${ }^{1} \ldots \ldots \ldots \ldots \ldots \ldots \ldots . . \ldots \ldots$

Table 7. Operating parameters in the HA mode for $73 \mathrm{wt} \%(\mathrm{Li}, \mathrm{K}, \mathrm{Na}) \mathrm{NO}_{3} /$ water system from HEATPUMP program $\ldots \ldots \ldots \ldots \ldots \ldots \ldots \ldots$

Table 8. Operating parameters in the $\mathrm{HA}$ mode for $73 \mathrm{wt} \%$ ( $\mathrm{Li}, \mathrm{K}, \mathrm{Na}) \mathrm{NO}_{3} /$ water

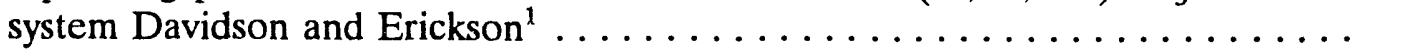

Table 9. Summary of Base Values of Operating Parameters for $(\mathrm{Li}, \mathrm{K}, \mathrm{Na}) \mathrm{NO}_{3} /$ water

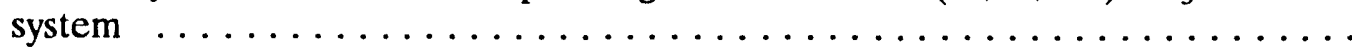

Table 10. Summary of Base Values of Operating Parameters for $\mathrm{LiBr} /$ water system $\ldots \ldots \quad 8$

Table 11. Effect of solution temperature leaving the absorber in TA mode for $(\mathrm{Li}, \mathrm{K}, \mathrm{Na}) \mathrm{NO}_{3}$ /water system

Table 12. Effect of solution temperature leaving the absorber in TA mode for

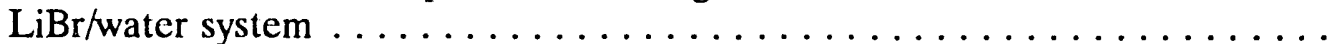

Table 13. Effect of solution temperature leaving the absorber in HA mode for $(\mathrm{Li}, \mathrm{K}, \mathrm{Na}) \mathrm{NO}_{3} /$ water system .

Table 14. Effect of solution temperature leaving the absorber in HA mode for $\mathrm{LiBr} /$ water system 


\section{LIST OF FIGURES}

Figure 1. Total (UA) and COP values (TA mode) as a function of solution temperature leaving the absorber for $90 \mathrm{wt} \%$ ( $\mathrm{Li}, \mathrm{K}, \mathrm{Na}) \mathrm{NO}_{3}$ mixture leaving the

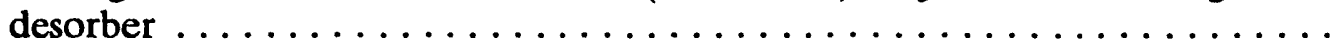

Figure 2. Total (UA) and COP values (HA mode) as a function of solution temperature leaving the absorber for $73 \mathrm{wt} \%(\mathrm{Li}, \mathrm{K}, \mathrm{Na}) \mathrm{NO}_{3}$ mixture leaving the

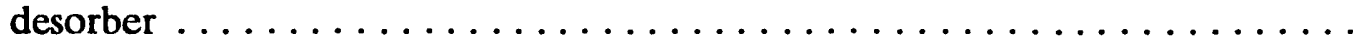

Figure 3. Total (UA) and COP values (TA mode) as a function of solution temperature leaving the absorber for $70 \mathrm{wt} \% \mathrm{LiBr}$ mixture leaving the desorber . . . . . . .

Figure 4. Total (UA) and COP values (HA mode) as a function of solution temperature leaving the absorber for $52.8 \mathrm{wt} \% \mathrm{LiBr}$ mixture leaving the desorber . . . . . . 


\section{NOMENCLATURE}

A

COP

$\mathrm{COP}_{\mathrm{nm}}$

$[\mathrm{LiBr}]$

$\left[(\mathrm{Li}, \mathrm{K}, \mathrm{Na}) \mathrm{NO}_{3}\right]$

$\Delta \dot{\mathrm{m}}_{\text {conc. }}$

$\mathrm{P}$

Q

$[\text { salt }]_{\mathrm{abs} \text { out }}$

$\mathrm{T}_{\text {abs. out }}$

$\mathrm{T}$

U

$\mathrm{X}$ heat transfer surface area

coefficient of performance

net measured coefficient of performance

concentration of $\mathrm{LiBr}$

concentration of $\mathrm{LiBr}$

concentrated solution mass flow rate

pressure

total heat transfer

concentration of solution leaving the absorber

temperature of solution leaving the absorber

temperature

overall heat transfer coefficient

operating parameter under consideration $\left(\mathrm{ft}^{2}\right)$

(wt\%)

(wt\%)

(lb/hr)

(psia)

(Btu/hr)

$(w t \%)$

$\left({ }^{\circ} \mathrm{F}\right)$

$\left({ }^{\circ} \mathrm{F}\right)$

(Btu/hr- ${ }^{\circ} \mathrm{F}-\mathrm{ft}^{2}$ ) 


\section{PREFACE}

This document was prepared for the U.S. Department of Energy (DOE) Office of Industrial Technologies (OIT) as part of the OIT Chemical Heat Pump Study. 


\begin{abstract}
An interactive computer code was developed to evaluate single stage absorption heat pump performance for temperature amplifier and heat amplifier modes using water as the refrigerant. This program performs the cycle calculations for single stage cycles based on the polynomial expressions developed to correlate experimental vapor-liquid-equilibrium (VLE) and specific enthalpyconcentration data for $\mathrm{LiBr} /$ water and $(\mathrm{Li}, \mathrm{K}, \mathrm{Na}) \mathrm{NO}_{3}$ /water systems as well as the properties of pure water. The operating parameters obtained by this program were tested against mass and energy balances in documented cases and the results show that the maximum deviation between coefficient of performance (COP) values obtained by this software and the ones previously calculated is less thar. $3 \%$. In addition, this program was used to study the effect of solution temperature leaving the absorber on the other operating parameters. This type of analysis could be used to improve and optimize cycle design.
\end{abstract}




\section{EXECUTTVE SUMMARY}

This report contains the results obtained by an interactive computer code developed to evaluate single stage absorption heat pump performance for temperature amplifier and heat amplifier modes using water as the refrigerant. This program performs the cycle calculations for single stage cycles based on the polynomial expressions developed to correlate experimental vapor-liquidequilibrium (VLE) and specific enthalpy-concentration data for $\mathrm{LiBr} /$ water and $(\mathrm{Li}, \mathrm{K}, \mathrm{Na}) \mathrm{NO}_{3} /$ water systems as well as the properties of pure water. The operating parameters obtained by this program were tested against mass and energy balances in documented cases and the results show that the maximum deviation between coefficient of performance (CUP) values obtained by this software and the ones previously calculated is less than $3 \%$. In addition, this program was used to study the effect of solution temperature leaving the absorber on the other operating parameters such as net measured COP, total heat transfer area (UA), and solution mass flow rate. Results show that the required UA as a function of solution temperature exhibits a minimum which could be used to determine the optimum cycle design. 


\section{INTRODUCTION}

An interactive computer code was developed to evaluate heat pump performance for a particular absorption heat pump configuration (single stage in temperature amplifier and heat amplifier modes) and working fluid (using water as the refrigerant). The performance of a heat pump containing $\mathrm{LiBr} /$ water solution or $(\mathrm{Li}, \mathrm{K}, \mathrm{Na}) \mathrm{NO}_{3}$ /water mixture can be calculated using data contained in the Duhring charts and specific enthalpy versus concentration diagrams which were presented algebraically, by polynomial equations. ${ }^{1,23}$ In addition, this prograrn uses the polynomial expressions obtained for the properties of pure water (refrigerant).

The results of this program were checked against the cycle analysis (mass and energy balances) given by Suciu and Rebello ${ }^{4}$ and Davidson and Erickson. ${ }^{1}$ In addition, this program is used to study the effect of the absorber outlet temperature on the other cycle parameters.

\section{DESCRIPTION OF THE COMRUTER CODE}

The computer code is written in QuickBasic 4.5 for cycle analysis (mass and energy balances) on the liquid-vapor, ( $\mathrm{Li}, \mathrm{K}, \mathrm{Na}) \mathrm{NO}_{3}$ /water and $\mathrm{LiBr}$ /water, single stage absorption heat pump. Mass and energy balances can be performed in temperature amplifier (TA) and heat amplifier (HA) modes. The program is divided into three modules (MODULEI.BAS, MODULEII.BAS, and MODULIII.BAS). The listing of these modules is given in Appendix A. The code listing appended to the report is useful to the users interested in studying and/or expanding this computer code to include more fluids with the help of the documentation supplied in the modules (main program and subroutines).

The executable form of this program is HEATPUMP.EXE which can be run on a regular PC with VGA or EGA graphics card; a copy of which is provided with this report for your use. If the appropiate graphics card is not available, this program will bypass the logos provided with this code. These logos include block diagrams of single stage cycle in TA and HA modes. To run the program, type HEATPUMP and hit <ENTER>, the rest should be self explanatory.

This program is written with the assumption that the user is familiar with the single stage absorption heat pump. A brief description of the input parameters for the TA and HA modes is provided to prepare the user for the type of inputs required to perform the desired cycle analysis. The program accepts the inputs in severa' units by toggling between them, however, the outputs are given in English units. The program gives the user the option of entering the inputs in the individual screen format or in the tabular format. In either case, the user has the option of changing the units of each input and/or going back to change any of the inputs. This program uses the approach temperatures to calculate the required heat transfer area (UA) in each of the units (absorber, condenser, evaporator, desorber, and solution heat exchanger).

The computer code is furnished with a routine which checks each stream to make sure that the solution in the streams is above its corresponding crystallization temperature. If this condition should arise, the program gives the user a warning for possible crystallization and the stream where the crystallization may occur. In this case, the user has to re-evaluate and re-enter the inputs. 


\section{CYCLE ANALYSIS ON THE LIQUID-VAPOR ABSORPTION HEAT PUMP}

This program was tested in the TA mode against the mass and energy balances given by Suciu and Rebello ${ }^{4}$ and Davidson and Erickson. ${ }^{1}$ Tables 1 and 2 show the results from HEATPUMP program and Suciu and Rebello 4 respectively $(70 \mathrm{wt} \% \mathrm{LiBr} /$ water solution, $[\mathrm{LiBr}]=70 \mathrm{wt} \%)$. The absorber output capacity is $2 \mathrm{MM} \mathrm{Btu} / \mathrm{hr}\left(2 \times 10^{6} \mathrm{Btu} / \mathrm{hr}\right)$. The deviation between parameters is very small (Tables 1 and 2) except in the pressure and concentration of the solution entering the generator. This is due to a more accurate throttle calculation in the computer code. Throttling is a constant enthalpy (isenthalpic) process with a decrease in temperature and pressure which results in a mixture of liquid solution and water vapor. The coefficient of performance (COP) obtained by this software is 0.483 which compares well with the value of 0.481 calculated by Suciu and Rebello. ${ }^{4}$ Tables 3 and 4 show the results obtained from the program and Davidson and Erickson ${ }^{1}$ respectively, $90 \mathrm{wt} \%(\mathrm{Li}, \mathrm{K}, \mathrm{Na}) \mathrm{NO}_{3} /$ water mixture. The absorber output capacity is $2.47 \mathrm{MM} \mathrm{Btu} / \mathrm{hr}$. The deviation between parameters is very small (Tables 3 and 4). However, the solution mass flow rates obtained by the program are about $33 \%$ less than the values obtained by Davidson and Erickson ${ }^{1}$ which is due to the concentration difference in the solution leaving the absorber. The COP values obtained by the software and Davidson and Erickson ${ }^{1}$ were 0.428 and 0.420 respectively.

This program was tested in the HA mode against the mass and energy balances given by Davidson and Erickson. ${ }^{1}$ Tables 5 and 6 show the results from HEATPUMP program and Davidson and Erickson ${ }^{1}$ respectively $(52.8 \mathrm{wt} \% \mathrm{LiBr} /$ water solution). The absorber output capacity is $3.75 \mathrm{MM}$ $\mathrm{Btu} / \mathrm{hr}$. Th. deviation between parameters is very small (Tables 5 and 6). The heating CCP obtained by this software is 1.78 which compares well with the value of 1.81 calculated by Davidson and Erickson. ${ }^{1}$ Tables 7 and 8 show the results obtained from the program and Davidson and Erickson ${ }^{1}$ respectively, $73 \mathrm{wt} \%(\mathrm{Li}, \mathrm{K}, \mathrm{Na}) \mathrm{NO}_{3} /$ water mixture. The absorber ouput capacity is $3.75 \mathrm{MM} \mathrm{Btu} / \mathrm{hr}$. The heating COP values obtained by the software and Davidson and Erickson ${ }^{1}$ were 1.86 and 1.87 respectively.

The effect of solution temperature leaving the absorber was simulated on two base cases (TA and $\mathrm{HA}$ ) for both $\mathrm{LiBr} /$ water solution and $(\mathrm{Li}, \mathrm{K}, \mathrm{Na}) \mathrm{NO}_{3}$ /water mixture. The summary of base values used for $(\mathrm{Li}, \mathrm{K}, \mathrm{Na}) \mathrm{NO}_{3} /$ water and $\mathrm{LiBr} /$ water cycle calculations is given in Tables 9 and 10 . Samples of the input and the output for these base values are given in Appendix B.

For absorption heat pump the heating COP is defined as the ratio of useful heat output divided by the high grade heat input. To account for parasitic pumping power, a net measured COP $\left(\mathrm{COP}_{\mathrm{nm}}\right)$ is defined by Davidson and Erickson ${ }^{1}$ as follows:

For temperature amplifier:

$$
\mathrm{COP}_{\mathrm{nm}}=\frac{\mathrm{Q}_{\text {absorber }}}{\left(\mathrm{Q}_{\text {evaporator }}+\mathrm{Q}_{\text {desorber }}+4 \times \text { Pumping Power }\right)}
$$

For heat amplifier:

$$
\mathrm{COP}_{\mathrm{nm}}=\frac{\left(\mathrm{Q}_{\text {absorber }}+\mathrm{Q}_{\text {condenser }}\right)}{\left(\mathrm{Q}_{\text {desorber }}+4 \times \text { Pumping Power }\right)}
$$

The factor of four in these equations is to convert the pumping power to the prime energy, assuming 
$25 \%$ efficiency at the point of use. The pumping power is calculated by applying a $60 \%$ efficiency (mechanical efficiency) to the calculated ideal pump work. It should be noted that in the calculation of ideal pump work all frictional losses are neglected (the only friction is that occuring in the pump itself and is accounted for by the mechanical efficiency).

Table 1. Operating parameters in the TA mode for $70 \mathrm{wt} \% \mathrm{LiBr} /$ water system from HEATPUMP program

\begin{tabular}{|c|c|c|c|c|c|}
\hline Streams & $\begin{array}{c}\mathrm{T} \\
\left({ }^{\circ} \mathrm{F}\right)\end{array}$ & $\begin{array}{c}\mathrm{P} \\
(\mathrm{psia})\end{array}$ & $\begin{array}{c}{[\mathrm{LiBr}]} \\
(\mathrm{wt} \%)\end{array}$ & $\begin{array}{c}\text { Enthalpy } \\
(\mathrm{Btu} / \mathrm{lb})\end{array}$ & $\begin{array}{c}\text { Mass Flow rate } \\
(\mathrm{lb} / \mathrm{hr})\end{array}$ \\
\hline Steam from gen. & 225.0 & 0.94 & 0.0 & 1160.6 & 1960.1 \\
Water from con. & 99.6 & 0.94 & 0.0 & 67.6 & 1960.1 \\
Steam icm evap. & 215.0 & 15.59 & 0.0 & 1151.5 & 1960.1 \\
Solution from abs. & 348.0 & 15.59 & 66.0 & 168.3 & 34371.5 \\
Solution to gen. & 230.0 & 0.94 & 66.4 & 119.4 & $34371.5^{*}$ \\
Solution from gen. & 225.0 & 0.94 & 70.0 & 125.2 & 32411.4 \\
Solution to abs. & 338.0 & 15.59 & 70.0 & 170.6 & 32411.4 \\
\hline
\end{tabular}

- A mixture of solution and water vapor.

Table 2. Operating parameters in the TA mode for $70 \mathrm{wt} \% \mathrm{LiBr} /$ water system from Suciu and Rebello ${ }^{4}$

\begin{tabular}{|c|c|c|c|c|c|}
\hline Streams & $\begin{array}{c}\mathrm{T} \\
\left({ }^{\circ} \mathrm{F}\right)\end{array}$ & $\begin{array}{c}\mathrm{P} \\
(\mathrm{psia})\end{array}$ & $\begin{array}{c}{[\mathrm{LiBr}]} \\
(\mathrm{wt} \%)\end{array}$ & $\begin{array}{c}\text { Enthalpy } \\
(\mathrm{Btu} / \mathrm{lb})\end{array}$ & $\begin{array}{c}\text { Mass Flow rate } \\
(\mathrm{lb} / \mathrm{hr})\end{array}$ \\
\hline Steam from gen. & 230.0 & 0.95 & 0.0 & 1164.0 & 1970.0 \\
Water from con. & 100.0 & 0.95 & 0.0 & 68.0 & 1970.0 \\
Steam from evap. & 215.0 & 15.50 & 0.0 & 1151.5 & 1970.0 \\
Solution from abs. & 348.0 & 15.50 & 65.8 & 167.0 & 32840.0 \\
Solution to gen. & 230.0 & 1.28 & 68.6 & 125.6 & $32840.0^{*}$ \\
Solution from gen. & 225.0 & 0.95 & 70.0 & 125.0 & 30870.0 \\
Solution to abs. & 338.0 & 15.50 & 70.0 & 169.0 & 30870.0 \\
\hline
\end{tabular}

- A mixture of solution and water vapor. 
Table 3. Operating parameters in the TA mode for $90 \mathrm{wt} \%(\mathrm{Li}, \mathrm{K}, \mathrm{Na}) \mathrm{NO}_{3} /$ water system from HEATPUMP program

\begin{tabular}{|c|c|c|c|c|c|}
\hline Streams & $\begin{array}{c}\mathrm{T} \\
\left({ }^{\circ} \mathrm{F}\right)\end{array}$ & $\begin{array}{c}\mathrm{P} \\
(\mathrm{psia})\end{array}$ & $\begin{array}{c}{\left[(\mathrm{Li}, \mathrm{K}, \mathrm{Na}) \mathrm{NO}_{3}\right]} \\
(\mathrm{wt} \%)\end{array}$ & $\begin{array}{c}\text { Enthalpy } \\
(\mathrm{Btu} / \mathrm{lb})\end{array}$ & $\begin{array}{c}\text { Mass Flow rate } \\
(\mathrm{lb} / \mathrm{hr})\end{array}$ \\
\hline Steam from gen. & 327.9 & 8.13 & 0.0 & 1205.2 & 3064.1 \\
W'ater from con. & 183.6 & 8.13 & 0.0 & 151.5 & 3064.1 \\
Steam from evap. & 327.9 & 100.75 & 0.0 & 1187.3 & 3064.1 \\
Solution from abs. & 500.0 & 100.75 & 85.8 & 299.6 & 66336.7 \\
Solution to gen. & 329.0 & 8.13 & 86.8 & 237.5 & $66336.7^{*}$ \\
Solution from gen. & 327.9 & 8.13 & 90.0 & 241.2 & 63272.6 \\
Solution to abs. & 482.0 & 100.75 & 90.0 & 295.6 & 63272.6 \\
\hline
\end{tabular}

* A mixture of solution and water vapor.

Table 4. Operating parameters in the TA mode for $90 \mathrm{wt} \%(\mathrm{Li}, \mathrm{K}, \mathrm{Na}) \mathrm{NO}_{3} /$ water system from Davidson and Erickson ${ }^{1}$

\begin{tabular}{|c|c|c|c|c|c|}
\hline Streams & $\begin{array}{c}\mathrm{T} \\
\left({ }^{\circ} \mathrm{F}\right)\end{array}$ & $\begin{array}{c}\mathrm{P} \\
(\mathrm{psia})\end{array}$ & $\begin{array}{c}{\left[(\mathrm{Li}, \mathrm{K}, \mathrm{Na}) \mathrm{NO}_{3}\right]} \\
(\mathrm{wt} \%)\end{array}$ & $\begin{array}{c}\text { Enthalpy } \\
(\mathrm{Btu} / \mathrm{lb})\end{array}$ & $\begin{array}{c}\text { Mass Flow rate } \\
(\mathrm{lb} / \mathrm{hr})\end{array}$ \\
\hline Steam from gen. & 327.9 & 8.72 & 0.0 & 1207.9 & 3243.2 \\
Water from con. & 186.8 & 8.72 & 0.0 & 154.9 & 3243.2 \\
Steam from evap. & 327.9 & 99.96 & 0.0 & 1188.9 & 3243.2 \\
Solution from abs. & 500.0 & 99.96 & 87.0 & 302.1 & 97215.9 \\
Solution to gen. & 345.9 & 8.72 & 87.0 & 251.7 & 97215.9 \\
Solution from gen. & 327.9 & 8.72 & 90.0 & 245.7 & 93964.8 \\
Solution to abs. & 482.0 & 99.96 & 90.0 & 297.3 & 93964.8 \\
\hline
\end{tabular}


Table 5. Operating parameters in the HA mode for $52.8 \mathrm{wt} \% \mathrm{LiBr} /$ water system from HEATPUMP program

\begin{tabular}{|c|c|c|c|c|c|}
\hline Streams & $\begin{array}{c}\mathrm{T} \\
\left({ }^{\circ} \mathrm{F}\right)\end{array}$ & $\begin{array}{c}\mathrm{P} \\
(\mathrm{psia})\end{array}$ & $\begin{array}{c}{[\mathrm{LiBr}]} \\
(\mathrm{wt} \%)\end{array}$ & $\begin{array}{c}\text { Enthalpy } \\
(\mathrm{Btu} / \mathrm{lb})\end{array}$ & $\begin{array}{c}\text { Mass Flow rate } \\
(\mathrm{lb} / \mathrm{hr})\end{array}$ \\
\hline Steam from gen. & 257.1 & 9.60 & 0.0 & 1172.3 & 3171.5 \\
Water from con. & 191.3 & 9.60 & 0.0 & 159.2 & 3171.5 \\
Steam from evap. & 142.2 & 3.05 & 0.0 & 1122.4 & 3171.5 \\
Solution from abs. & 191.3 & 3.05 & 49.8 & 81.1 & 55924.0 \\
Solution to gen. & 237.3 & 9.60 & 49.8 & 105.5 & 55924.0 \\
Sulution from gen. & 257.1 & 9.60 & 52.8 & 115.5 & 52752.5 \\
Solution to abs. & 201.4 & 3.05 & 52.9 & 87.1 & $52752.5^{*}$ \\
\hline
\end{tabular}

* A mixture of solution and water vapor.

Table 6. Operating parameters in the HA mode for $52.8 \mathrm{wt} \% \mathrm{LiBr} /$ water system fiom Davidson and Erickson ${ }^{1}$

\begin{tabular}{|c|c|c|c|c|c|}
\hline Streams & $\begin{array}{c}\mathrm{T} \\
\left({ }^{\circ} \mathrm{F}\right)\end{array}$ & $\begin{array}{c}\mathrm{P} \\
(\mathrm{psia})\end{array}$ & $\begin{array}{c}{[\mathrm{LiB} \text { r }]} \\
(\mathrm{wt} \%)\end{array}$ & $\begin{array}{c}\text { Enthalpy } \\
(\mathrm{Btu} / \mathrm{lb})\end{array}$ & $\begin{array}{c}\text { Mass Flow rate } \\
(\mathrm{lb} / \mathrm{hr})\end{array}$ \\
\hline Steam from gen. & 257.2 & 9.61 & 0.0 & 1175.2 & 3520.7 \\
Water from con. & 191.3 & 9.61 & 0.0 & 159.1 & 3520.7 \\
Steam from evap. & 142.2 & 3.06 & 0.0 & 1124.0 & 3520.7 \\
Solution from abs. & 191.3 & 3.06 & 49.8 & 51.2 & 61929.5 \\
Solution to gen. & 242.1 & 9.61 & 49.8 & 108.3 & 61929.5 \\
Solution from gen. & 257.2 & 9.61 & 52.8 & 115.8 & 58440.5 \\
Solution to abs. & 201.4 & 3.06 & 52.8 & 87.2 & 58440.5 \\
\hline
\end{tabular}


Table 7. Operating parameters in the $\mathrm{HA}$ mode for $73 \mathrm{wt} \%(\mathrm{Li}, \mathrm{K}, \mathrm{Na}) \mathrm{NO}_{3}$ /water system from HEATPUMP program

\begin{tabular}{|c|c|c|c|c|c|}
\hline Streams & $\begin{array}{c}\mathrm{T} \\
\left({ }^{\circ} \mathrm{F}\right)\end{array}$ & $\begin{array}{c}\mathrm{P} \\
(\mathrm{psia})\end{array}$ & $\begin{array}{c}{\left[(\mathrm{Li}, \mathrm{K}, \mathrm{Na}) \mathrm{NO}_{3}\right]} \\
(\mathrm{wt} \%)\end{array}$ & $\begin{array}{c}\text { Enthalpy } \\
(\mathrm{Btu} / \mathrm{lb})\end{array}$ & $\begin{array}{c}\text { Mass Flow rate } \\
(\mathrm{lb} / \mathrm{hr})\end{array}$ \\
\hline Steam from gen. & 259.2 & 9.60 & 0.0 & 1173.2 & 3511.6 \\
Water from con. & 191.3 & 9.60 & 0.0 & 159.2 & 3511.6 \\
Steam from evap. & 142.2 & 3.05 & 0.0 & 1122.4 & 3511.6 \\
Solution from abs. & 192.2 & 3.05 & 69.7 & 176.8 & 78665.1 \\
Solution to gen. & 240.8 & 9.60 & 69.7 & 197.0 & 78665.1 \\
Solution from gen. & 259.2 & 9.60 & 73.0 & 203.7 & 75153.6 \\
Solution to abs. & 202.3 & 3.05 & 73.2 & 180.5 & 75153.6 \\
\hline
\end{tabular}

* A mixture of solution and water vapor.

Table 8. Operating parameters in the $\mathrm{HA}$ mode for $73 \mathrm{wt} \%(\mathrm{Li}, \mathrm{K}, \mathrm{Na}) \mathrm{NO}_{3}$ /water system Davidson and Erickson ${ }^{1}$

\begin{tabular}{|c|c|c|c|c|c|}
\hline Streams & $\begin{array}{c}\mathrm{T} \\
\left({ }^{\circ} \mathrm{F}\right)\end{array}$ & $\begin{array}{c}\mathrm{P} \\
(\mathrm{psia})\end{array}$ & $\begin{array}{c}{\left[(\mathrm{Li}, \mathrm{K}, \mathrm{Na}) \mathrm{NO}_{3}\right]} \\
(\mathrm{wt} \%)\end{array}$ & $\begin{array}{c}\text { Enthalpy } \\
(\mathrm{Btu} / \mathrm{lb})\end{array}$ & $\begin{array}{c}\text { Mass Flow rate } \\
(\mathrm{lb} / \mathrm{hr})\end{array}$ \\
\hline Steam from gen. & 257.0 & 8.56 & 0.0 & 1174.7 & 3520.7 \\
Water from con. & 191.3 & 8.56 & 0.0 & 154.1 & 3520.7 \\
Steam from evap. & 142.2 & 3.06 & 0.0 & 1123.5 & 3520.7 \\
Solution from abs. & 191.3 & 3.06 & 70.0 & 171.0 & 85638.8 \\
Solution to gen. & 246.7 & 8.56 & 70.0 & 197.7 & 85638.8 \\
Solution from gen. & 257.0 & 8.56 & 73.0 & 203.6 & 82149.8 \\
Solution to abs. & 201.4 & 3.06 & 73.0 & 175.8 & 82149.8 \\
\hline
\end{tabular}


Table 9. Summary of Base Values of Operating Parameters for ( $\mathrm{Li}, \mathrm{K}, \mathrm{Na}) \mathrm{NO}_{3} /$ water system

\begin{tabular}{|c|c|c|}
\hline Parameters & TA & HA \\
\hline \multicolumn{3}{|l|}{ Inputs: } \\
\hline Concentration of solution leaving the desorber (wt\%) & 90.0 & 73.0 \\
\hline Waste heat inlet temperature entering the evaporator $\left({ }^{\circ} \mathrm{F}\right)$ & 345.9 & 151.2 \\
\hline Absorber capacity (MM Btu/hr) & 2.47 & 3.75 \\
\hline Cooling water temperature entering the absorber $\left({ }^{\circ} \mathrm{F}\right)$ & 482.0 & 181.4 \\
\hline Desorber temperature $\left({ }^{\circ} \mathrm{F}\right)$ & 329.0 & 259.2 \\
\hline Waste heat inlet temperature entering the generator $\left({ }^{\circ} \mathrm{F}\right)$ & 345.9 & 277.2 \\
\hline Cooling water temperature entering the condenser $\left({ }^{\circ} \mathrm{F}\right)$ & 150.8 & 181.4 \\
\hline \multicolumn{3}{|l|}{ Outputs: } \\
\hline Generator Pressure (psia) & 8.13 & 9.60 \\
\hline Condenser Pressure (psia) & 8.13 & 9.60 \\
\hline Absorber Pressure (psia) & 100.75 & 3.05 \\
\hline Evaporator Pressure (psia) & 100.75 & 3.05 \\
\hline Net measured COP & 0.4383 & 1.8810 \\
\hline Heating COP & 0.4427 & 1.8836 \\
\hline Concentrated solution flow rate $(\mathrm{lb} / \mathrm{hr})$ & 47473.51 & 61678.82 \\
\hline Total (UA) required $\left(\mathrm{Btu} / \mathrm{hr}-{ }^{\circ} \mathrm{F}\right)$ & 554144.8 & 925188.8 \\
\hline Concentration of solution leaving the absorber (wt $\%$ ) & 84.7 & 69.0 \\
\hline Temperature of solution leaving the absorber $\left({ }^{\circ} \mathrm{F}\right)$ & 491.0 & 190.4 \\
\hline
\end{tabular}


Table 10. Summary of Base Values of Operating Parameters for LiBr/water system

\begin{tabular}{|c|c|c|}
\hline Parameters & TA & HA \\
\hline \multicolumn{3}{|l|}{ Inputs: } \\
\hline Concentration of solution leaving the desorber (wt \%) & 70.0 & 52.8 \\
\hline Waste heat inlet temperature entering the evaporator $\left({ }^{\circ} \mathrm{F}\right)$ & 235.0 & 151.2 \\
\hline Absorber capacity (MM Btu/hr) & 2.0 & 3.75 \\
\hline Cooling water temperature entering the absorber $\left({ }^{\circ} \mathrm{F}\right)$ & 338.0 & 181.4 \\
\hline Desorber temperature $\left({ }^{\circ} \mathrm{F}\right)$ & 230.0 & 257.1 \\
\hline Waste heat inlet temperature entering the generator $\left({ }^{\circ} \mathrm{F}\right)$ & 235.0 & 275.1 \\
\hline Cooling water temperature entering the condenser $\left({ }^{\circ} \mathrm{F}\right)$ & 80.0 & 181.4 \\
\hline \multicolumn{3}{|l|}{ Outputs: } \\
\hline Generator Pressure (psia) & 0.94 & 9.60 \\
\hline Condenser Pressure (psia) & 0.94 & 9.60 \\
\hline Absorber Pressure (psia) & 15.59 & 3.05 \\
\hline Evaporator Pressure (psia) & 15.59 & 3.05 \\
\hline Net measured COP & 0.4843 & 1.7795 \\
\hline Heating COP & 0.4849 & 1.7817 \\
\hline Concentrated solution flow rate $(\mathrm{lb} / \mathrm{hr})$ & 28448.4 & 52752.5 \\
\hline Total (UA) required $\left(\mathrm{Btu} / \mathrm{hr}-{ }^{\circ} \mathrm{F}\right)$ & 597427.1 & 856097.4 \\
\hline Concentration of solution leaving the absorber (wt $\%$ ) & 65.5 & 49.8 \\
\hline Temperature of solution leaving the absorber $\left({ }^{\circ} \mathrm{F}\right)$ & 345.0 & 191.3 \\
\hline
\end{tabular}

The simulated results show that increasing the temperature $\left(\mathrm{T}_{\text {abs. out }}\right)$ of solution leaving the absorber would decrease the COP and increase the solution flow rate ( $\dot{\mathrm{m}}_{\text {conc. }}$ ). The total (UA) required for heat transfer decreases with increasing temperature and concentration of soluiion leaving the absorber. However, a point is reached where the (UA) starts to increase with the temperature and concentration of the solution leaving the absorber (Tables 11,12,13, and 14). The results are based on a percent relative deviation from the base values of each parameter. Tables 11 and 13 show the effect of $\mathrm{T}_{\text {abs. out }}$ for $(\mathrm{Li}, \mathrm{K}, \mathrm{Na}) \mathrm{NO}_{3} /$ water system on various parameters ([salt $]_{\text {abs. out }}, \mathrm{COP}_{\mathrm{nm}}, \mathrm{UA}$, and $\dot{m}_{\text {conc. }}$ ) while Figures 1 and 2 show the effect of $T_{\text {abs. out }}$ on $\mathrm{COP}_{\mathrm{nm}}$ and UA. Results show that for $(\mathrm{Li}, \mathrm{K}, \mathrm{Na}) \mathrm{NO}_{3}$ in the TA mode an increase of $0.9 \%$ from the base value of $\mathrm{T}_{\text {abs. out }}$ would cause a decrease in the COP and UA of $1.0 \%$ and $8.2 \%$ respectively and an increase of $14.6 \%$ in the solution flow rate (amount of required salt). The simulated results show that for ( $\mathrm{Li}, \mathrm{K}, \mathrm{Na}) \mathrm{NO}_{3}$ in the HA mode an increase of $0.9 \%$ from the base value of $\mathrm{T}_{\text {abs. out }}$ would cause a decrease in the COP 
and UA of $1.2 \%$ and $3.0 \%$ respectively and an increase of $21.8 \%$ in the solution flow rate. It should be noted that the concentration of $(\mathrm{Li}, \mathrm{K}, \mathrm{Na}) \mathrm{NO}_{3}$ solution in the TA mode is close to 90 wt $\%$ as compared to about 73 wt\% for the HA mode.

The effect of $\mathrm{T}_{\mathrm{abs} \text { out }}$ for $\mathrm{LiBr} /$ water system on various parameters ([salt $]_{\mathrm{abs} \text {. out }}, \mathrm{COP}_{\mathrm{nm}}, \mathrm{UA}$, and $\dot{m}_{\text {conc. }}$ ) are shown in Tables 12 and 14 while Figures 3 and 4 show the effect of $T_{\text {abs. out }}$ on $C_{\mathrm{nm}}$ and UA. Results show that for $\mathrm{LiBr}$ in the TA mode an increase of $0.9 \%$ from the base value of $\mathrm{T}_{\text {abs. out }}$ would cause a decrease in the COP and UA of $0.4 \%$ and $3.0 \%$ respectively and an increase of $13.9 \%$ in the solution flow rate. The simulated results show that for $\mathrm{LiBr}$ in the $\mathrm{HA}$ mode an increase of $1.4 \%$ from the base value of $\mathrm{T}_{\text {abs. out }}$ would cause a decrease in the COP and UA of $1.8 \%$ and $3.6 \%$ respectively and an increase of $33.6 \%$ in the solution flow rate.

Table 11. Effect of solution temperature leaving the absorber in TA mode for $(\mathrm{Li}, \mathrm{K}, \mathrm{Na}) \mathrm{NO}_{3}$ /water system

\begin{tabular}{|c|c|c|c|c|}
\hline$\% \Delta \mathrm{T}_{\text {abs. out }}$ & $\% \Delta[\text { salt }]_{\text {abs. out }}$ & $\% \Delta \mathrm{COP}_{\mathrm{nm}}$ & $\% \Delta(\mathrm{UA})_{\text {total }}$ & $\% \Delta \dot{\mathrm{m}}_{\text {conc. }}$ \\
\hline 0.92 & 0.71 & -1.05 & -8.21 & 14.61 \\
1.47 & 1.06 & -1.78 & -9.68 & 25.22 \\
1.65 & 1.18 & -2.05 & -9.78 & 29.14 \\
1.83 & 1.30 & -2.35 & -9.70 & 33.28 \\
2.02 & 1.53 & -2.65 & -9.47 & 37.66 \\
3.67 & 2.60 & -6.21 & -0.04 & 92.32 \\
\hline
\end{tabular}

where: $\% \Delta \mathrm{X}=\frac{\left(\mathrm{X}-\mathrm{X}_{\text {base value }}\right)}{\mathrm{X}_{\text {base value }}} \times 100 \%$

Table 12 Effect of solution temperature leaving the absorber in TA mode for LiBr/water system

\begin{tabular}{|c|c|c|c|c|}
\hline$\% \Delta \mathrm{T}_{\text {abs. out }}$ & $\% \Delta[\text { salt }]_{\text {abs. out }}$ & $\% \Delta \mathrm{COP}_{\mathrm{nm}}$ & $\% \Delta(\mathrm{UA})_{\text {total }}$ & $\% \Delta \dot{\mathrm{m}}_{\text {conc. }}$ \\
\hline 0.58 & 0.46 & -0.29 & -2.40 & 8.93 \\
0.87 & 0.76 & -0.43 & -2.99 & 13.93 \\
1.16 & 1.07 & -0.60 & -3.28 & 19.34 \\
1.30 & 1.07 & -0.70 & -3.32 & 22.22 \\
1.45 & 1.22 & -0.78 & -3.27 & 25.22 \\
2.32 & 1.98 & -1.42 & -2.80 & 46.32 \\
\hline
\end{tabular}

where: $\% \Delta \mathrm{X}=\frac{\left(\mathrm{X}-\mathrm{X}_{\text {base value }}\right)}{\mathrm{X}_{\text {base value }}} \times 100 \%$ 
Table 13. Effect of solution temperature leaving the atsorber in HA mode for $(\mathrm{Li}, \mathrm{K}, \mathrm{Na}) \mathrm{NO}_{3}$ /water system

\begin{tabular}{|c|c|c|c|c|}
\hline$\% \Delta \mathrm{T}_{\text {abs. out }}$ & $\% \Delta[\text { salt }]_{\text {abs. out }}$ & $\% \Delta \mathrm{COP}_{\mathrm{nm}}$ & $\% \Delta(\mathrm{UA})_{\text {total }}$ & $\% \Delta \dot{\mathrm{m}}_{\text {conc. }}$ \\
\hline 0.95 & 1.01 & -1.23 & -2.96 & 21.85 \\
2.36 & 2.75 & -4.14 & -5.39 & 75.70 \\
2.84 & 3.19 & -5.66 & -5.65 & 104.30 \\
3.78 & 4.20 & -10.58 & -4.95 & 197.74 \\
4.73 & 5.22 & -22.75 & -0.43 & 428.31 \\
5.20 & 5.65 & -39.70 & 7.06 & 744.24 \\
\hline
\end{tabular}

where: $\% \Delta X=\frac{\left(X-X_{\text {base value }}\right)}{X_{\text {base value }}} \times 100 \%$

Table 14. Effect of solution temperature leaving the absorber in HA mode for LiBr/water system

\begin{tabular}{|c|c|c|c|c|}
\hline$\% \Delta \mathrm{T}_{\text {abs. out }}$ & $\% \Delta[\text { salt }]_{\text {abs. out }}$ & $\% \Delta \mathrm{COP}_{\mathrm{nm}}$ & $\% \Delta(\mathrm{UA})_{\text {total }}$ & $\% \Delta \dot{\mathrm{m}}_{\text {conc. }}$ \\
\hline 1.41 & 1.61 & -1.82 & -3.55 & 33.64 \\
1.88 & 2.21 & -2.69 & -4.24 & 49.89 \\
2.35 & 2.81 & -3.77 & -4.67 & 70.26 \\
2.82 & 3.21 & -5.17 & -4.82 & 96.54 \\
3.29 & 3.82 & -7.04 & -4.61 & 131.72 \\
4.23 & 4.82 & -13.67 & -2.35 & 256.23 \\
\hline
\end{tabular}

where: $\% \Delta \mathrm{X}=\frac{\left(\mathrm{X}-\mathrm{X}_{\text {base value }}\right)}{\mathrm{X}_{\text {base value }}} \times 100 \%$ 


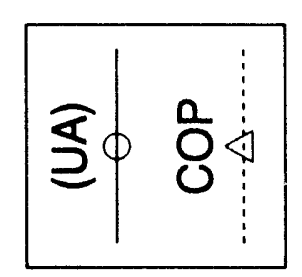

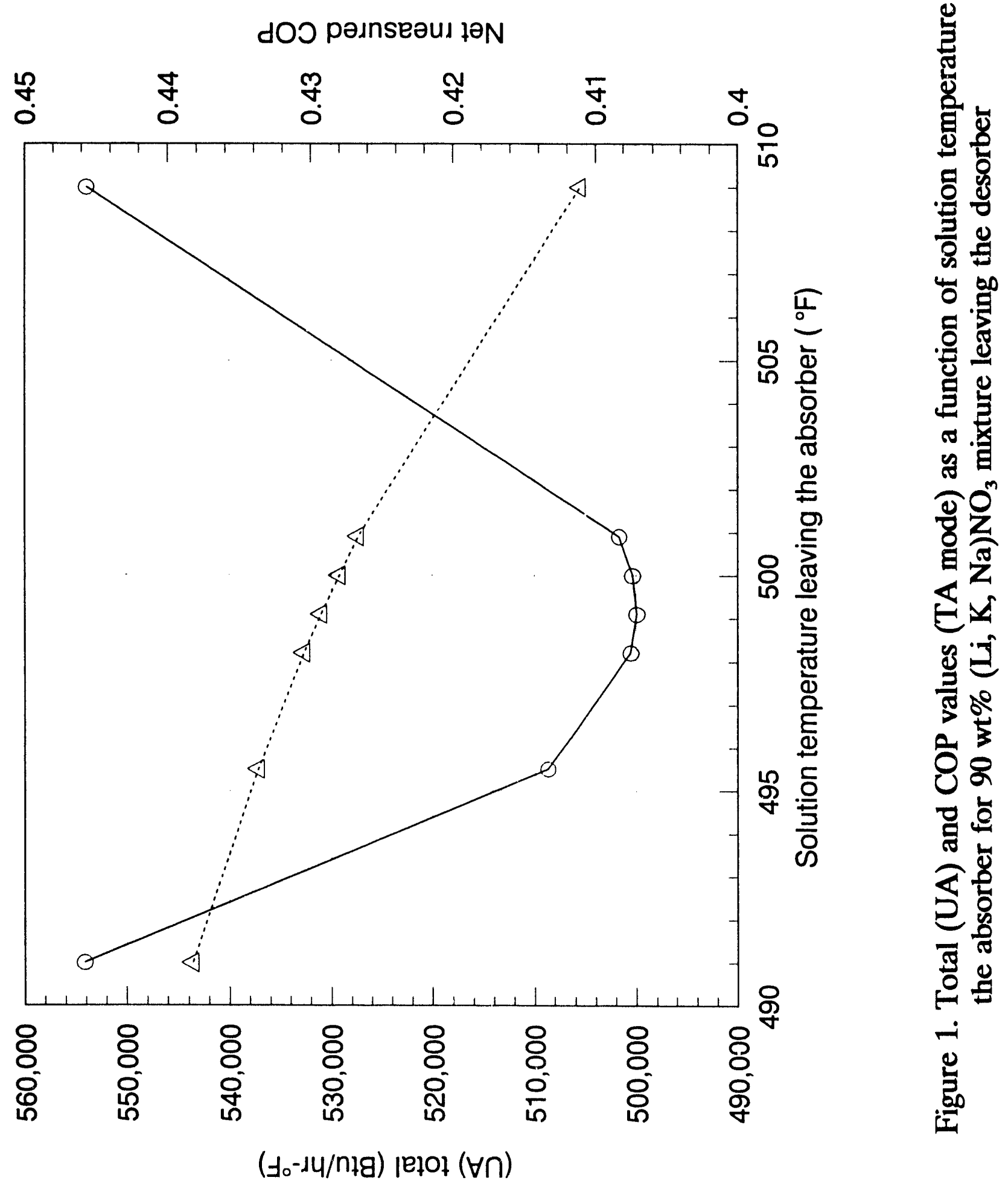




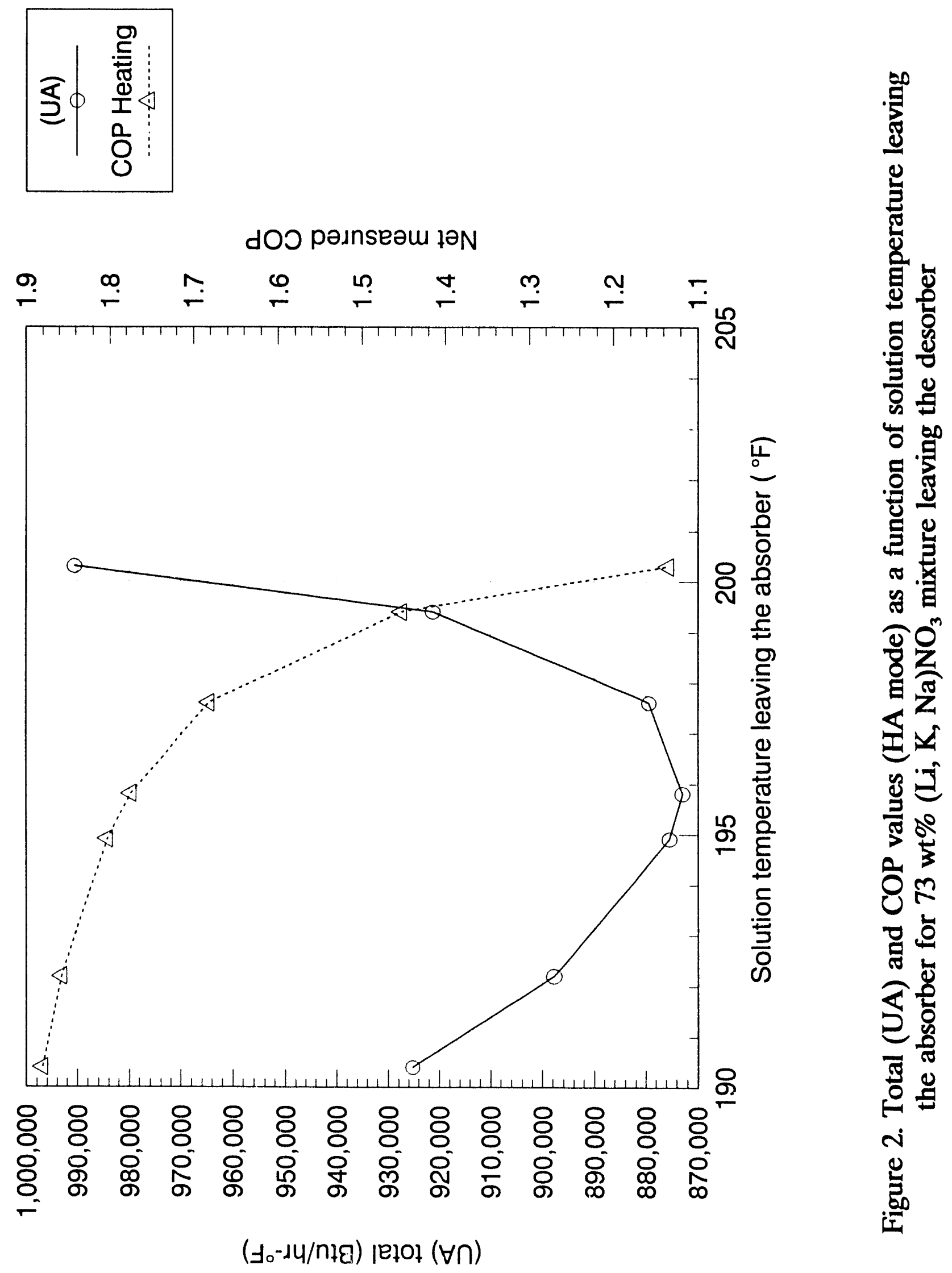



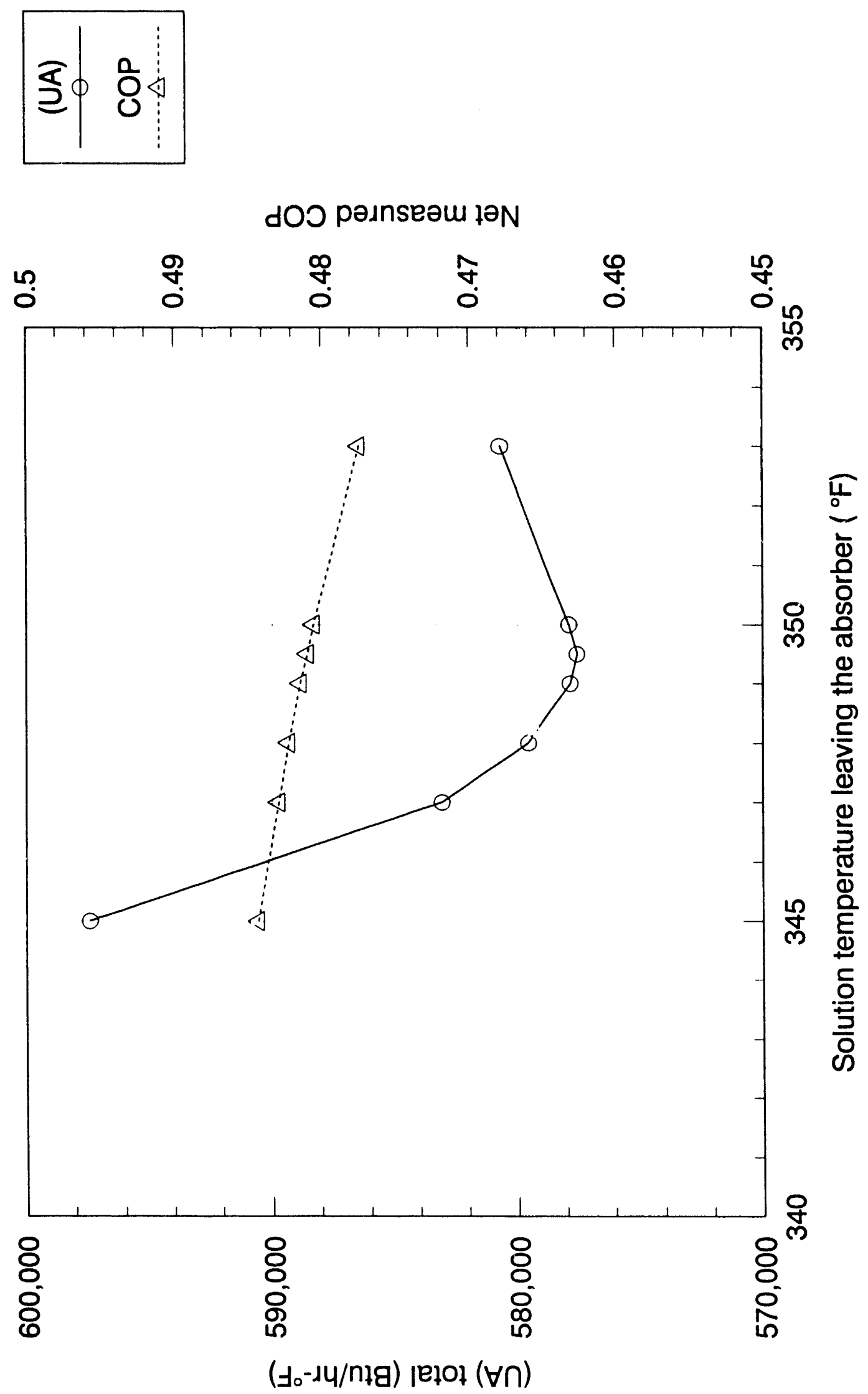

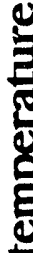

뭉

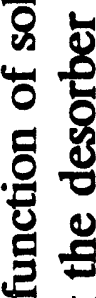

$\sim 0$

สิ

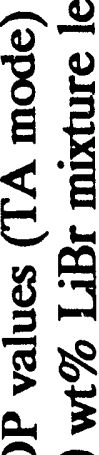

오

농

ำ

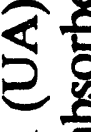

퐁

m.

点 

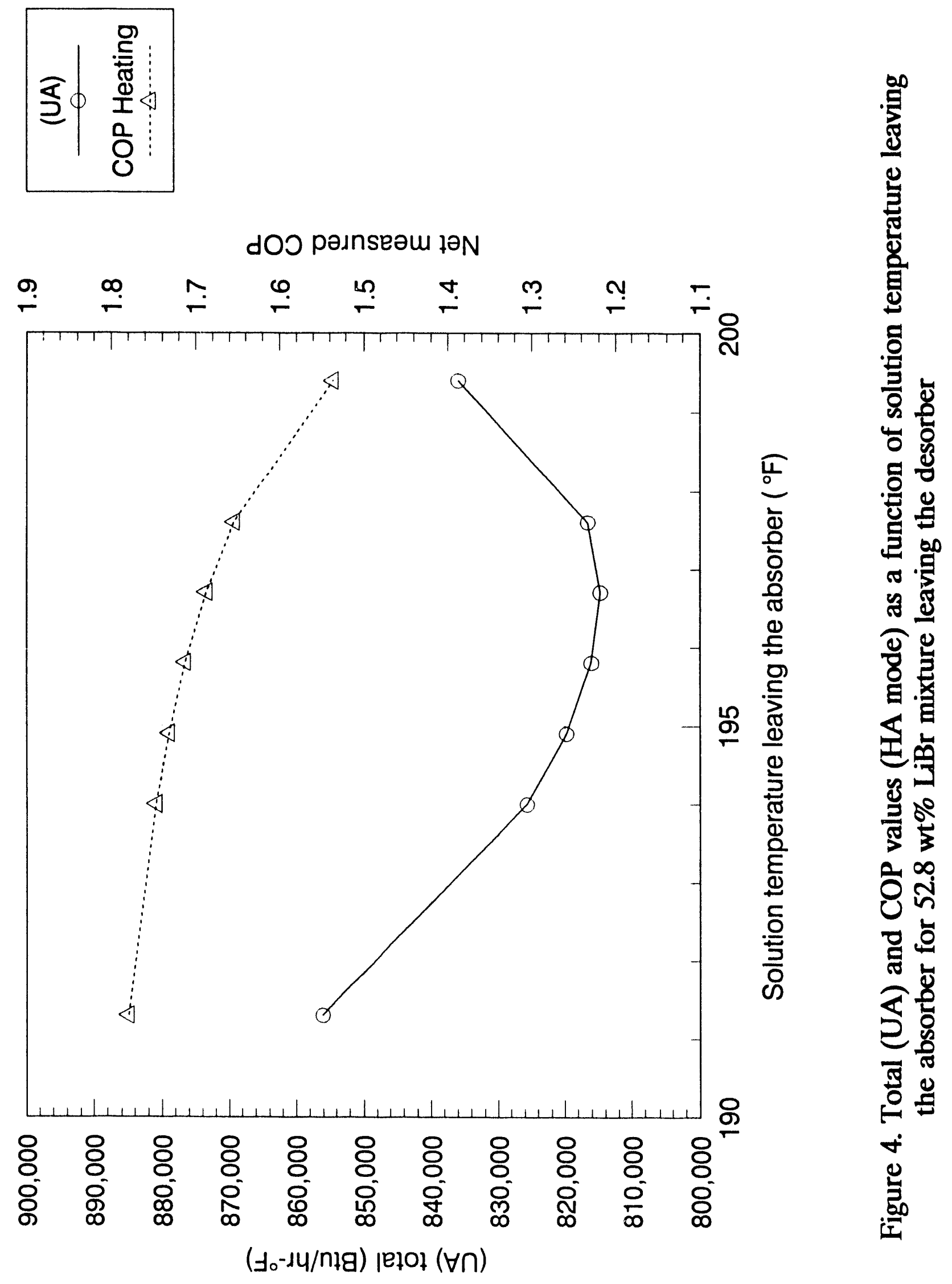


\section{CONCLUSIONS}

An interactive computer code was developed to evaluate single stage absorption heat pump performance for temperature amplifier and heat amplifier modes using water as the refrigerant. This program was tested against documented cases. The results show that the maximum deviation between the coefficient of performance (COP) values obtained by this software and the ones previously calculated is less than $3 \%$. In addition, this program was used to study the effect of solution temperature leaving the absorber on the other operating parameters such as net measured COP, total UA required, and solution mass flow rate. Results show that the required UA as a function of solution temperature exhibits a minimum which could be used to determine the optimum cycle design. 


\section{REFERENCES}

1. W. F. Davidson and D. C. Erickson, New High Temperature Absorbent for Absorption Heat Pumps, ORNL/Sub/85-22013/1, Oak Ridge National Laboratory, July 1986.

2. M. R. Ally, Thermodynamic Properties of Aqueous Ternary Solutions Relevant to Chemical Heat Pumps, ORNL/TM-10258, Oak Ridge National Laboratory, March 1987.

3. ASHRAE, 1989 Fundamentals, American Society of Heating, Refrigeration, and AirConditioning Engineers, pp. 17.71-17.72.

4. D. F. Suciu and W. J. Rebello, Assessment of the BCL and ORNL Chemical Heat Pumps, EGG-CSH-6223, Idaho National Engineering Laboratory, April 1983. 
Appendix A

Listing of Computer Code 


\section{MODULEL.BAS}

DECLARE SUB denalk (tn!, wt!, rbosoln!)

DECLARE SUB denlibe ( $(n$, wt, thosoln!)

DECLARE SUB denh2o (tn, rhoh2o!)

DECLARE SUB condabein (lowin!)

DECLARE SUB xhtcalalkHA (hxt!, T!, wtout!, wt!, hvapor!, wtabsout!)

DECLARE SUB xtcalLiBrHA (bxt!, T1, wtout!, wt!, hvapor!, wtabsout!)

DECLARE SUB maincboiceii ()

DECLARE SUB tabdata2 (ESTIDS, mat\$, conS, qout!, towin!, twastedesin!, twasteevapin!, tcapp!, teapp!, tdapp!, taapp!, thxapp!)

DECLARE SUB INPTWASTEDES (twastedesin!, twastedesinS, twastedesinUNITS, trapS, aaaa!)

DECLARE SUB wastebeatevapin (twasteevapin!)

DECLARE SUB wastebeatdesin (twastedesin!)

DECLARE SUB logoTA O

DECLARE SUB logoHA ()

DECLARE SUB haLiBr (tf!, wh, hxt1!)

DECLARE SUB BoostTalk (P!, wt!, tmaxd)

DECLARE SUB abswtoutalk (T!, P!, wtout!, wt!)

DECLARE SUB throutcalaik (bxt!, wt!, throut!)

DECLARE SUB xhtcalalk (hxt!, T!, wtout!, wt!, bvapor, wtabsin)

DECLARE SUB bxtalk (T1!, wt!, bxt)

DECLARE SUB prealk (tul, w!, psat!)

DECLAARE SUB bgsuper (psat!, Hg!, tsat!, T!, hsuperheat!)

DECLARE SUB TSATH2O (P!, T1!)

DECLARE SUB abswtoutliBr (TI, P!, whout!, wt!)

DECLARE SUB throutcalLiBr (hxe!, wt!, thxout!)

DECLARE SUB xhtcalLiBr (hxt!, T?, whout!, wt!, hvapor, wtabsin)

DECLARE SUB preLiBr (un, wt!, psat!)

DECLARE SUB BoostTLiBr (P!, wt!, tmax!)

DECLARE SUB hgwater (U!, Hg!)

DE.CLARE SUB hiwater (n!, h!)

DECLARE SUB preh2o (tn!, ?!)

DECLARE SUB TCABSIN (tcain!)

DECLARE SUB Tdesorber (tdeso!)

DECLARE SUB inptcain (tcain!, tcainS, tcainUNTTS, trap\$)

DECLARE SUB inpldeso (Ideso!, IdesoS, tdesoUNTTS, trapS)

DECLARE SUB wtabs (wts, wt!)

DECLARE SUB desTapp (tdapp!)

DECLARE SUB AbsTapp (taapp!)

DECLARE SUB HXTapp (hhopp!)

DECLARE SUB inptcapp (tcapp!, tcappS, tcappUNITS, trap\$)

DECLARE SUB inpteapp (teapp!, teappS, teappUNIT, trap\$)

DECLARE SUB inptdapp (tdapp!, tdappS, tdappUNITS, trapS)

DECLARE SUB inptaapp (taapp!, taapp\$, taappUNTTS, trap\$)

DECLARE SUB inpthrapp (thrapp!, thxappS, thxappUNITS, trapS)

DFCLARE SUB condtapp (tcapp!)

DECLARE SUB evaTapp (teapp!)

DECLARE SUB waterpre (Uf!, bf!, Hg!, psat!, T1!)

DECLARE SUB inptcwin (cowin!, towins, towinUNITS, traps, ccc!)

DECLARE SUB INPTWASTE (twaste!, twasteS, twasteUNITS, (raps, aaa!)

DECLARE SUB wasteheatin (twaste!)

DECLARE SUB INPqout (qout!, qouts, qoutUNTTS, trap\$, bbb)

DECLARE SUB RUNID (ESTIDS, trapS)

DECLARE SUB condhroin (lowin)

DECLARE SUB qtout (qout)

DECLARE SUB tabdata (ESTIDS, matS, con\$, qout!, towin!, twaste, tcapp, teapp, tdapp, taapp, thapp, tcain, tdeso)

DECLARE SUB MAINMENU ()

DECLARE SUB TITLESCR ()

DECLARE SUB mainchoicei ()

DECLARE SUB mixture ()

DECLARE SUB noise 0

DECLARE SUB border ()

COMMON SHARED frg, bac, escflag

frg $=14:$ bac $=1$

- SETTING THE FUNCTION KEYS TO A VARIABLE - FUNCTION KEY $1<F 1>=" A$ ",

- FUNCTION KEY $2<$ P2> = "B" ETC

KEY 1, "A"

KEY 2 "B'

KEY 3 , ${ }^{\circ} \mathrm{C}$

KEY 4, "D"

KEY $5,{ }^{\circ}$ "

KEY $6, " F$

KEY 7, " $G$ "

KEY \& " $\mathrm{H}^{\circ}$

KEY 9, "l" 
KEY $10, " \mathrm{~J}$

PRGSTART:

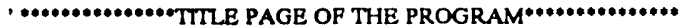

CALL TTTLESCR

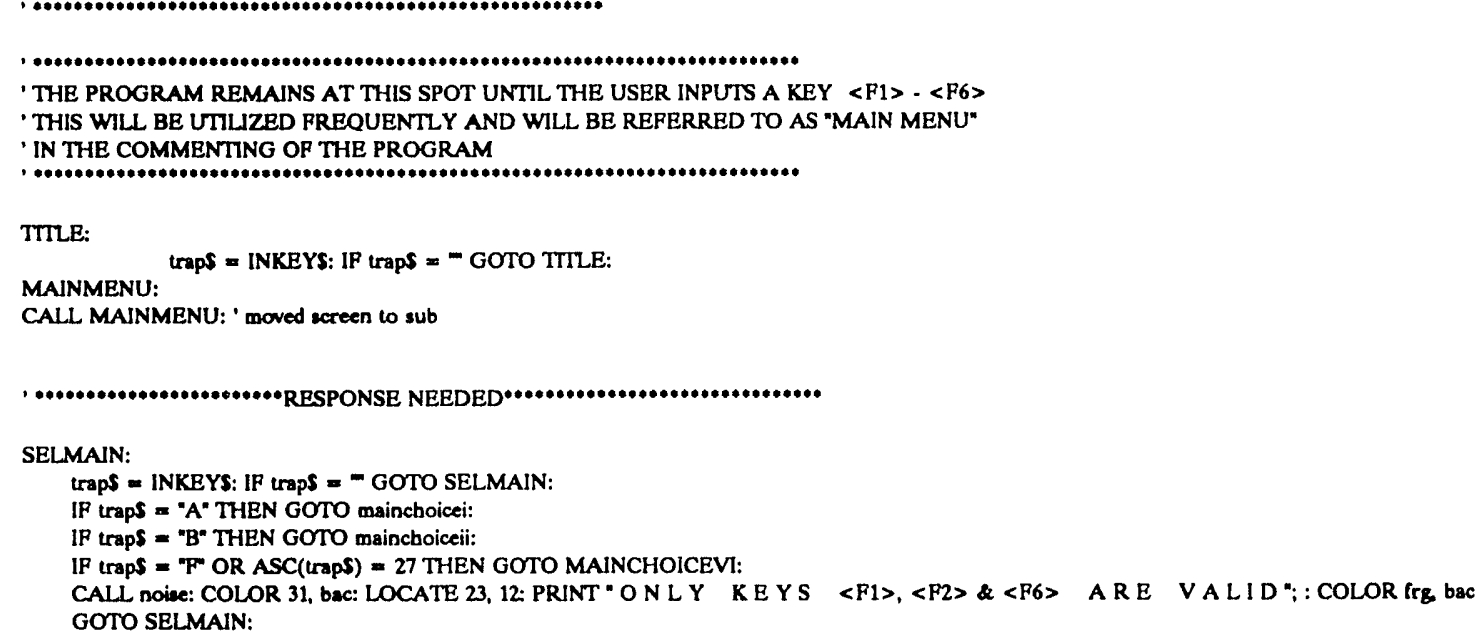

TITLE:

traps = INKEYS: IP traps = - GOTO TTILE:
MAINMENU:
CALL MAINMENU: ' moved screen to sub

$[\cdots \cdots \cdots \cdots \cdots \cdots \cdots \cdots \cdots \cdots \cdots \cdots \cdot$ RESPONSE NEEDED $\cdots \cdots \cdots \cdots \cdots \cdots \cdots \cdots \cdots \cdots \cdots \cdots \cdots$

SELMAIN:

traps $=$ INKEYS: IF traps $=-$ GOTO SELMAIN

IF trapS = "A" THEN GOTO mainchoicei:

IP traps = "B" THEN GOTO mainchoiceil:

IF traps = "F" OR ASC(trapS) $=27$ THEN GOTO MAINCHOICEVI:

CALL noive: COLOR 31, bac: LOCATE 23, 12: PRINT" ONLY KEYS <F1>, <P2> \& <F6> ARE VALID ": : COLOR frg, bac GOTO SELMAIN:

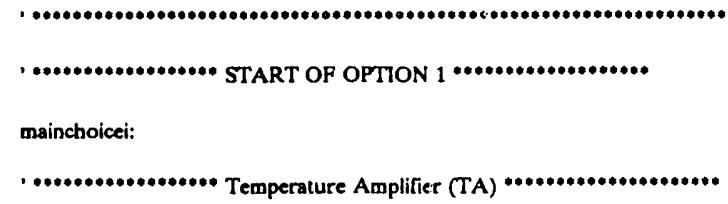

CALL LogoTA

-

mix 1:

CALL mixture: Worting fluid

trapS = INKEYS: IF traps = - GOTO mix1:

If trap: $=$ "A" THEN mats $=$ "LiBt": GOTO mix2:

IF traps = "B" THEN matS $="(\mathrm{Li}, \mathrm{K}, \mathrm{Na})$ NO3": GOTO mix2:

IF traps $=$ "C" THEN mats $=$ "Other": GOTO MAINMENU:

IF trap $\$=$ "D" OR ASC(trap\$) $=27$ THEN GOTO MAINMENU:

CALL noise: COLOR 31, bac: LOCATE 23, 12: PRINT "ONLY KEYS <F1>. <F4> ARE VALID": : COLOR frg, bac GOTO mix1:

mix2:

CALL wtabs(cons, $w$ ) Wt\% of solution leaving the desorber (generator)

IP eschag = 1 GOTO mainchoicei: 'ESCAPE ROUTE

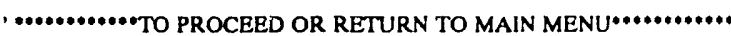

CALL mairatyicei: REM moved screen to sub

INIDIS:

trapS = INKEYS: IF trapS = - GOTO INIDIS:

.

' IF USER DECIDES TO ESCAPE AND GO BACK TO PREVIOUS MENU (MAIN MENU)

,.$\cdots \cdots$

IF ASC(trapS) $=27$ GOTO MAINMENU:

IF traps = "A" GOTO PROCEED:

PROCEED:

CLS : CALL border: LOCATE S, S: PRINT "DO YOU WISH TO ENTER THE DATA IN TABULAR FORM OR BY INDIVIDUAL SCREENS?

' THE USER CAN ENTER THE DATA ETTHER BY INDIVIDUAL SCREENS OR AT ONE TTME TOGGLING BEIWEEN DATA INPUT 
' THE USER CAN ESCAPE BACK TO PREVIOUS MENU (ESCAPE ROUTE)

NEEDCOR

LOCATE 23, 2: PRINT "<F1>-TABULAR INPUT <F2>-INDIVIDUAL SCREEN INPUT <ESC>-BACK TO PREVIOUS MENU"

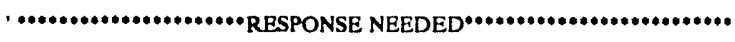

traps $=-$

WHILE traps $=-$

traps $=$ INKEYS

IP traps = "A" THEN

CLS

CALL tabdata(ESTIDS, matS, conS, qout, tcwin, twaste, tcapp, teapp, tdapp, taapp, thrapp, tcain, tdeso)

$$
\begin{aligned}
& \text { IF esflag = } 1 \text { THEN } \\
& \text { GOTO mainchoicei: } \\
& \text { END IF }
\end{aligned}
$$

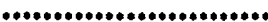

- IF USER WANTS TO GO BACK ESCFLAG BECOMES 1 FROM SUBROUTTNE TABDATA

'IP USBR WANTS TO GO BACK ESCFLAG BECOMES 1 FROM SUBRO

IF tdeso $>=$ twaste T! IEN

CALL noise

CLS : CALL border

LOCATE 15, 10. PRINT "You bave entered a temperature for the desorber which is "

LOCATE 16, 10. PRINT "greater than waste beat temperature."

LOCATE 19, 26: PRINT " PLEASE RE-ENTER"

LOCATE 23, 26: PRINT "PRESS ANY KEY TO CONTINUE"

DO WHILE INKEYS $=-$ : LOOP

CALL tabdata(ESTIDS, matS, conS, qout, tcwin, twaste, tcapp, teapp, tdapp, taapp, thrapp, tcain, tdeso)

END IP

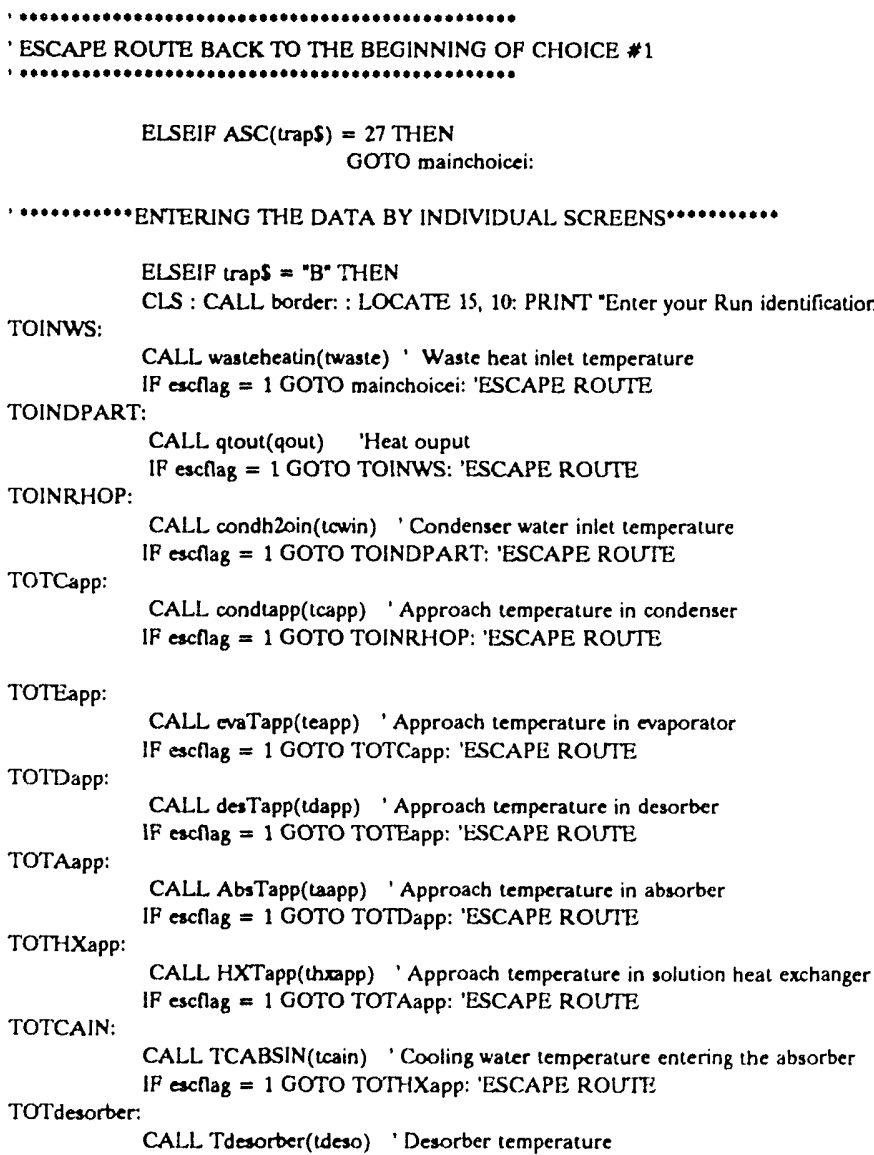

CALL TCABSIN(tcain) 'Cooling water temperature entering the absorber

TOTdesorber: IF eaclag = 1 GOTO TOTHXapp: 'ESCAPE ROUTE

CALL Tdesorber(tdeso) 'Desorber temperature 


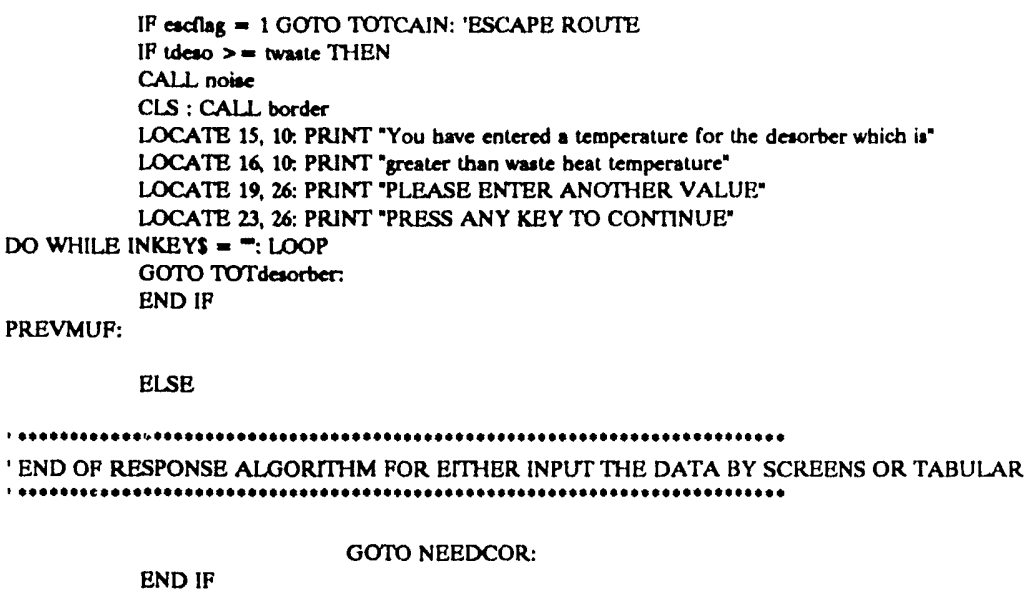

LiBr solution

IF mats = "LiBr" THEN

CALL. haLiBr(tderout, wh, hdesout)

CALL preLiBr(tdesout, wh, pdesin)

prefconout $=$ pdesin

CALL TSATH2O(prefconouh, trefconout)

tcwout $=$ trefconout - tcapp

CALL hfwater(trefconoul, h(refconout) CALL hfwater(tcwouth howout)

CALL Boost'TLiBr(pevapout, wh, Imax)

CALL hxtLiBr(tabsin, wh, habsin)

CALL abswtoutLiBr(tabsout, pevapoul, wtout wt)

CALL hatLiBr(tabsout, wrouth habsout)

beta $=w t /$ (wt - wtout)

alpha $=$ wtout $/(w t \cdot w$ tout $)$

hhxoul $=$ habsout - alpha $/$ beta $\cdot$ (habsin - hdesout)

CALL hgwater(trefconout, $\mathrm{Hg}_{\mathrm{g}}$ )

CALL hgsuper(pdesin, $\mathrm{Hg}_{\mathrm{g}}$ trefconout, tdeso, hdesvapout)

CALL throutca!LiBr(hhrout, whouth thxout)

CALL thtcalLiBr(throut, tdeso, wt 1, whouth hdesvapouth wt)

If esclag $=1$ THEN GOTO MAINMENU:

CALL hgwater(trefconouh, $\mathrm{H}_{g}$ )

CAl.L hgsuper(pdesin, $\mathrm{Hg}_{\mathrm{g}}$ trefconout, tdesout, hdesvapout) 
........ Checting the cryatalization temperature of the streams .......

CALL TeryiliBr(wrout, tabeouth terysabsouth teryicodeabeout)

CALL TcryulBr(wtl, tdeso, taryudesin, teryscodedeain)

CALL TcrysLiBr(wh, tdeacut, taryidesoult, teryacodedesout)

CALL TerysLiBr(wh, tabein, teryabain, teryacodesbain)

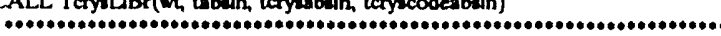

.

ELSEIP mats = "(L, K, Na) NO3" THEN

CALL hxtalk (tdesoul, wh bdesout)

CALL prealk(tdesout, $m$, pdesin)

prefconout = pdesin

CALL. TSATH2O(prefconoul, trefconout)

tcwout $=$ trefconout - tcapp

CALL bfwater(trefconouth bfrefconout)

CALL hfwater(towouth howout)

CALL Boost Talk (pevapout, $w$, umax)

CALL, hxalk(tabsin, wh, habain)

CALL abowtoutalk (Labrout, pevapout, wtout, wt)

CALL hxtalk (tabsout, whoul, habeout)

beta $=w t /(w t-$ wout $)$

alpha $=$ wtout / ( $m$ - whout)

hhrout = habsout - alpha / beta " (habsin - hdesout)

CALL hgwater(trefconoul, $\mathrm{H}_{\mathrm{g}}$ )

CALL hgsuper(pdesin, $\mathrm{H}_{\mathrm{g}}$ trefconout, tdeso, hdervapout)

CALL throutcalalk(hhrout, wrout, throut)

CALL thicalalk(bhroul, ideso, w1, whouth hdesvapouth wr)

IF eacllag = 1 THEN GOTO MAINMENU:

CALL hgwater(trefconout, $\mathrm{Hg}$ )

CALL ngsuper(pdesin, $\mathrm{H}_{B}$, trefconout, tdesout, hdesvapout)

CALL hxtalk(Ldeso, $m$ 1, hdesin)

CALL denaik(tdesouth wh, thosoln')

........ Checting the crystallization temperature of the streams .......

CALL Tcrysalk (whout, tabeout, tcrysabsout, tcryscodeabsout)

CALL Tcrysalk(wt), tdeso, teryadesin, tcryscodedesin)

CALL Tcrysalk(wh, tdesout, tcrysdesout, tcryscodedesout)

CALL Tcrysalk(wt, tabsin, tcrysabsin, teryscodeabsin)

END IF

$\cdot \cdots \cdots+\cdots \cdot \cdots \cdot \cdot$ Determination of COP and mass flow rates"..............

$\mathrm{QA}=$ hgevapout + alpha ' habsin $\cdot$ beta " habsout

gamma $=\mathrm{QA} /$ (hgcaout $\cdot$ hfcain)

$\mathrm{QE}=$ hgevapout - hfrefconout

delta $=\mathrm{QE} /$ (hwastein $\cdot$ twasteout)

$\mathrm{QD}=$ alpha " hdesout + hdesvapout - beta $\cdot$ hhxout

phi $=\mathrm{QD} /$ (bwastein - hwasteout)

$\mathrm{QC}=$ hdesvapout $\cdot$ hfrefconout

sy $=\mathrm{QC} /$ (howout $\cdot$ howin)

$\mathrm{COP}=\mathrm{QA} /(\mathrm{QE}+\mathrm{QD})$

msteam $=$ qout $/$ (hgcaout - hfcain $)$

$\mathrm{mw}=\mathrm{msteam} / \mathrm{gamma}$

msolconc $=$ alpha $\cdot \mathrm{mw}$

msoldilut $=$ beta ${ }^{\circ} \mathrm{mw}$

mevawaste $=$ delta ${ }^{\circ} \mathrm{mw}$

mdeswaste $=\mathrm{phi} \cdot \mathrm{mw}$

mconh2o $=8 y * \mathrm{mw}$

CAlLL denh2o(trefconoul, theh2o)

.......... assuming $60 \%$ efficiency for the pumps $\ldots . . . \ldots . . . . .$. 
$\begin{array}{ll}\text { WPabs }=\text { (pevapout } \cdot \text { pdeain }) \bullet 144 / \text { thosoln } / .6 & 144 \text { corverts from }(1 / \mathrm{in} \wedge 2) \text { to }(1 / \mathrm{f} \wedge \text { ^ }) \\ \text { PBabe }=\text { WPabs } \bullet \text { meolconc } \bullet .0012851 & 1.2851 \mathrm{E}-3 \text { converts } \mathrm{ft} \cdot \mathrm{lb} \text { to } \mathrm{Btu} / \mathrm{hr}\end{array}$

WPcon $=$ (pevapout - pdesin $) \cdot 144 /$ thoh $20 / .6$

$\mathrm{PBcon}=$ WPcon ${ }^{*} \mathrm{mw} \cdot .0012851$

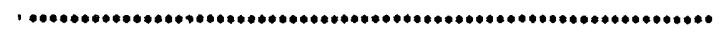

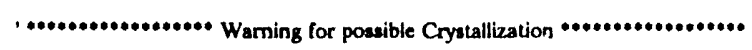

IF tcryscodeabeout $=1$ OR tcryscodedesin $=1$ OR tcryscodedesout $=1$ OR tcryscodeabsin $=1$ THEN

CLS : CALL border

iill $=0$

LOCATE 3, 3: PRINT DATES

LOCATE 3, 26: PRINT "Run Identity "; ESTIDS

LOCATE 5, 3: PRuNT "Worting luid "; cons: " wt\% ": mats

If teryecodeabeout $=1$ THEN

iill = iill + 1: LOCATE $(6+$ iill), 3: PRINT "Sol'n from sbsorber is below crystallization temperature of; terysabsout; " Deg. F" iill = iill + 1: LOCATE $(6+$ iitl), 3: PRINT wtout; " wt\% Sol'n from absorber at "; tabsout; " Deg. F"

END IP

IF teryecodedesin $=1$ THEN

iill = iill + 1: LOCATE (7 + iill), 3: PRINT "Sol'n to generator is below crystallization temperature of"; tcrysdesin; " Deg. F" iill = iill + 1: LOCATE $(7+$ iill), 3: PRINT wt 1; " wt\% Sol'n to generator at "; tdeso; " Deg. F"

END IP

IP teryscodedesout $=1$ THEN

iill = iill + 1: LOCATE $(8+$ till), 3: PRINT "Sol'n from generator is below crystallization temperature of"; tcrysdesout; " Deg F" iill = iill + 1: LOCATE $(8+$ iill), 3: PRINT wt; " wt\% Sol'n from generator at "; tdesout; " Deg. F"

END IP

IF tcryscodeabsin $=1$ THEN

iill = iill + 1: LOCATE $(9+$ iill), 3: PRINT Sol'n to absorber is below crystallization temperature of"; tcrysabsin; " Deg F"

iill = iill + 1: LOCATE (9 + iill), 3: PRINT wt; " wt\% Sol'n to absorber at "; tabsin; " Deq F"

END IP

CALL noise: COLOR 31, bac: LOCATE 19, 24: PRINT "WARNING: Freeze-up is Possible"

LOCATE 21, 26: PRINT "PLEASE CHECK YOUR INPUTS": COLOR frg, bac

LOCATE 23, 26: PRINT "PRESS ANY KEY TO CONTTNUE"

DO WHILE INKEYS $\approx-$ : LOOP

GOTO mainchoicei:

END IF

CLS : CALL border

LOCATE 3, 3: PRINT DATES

LOCATE 3, 26: PRINT "Run Identity "; ESTIDS

LOCATE S, 3: PRINT "Working fluid "; con\$; " wt\% "; mats

LOCATE 6, 3: PRINT "Maximum possible boost temperature "; tmax, "Deg. F"

LOCATE 7, 3: PRINT "Concentration of solution entering the absorber"; wt: " wt\%"

LOCATE 8, 3: PRINT "Concentration of solution leaving the absorber"; wtout; " wt\%"

LOCATE 9, 3: PRINT "Temperature of solution leaving the absorber "; tabsout; " Deg, F "

LOCATE 10, 3: PRINT "Temperature of solution leaving the desorber "; tdesout; " Deg. F

LOCATE 11, 3: PRINT "Lift temperature "; (tabsout - tdesout); " Deg. F"

LOCATE 12, 3: PRINT "Concentration of solution entering the desorber "; wt1: " wt\%"

LOCATE 13, 3: PRINT "COP "; COP

LOCATE 14, 3: PRINT "Steam flow rate "; msteam; " $\mathrm{b} / \mathrm{hr}$ for a capacity of "; qout; " Btu/hr"

LOCATE 15, 3: PRINT "Refrigerant (water) now rate "; mw; " $\mathrm{lb} / \mathrm{hr} "$

LOCATE 16, 3: PRINT "Concentrated solution how rate "; nusolconc; "lb/hr"

LOCATE 17, 3: PRINT "Dilute solution flow rate "; msoldilut; " $1 \mathrm{~b} / \mathrm{hr}$ "

LOCATE 18, 3: PRINT "Evaporator waste flow rate "; mevawaste; " $\mathrm{lb} / \mathrm{hr}$ "

LOCATE 19, 3: PRINT "Desorber waste flow rate "; mdeswaste; " Ib/hr"

LOCATE 20, 3: PRINT "Condenser water flow rate "; meonh2o; " Ib/hr"

LOCATE 23, 26: PRINT "PRESS ANY KEY TO CONTTNUE"

DO WHILE INKEYS $=-$ : LOOP

- Calculation of UA for absotber, desorber, evaporator, condenser,

and solution beat exchanger.

r.

Qabsorber $=\mathrm{mw} \cdot \mathrm{QA}$

Qdesorber $=\mathrm{mw}^{\bullet} \mathrm{QD}$

Qevaporator $=\mathrm{mw} \cdot \mathrm{QR}$

Qcondenser $=\mathrm{mw} \cdot \mathrm{OC}$

$\mathrm{QHX}=$ (habsout - hhxout) " msoldilut

DeltaTlmEVA $=(($ twaste - tevapout $)-($ twasteout - trefconout $)) /$ LOG $(($ twaste - tevapout $) /($ twasteout - trefconout $))$

UAevaporator $=$ Qevaporator $/$ DeltaTimEVA

DeltaTlmCON $=\left((\right.$ trefconout - towin $) \cdot\left(\right.$ tdesout $\left.\left.-t_{\text {cwout }}\right)\right) / \mathrm{LOG}(($ trefconout - tcwin $) /($ tdesout - tcwout $))$

UAcondenser $=$ Ocondenser / DeltaThmCON

DeltaTmDES $=(($ twaste - tdesout $)-($ twasteout - tdeso $)) / \operatorname{LOG}(($ twaste - tdesout $) /($ twasteout - tdeso $))$

UAdesorber $=$ Qdesorber $/$ Delta'ThmDES 
DeltaTlmHX $=(($ tabsout - tabsin $) \cdot($ throut - tdesout $)) / L O G(($ tabsout - tabsin $) /($ throut - tdesout $))$

$\mathrm{UAHX}=\mathrm{QHX} /$ DeltaTImHX

- Assuming temperature of wolution after entering the sbeorber is 22 degrees $F$
' higher than the concentrated solution leaving the heat exchanger.

$3 x=$ tabsin +22

DeltaThmABS $=(($ tabsout - tcain $)-($ t3x - tcaout $)) / \operatorname{LOG}(($ tabsout - tcain $) /($ t3x - tcaout $))$

UAabsorber = Qabsorber / DeltaTlmABS

CLS : CALL border

LOCATE 3, 3: PRINT DATES

LOCATE 3, 26: PRINT "Run Identity "; ESTIDS

LOCATE 5, 3: PRINT Worting fluid "; cons: " m\% "; mats

LOCATE 6, 3: PRINT "Maximum poesible boost temperature "; tmax " Deg. $\mathrm{F}^{m}$

LOCATE 7, 3: PRINT Total beat transferted in the aberber "; Qabsorber, " Btuhr"

LOCATE \& 3: PRINT Tolal beat tranaferted in the deworber "; Qdesorber, "Btu/hr"

LOCATE 9, 3: PRINT Total heat transferred in the condenser "; Qcondenser; " Btu/hr"

LOCATE 10. 3: PRINT "Total heat transferred in the evaporator "; Qevaporator, "Btu/hr"

LOCATE 11, 3: PRINT "Total beat cransferted in the solution HX "; QHX; " Btu/hr"

LOCATE 12, 3: PRINT "Required UA for the absorber "; UAabsorber; " Btu/hr-Deg F"

LOCATE 13, 3: PRINT "Required UA for the desorber "; UAdesorber; " Btu/hr. Deg F

LOCATE 14, 3: PRINT "Required UA for the condenser "; UAcondenser; "Btu/hr-Deq. F"

LOCATE 15, 3: PRINT "Required UA for the evaporator"; UAevaporator; " Btu/hr-Deg F

LOCATE 16, 3: PRINT "Required UA for the solution HX "; UAHX; " Btu/hr-Deg. F"

LOCATE 17, 3: PRINT Total UA required "; (UAabsorber + UAdesorber + UAcondenser + UAevaporator + UAHLX); " Btu/hr-Deg. F"

LOCATE 18, 3: PRINT "Power supplied to pump after desorter "; PBabs; "Btu/hr"

LOCATE 19, 3: PRINT "Power supplied to pump after condenser ": PBcon; "Btuhr"

LOCATE 20, 3: PRINT Total power supplied to both pumps "; (PBabs + PBcon); " Btu/hr"

LOCATE 21, 3: PRINT "COP corrected for parasitic pumping power "; Qabsorber / (Qevaporator + Qdesorter + 4 * (PBabs + PBcon))

LOCATE 23, 26: PRINT "PRESS ANY KEY TO CONTINUE"

DO WHILE INKEYS $=-$ : LOOP

CLS : CALL border

LOCATE 3, 3: PRINT DATES

LOCATE 3, 30: PRINT "Run Identity ": ESTIDS

LOCATE S, 29. PRINT "Operating parameters"

LOCATE 7, 22: PRINT "Worting fluid "; cons; " wt\% "; mats

FOR jii $=1$ TO 38: LOCATE \& $(20+$ ijii): PRINT CHRS(205): NEXT jij

LOCATE 10, 5: PRINT - Stream $T$ P wt\% Enthalpy

LOCATE 11, S: PRINT "Description (Deq F) (psia) (Btu/b) (Ib/hr)"

FOR jii = 1 TO 74: LOCATE $12(3+\mathrm{jjii})$ : PRINT CHRS(19): NEXT jiii

$a b c=0$

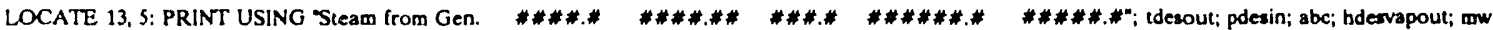

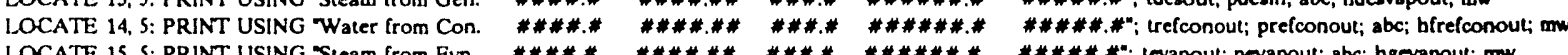

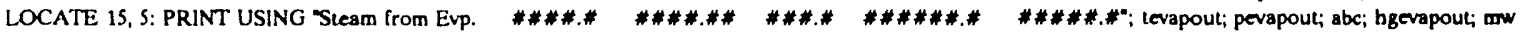

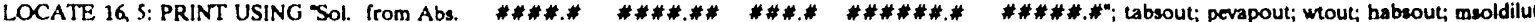

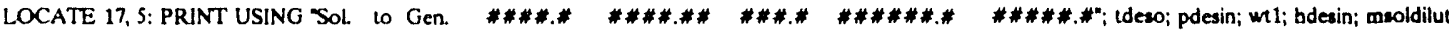

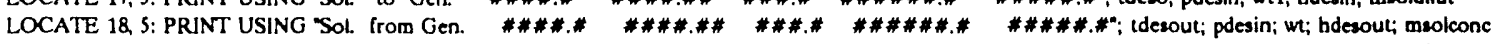

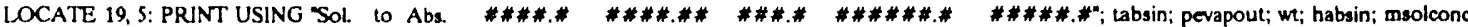

FOR ijii $=1$ TO $74:$ LOCATE 20, $(3+$ jiii): PRINT CHRS(196): NEXT jiii

LOCATE 23, 28: PRINT "PRESS ANY KEY TO CONITNUE"

DO WHILE INKEYS $=-$ : LOOP

GOTO MAINMENU:

ENDop1:

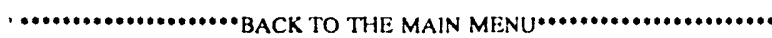

END OF OPTION $1 \cdots \ldots \ldots \ldots \ldots \ldots \ldots$

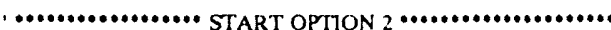

mainchoiceii:

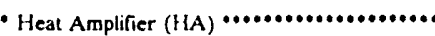

CALL logoHA

$\cdots \cdots \cdots \cdots \cdots \cdots \cdots * \bullet$ DESIRED WORKING FLUID $* \cdots \cdots \cdots \cdots \cdots \cdots$

.

mixlii:

CALL mixture: Working nuid

traps = INKEYS: IF trap $\$=-$ GOTO mixlii:

IF traps = "A" THEN mals = "LiBr": GOOTO mixii: 


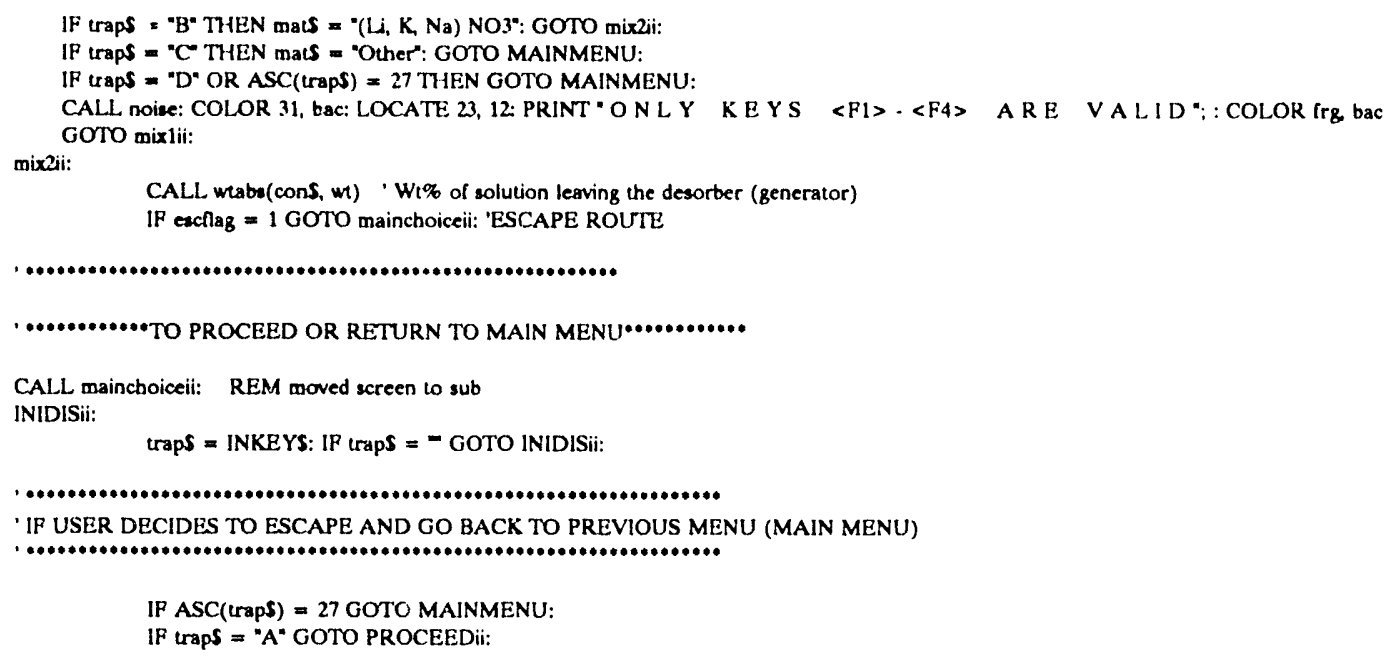

CALL tabdata2(ESTDS, matS, conS, qout, tewin, twastedesin, twasteevapin, tcapp, teapp, tdapp, taapp, thrapp)

-

' IF USER WANIS TO GO BACK ESCFLAG BECOMES I FROM SUBROUTINE TABDATA

.........................................................

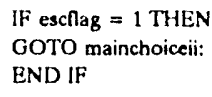




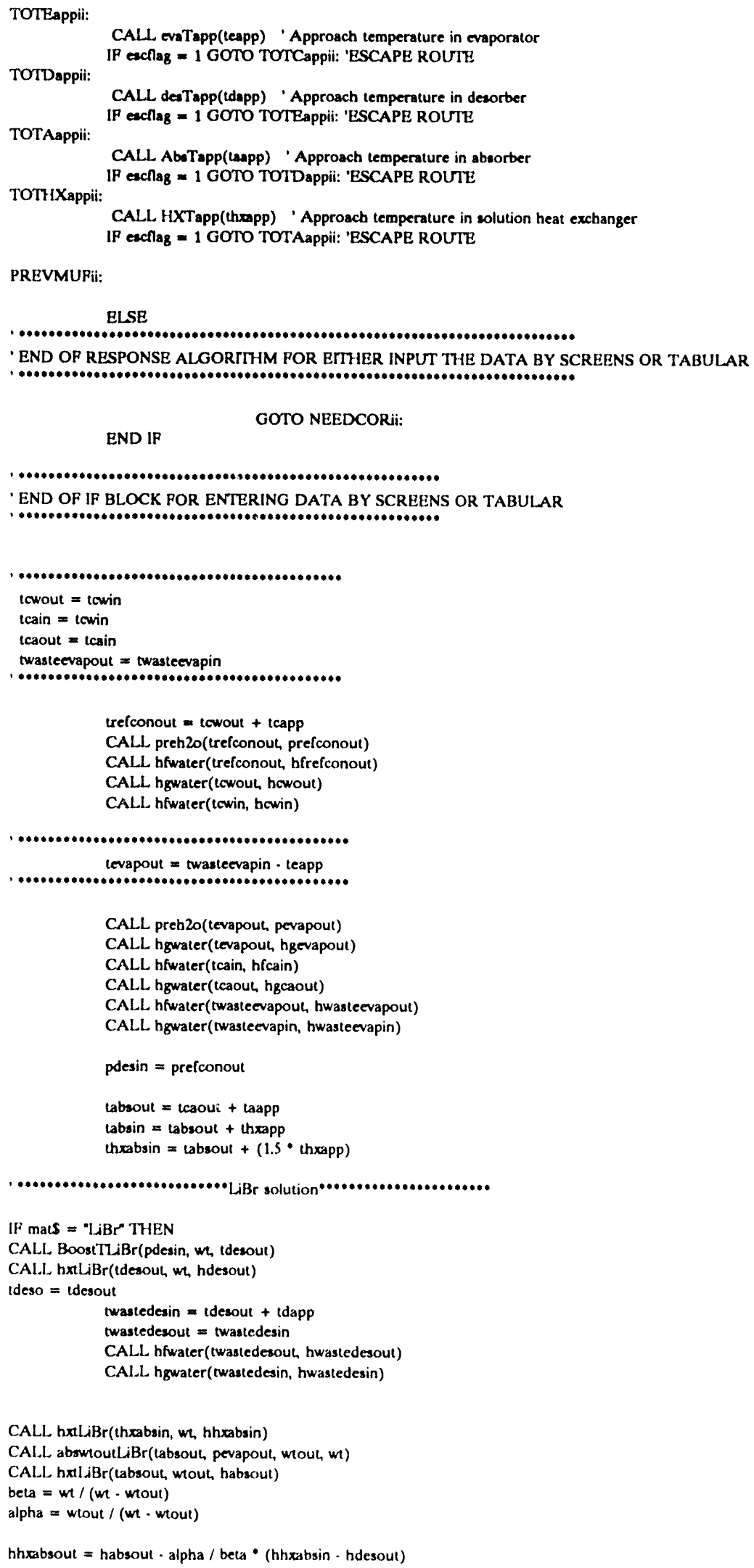

CALL hxtLiBr(thxabsin, wh, hhxabsin)

CALL abswtoutliBr(tabsout, pevapout, wtouh wt)

CALL hxtLiBr(tabsout, wtout, habsout)

beta $=w t /(w t \cdot w t o u t)$

alpha $=$ wtout $/$ (wt - wtout $)$

hhxabsout $=$ habsout - alpha $/$ beta $\cdot($ hhxabsin - hdesout $)$ 
CALL ISATH2O(pevapout, tsat)

CALL hgwater(taat, $\left.\mathrm{H}_{\mathrm{g}}\right)$

CALL hgauper(pevapouc, $\mathrm{H}_{\mathrm{g}}$ Lat, labsin, habsvapin)

CALL, throutcalLiBr(hhrabsout, whout, throut)

hdesin = bhobsout

CALL TSATH2O(pdeain, tsat1)

CALL, bgwater(taat $1, \mathrm{H}_{\mathbf{g}} 1$ )

CALL, bgauper(pdesin, $\mathrm{HgI}_{\mathrm{g}}$ tsat 1, tdeso, hdesvapout)

CALL thtcalLBBrHA(htuxabein, tabsin, wt1, wh habsvapin, wtout)

IF exclag = 1 THEN GOOTO MAINMENU:

CALL hxtliBr(tabsin, wt1, habsin)

CALL denlibr(tabsoul, wtout, thowin)

. *.***. Checking the cryatallization temperature of the streams *......

CALL TcrysliBr(wtout, tabeout, tcrysabsout, teryscodeabsout)

CALL TeryoliBr(wrout, throuh teryodesin, teryscodedesin)

CALL TerysliBr(wt, tdesout, teryadesout, tcryscodedesout)

CALL. TcryaliBr( $w$ t, tabsin, tcrysabsin, tcryscodeabsin)

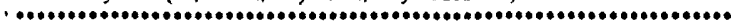

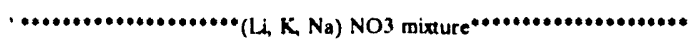

ELSEIP mats * "(L, K. Na) NOJ" THEN

CALL Boost Talk (pdesin, wh, tdesout)

CALL hxtalk(tdesout, wh, hdesout)

tdeso $=$ tdesout

twastedesin $=$ tdesout + tdapp

twastedesout $=$ twastedesin

CALL hfwater(twastedesoul, hwastedesout)

CALL hgwater(twastedesin, hwastedesin)

CALL hxtalk(thrabsin, wh, hhoabsin)

CALL abswtoutalk(tabsout, pevapout, wrout, wt)

CALI. hxtalk(tabsout, wtout, habsout)

beta $=w t /(w t$ - wtout $)$

alpha $=$ wtout $/(w t \cdot$ wtout $)$

hhxabsout $=$ habsout - alpha $/$ beta $\cdot($ hhos bsin - hdesout $)$

CALL. ISATT2O(pevapouh, tsat)

CALL hgwater $($ tsat, $\mathrm{Hg})$

CALL hgsuper(pevapout, Hg, tsat, tabsin, habsvapin)

CALL thxoutcalalk(bhxabsout, wtout, thxout)

hdesin $=$ hhos bout

CALL TSATH2O(pdesin, tsat1)

C.ALL Lgwater(tsat1, $H_{\text {g }}$ )

CALL hgsuper(pdesin, $H_{B} 1$, tsat1, tdeso, hdesvapout)

CALL xhtcalalkHA(bhrabsin, tabsin, wt 1, wh, habsvapin, wtout)

IF escilag = I THIEN GOTO MAINMENU:

CALL hxtalk(tabsin, wtl, habsin)

CALL denalk(Labsoul, wtoul, rhosoln)

........ Checking the crystallization temperature of the streams "......

CAl.L Tcrysalk (wroul, tabsouth tcrysabsout, tcryscodeabsout)

CALL Tcrysalk(wtout, throut, tcrysdesin, tcryscodedesin)

CALL. Tcrysalk (wt, tdesout, tcrysdesouth tcryscodedesout)

CAL.L. Tcrysalk(wt, tabsin, tcrysabsin, tcryscodeabsin)

C...........................................................................

END IF

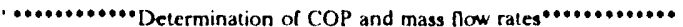

$\mathrm{QA}=$ hgevapout + alpha $\cdot$ hhxabsin $\cdot$ beta 'habsout

gamma $=Q A /$ (hgcaout - hfcain)

$\mathrm{QE}=$ hgevapout - hfrefconout 


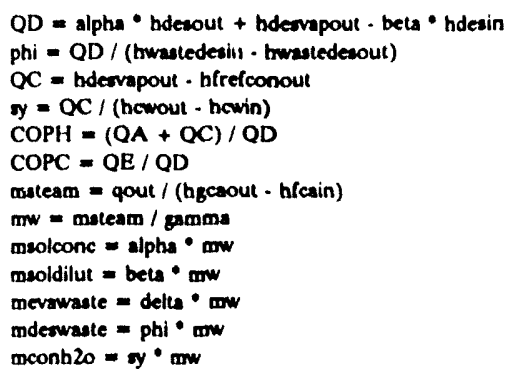

efficiency $=.6$ 'assuming $60 \%$ efficiency for the pumpe

WPabo = (pdesin - pevapout) $144 /$ mosoln $/ .6$ ' 144 converts from ( $/$ in ^ 2) to (1/ft^2)

PBabe = WPabe " meoldilut $\cdot .0012851 \quad 1.2851 \mathrm{E}-3$ converts $\mathrm{ft}-1 \mathrm{~b}$ to Btu/hr

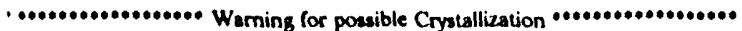

IF tcryacodeabsout $=1$ OR teryacodedesin $=1$ OR teryscodedesout $=1$ OR tcryscodeabsin $=1$ THEN CLS : CALL border

iill $=0$

LOCATE 3. 3: PRINT DATES

LOCATE 3. 26: PRINT "Run Identity "; ESTIDS

LOCATE 5, 3: PRINT Worting nuid "; cons; " wt\% ": mals

IF teryecodeabrout $=1$ THEN

iill = iill + 1: LOCATE $(6+$ iill), 3: PRINT Sol'n from absorber is below crystallization temperature of; tcrysabsout: "Deg. F" iill = iill + 1: LOCATE (6 + iill), 3: PRINT wtout; " w\% Sol'n from absorber at "; tabsout; " Deg. F"

END IF

IF tcryscodedesin $=1$ THEN

iill = iill + 1: LOCATE $(7+$ iill), 3: PRINT "Sol'n to generator is below crystallization temperature of"; teryadesin; " Deg. F" iill = iill + 1: LOCATE (7 + iill), 3: PRINT wtout; " wt\% Sol'n to generator at "; throut; " Deg. F"

END IF

IF teryscodedesout $=1$ THEN

iill = iill + 1: LOCATE $\left(8+\right.$ iill), 3: PRINT Sol'n from generator is below cryatallization temperature of; tcrysdesout; ${ }^{\circ}$ Deg $F^{*}$ iill = iill + 1: LOCATE $(8+$ iill), 3: PRINT wt: " wt\% Sol'n from generator at "; tdesout; " Deg. F" END IF

IF teryscodeabsin $=1$ THEN

iill x iill + 1: LOCATE $(9+$ iill), 3: PRINT "Sol'n to absorber is below crystallization temperature of"; tcrysabsin; " Deq. F" iill = iill + 1: LOCATE $\left(9+\right.$ iill), 3: PRINT wt; " $w \%$ Sol'n to absorber at "; tabsin; ${ }^{\circ}$ Deg. F" END IF

CALL noise: COLOR 31, bac: LOCATE 19, 24: PRINT "WARNING: Preeze-up is Possible" LOCATE 21, 26: PRINT "PLEASE CHECK YOUR INPUTS": COLOR frg bac LOCATE 23, 26: PRINT "PRESS ANY KEY TO CONTINUE"

DO WHILE INKEYS $=-:$ LOOP

GOTO mainchoiceii

END IF

\section{CLS : CALLL border}

LOCATE 3, 3: PRINT DATES

LOCATE 3, 26: PRINT "Run Identity *: ESIIDS

LOCATE S, 3: PRINT "Working Ruid "; con\$: "wt\%"; mals

LOCATE 7, 3: PRINT "Concentration of solution leaving the desorber": wt; " wt\%"

LOCATE 8. 3: PRINT "Concentration of solution leaving the absorber"; wtout; " wt\%"

LOCATE 9, 3: PRINT "Temperature of solution leaving the absorber "; tabsout: " Deg F"

LOCATE 10, 3: PRINT "Temperature of solution leaving the desorber "; tdesout; " Deg. $F$

LOCATE 11, 3: PRINT "Lift temperature "; (tabsout - tevapout); " Deg F"

LOCATE 12. 3: PRINT "Concentration of solution entering the absorber ": wt 1; "wr\%"

LOCATE 13, 3: PRINT "COP heating and cooling "; COPII; " and "; COPC

LOCATE 14, 3: PRINI "Steam now rate "; msteam; " lb/hr for a capacity of "; qout; " Btu/hr"

LOCATE 15, 3: PRINI" "Refrigerant (water) how rate "; mw; " Ib/hr"

LOCATE 16, 3: PRINT "Concentrated solution flow rate "; msolconc; " lb/hr"

L.OCATE 17, 3: PRINT "Dilute solution flow rate "; msoldilut; " Ib $/ \mathrm{hr}$ "

LOCATE 18, 3: PRINT "Evaporator waste now rate "; mevawaste; " Ib/hr"

LOCAIT 19, 3: PRINT "Desorber waste How rate ": mdeswaste; "Ib/hr"

L.OCATE 20, 3: PRINT "Condenser water flow rate "; mconh2o, " $\mathrm{lb} / \mathrm{hr}$

LOCATE 23, 26: PRINT "PRESS ANY KEY TO CONIINUE"

DO WHILLE INKEYS $=-$ : LOOP 


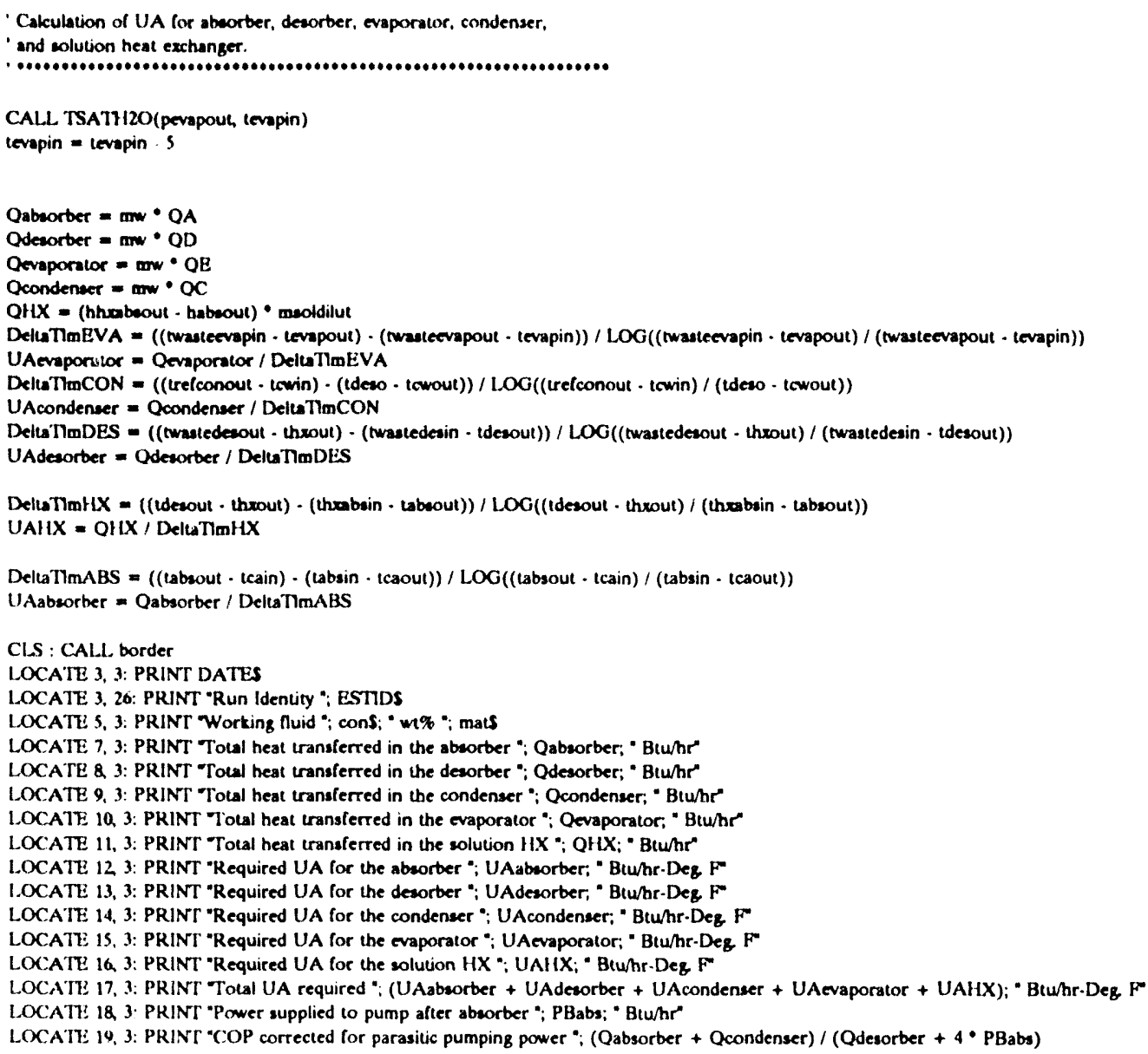

GOOTO MAINMENU

ENDop2: 


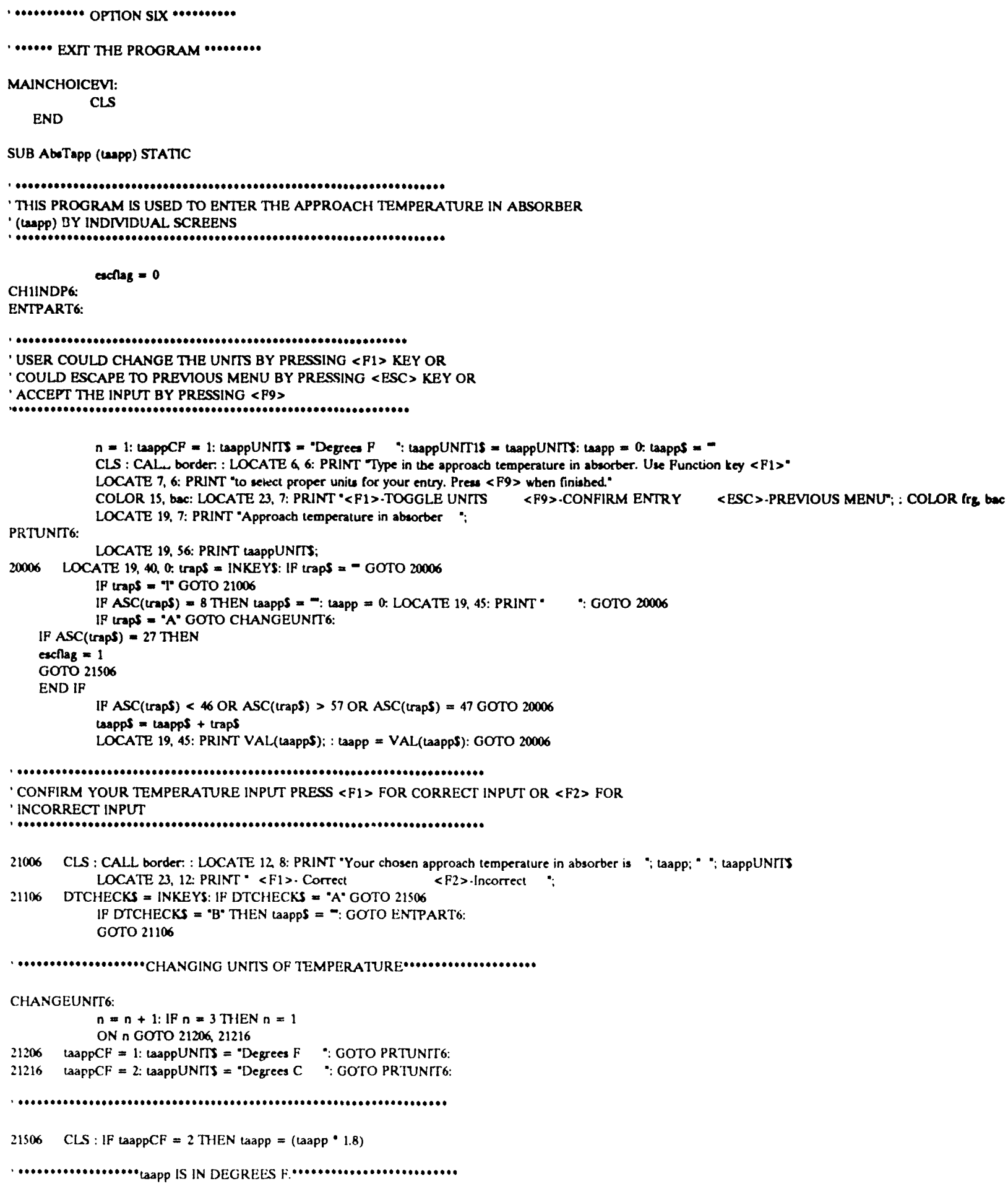

END SUB

SUB abswtoutalk (T, P, wtout, wt) STATTC 
"This program is used to calculate the wr\% of ( $\mathrm{L}, \mathrm{K}, \mathrm{Na}$ ) NO3 mixture

- (wtout) leaving the absorber from its pressure (P in pais) and

\section{Temperature (T in Deg F)}

\section{$i=0$. wtost $=m t$}

$C=6.21147: D=-2886.373: E=-337269.46 *$

$\log P=\operatorname{LOG}(P) / 2302585$

$\mathrm{T} 1=\left(-\mathrm{D}+\operatorname{SOR}\left(\mathrm{D} \wedge 2 \cdot 4^{*} \mathrm{E} \cdot(\mathrm{C}-\log P)\right)\right) /(2 \cdot(\mathrm{C}-\log P)) \cdot 459.72$

$3001 \mathrm{a}=-1.06427+.1020888^{\circ}$ wtout $-.00162566^{\circ}$ wtout $\wedge 2+8.93054 \mathrm{E}-055^{\circ}$ wtout $\wedge 3$

$\mathrm{B}=291.113 \cdot 13.0305^{\bullet}$ whout $+.187146^{\circ}$ whout $\wedge 2 \cdot 7.87688 \mathrm{E}-04 \cdot$ whout $\wedge 3$

$\mathrm{Ex}=\mathrm{T} \cdot(\mathrm{a} * \mathrm{~T} 1) \cdot \mathrm{B}$

aprime $=.102088 \cdot(2 \cdot .0016266) \cdot$ wtout $+(3 \cdot 893054 \mathrm{E}-06) \cdot$ whout $\wedge 2$

bprime $=(-13.0305)+(2 \cdot .187146+$ wtout $)-(3 \cdot 7.87688 \mathrm{E}-04) \cdot$ wtout $\wedge 2$

$\mathrm{d} f \mathrm{x}=($-aprime $\cdot \mathrm{T} 1) \cdot$ bprime

IF $\mathrm{i}>200$ GOTO 6001

whew $=$ whout $-(6 x ; d f x)$

IF ABS $(f x)>.0001$ THEN wtout $=$ wthew: $i=i+1$ : GOTO 3001

6011 IF ABS $(\mathrm{C} x)>.0001$ AND $\mathrm{i}>200$ THEN PRINT "Did not converge": END

wtout $=$ wtnew

END SUB

SUB abswtoutLiBr (T, P, wtoul, wr) STATTC

.

- This program is used to calculate the wt\% of $\mathrm{LiBr}$ solution (wtout)

' leaving the absorber from its pressure ( $P$ in psia) and Temperature

( $T$ in Deg F)

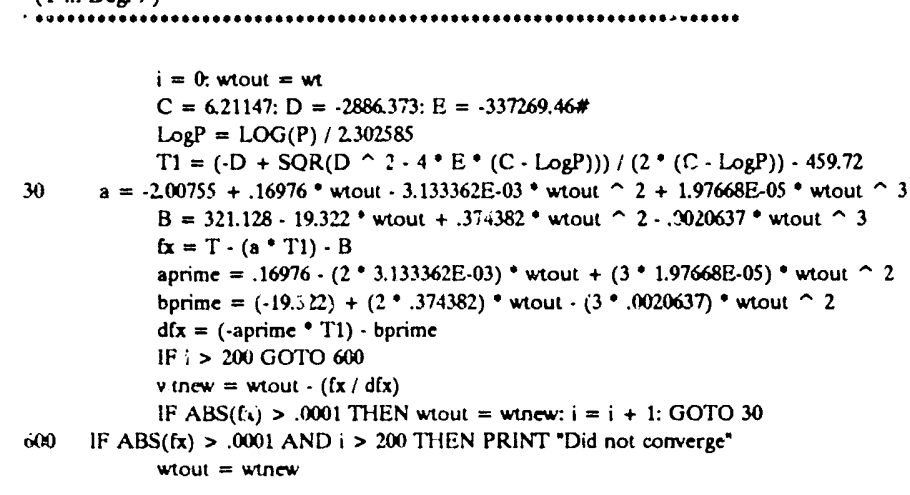

END SUB

SUB BoostTalk (P, wh tmax) STATIC

- Maximum Boost Temperature of Saturated ( $\mathrm{i}, \mathrm{K}, \mathrm{Na}$ ) NO3 /water (tmax)

Input P sat. (psia) and $w$ (wt\%) to calculate T sat (Deg. F).

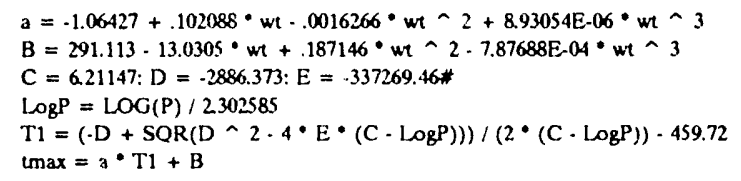

END SUB

SUB BoostTLiBr (P, wh, tmax) STATIC

Maximum Boost Temperature of Saturated LiBr (Lmax)

- Input P sal (psia) and wt (wt\%) to calculate T sat (Deg F)

...................................................................

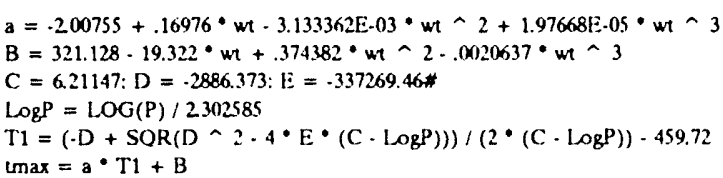


END SUB

SUB border STATIC

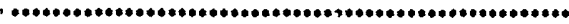

' THIS PROGRAM DRAY/S A BOX AROUND DESIRED SCREEN INPUTS

'THS DROGRAM DRAYS A BOX AROUND DESIRED ST

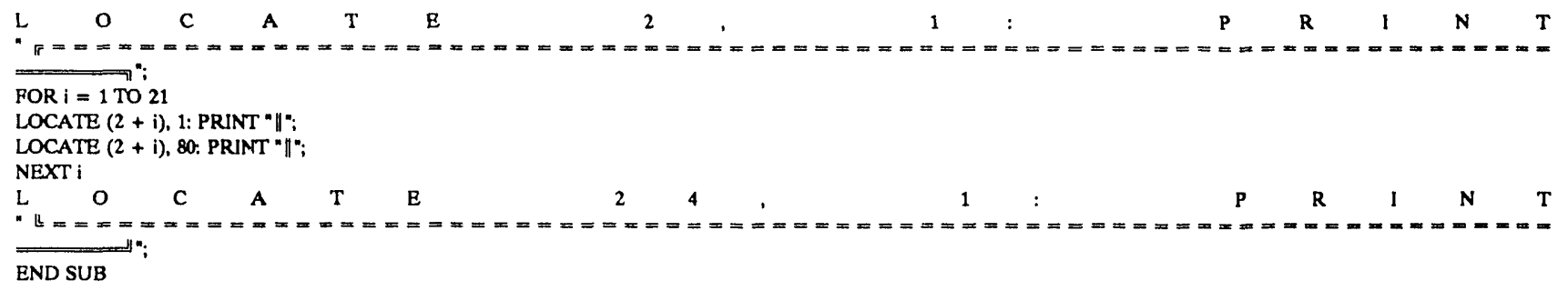

SUB condabsin (lowin)

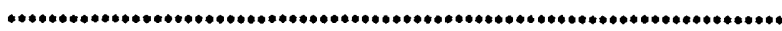

' THIS PROGRAM IS USED TO INPUT THE CONDENSER WATER INLET TEMPERATURE (LOWIn)

' BY INDIVIDUAL SCREENS

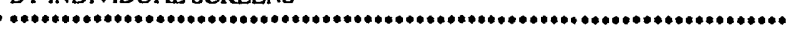

CHIINDPiii:

escllag $=0$

ENTPARTiii:

' USER COULD CHANGE THE UNITS BY PRESSING <F1 > KEY OR

' COULD ESCAPE TO PREVIOUS MENU BY PRESSING <ESC> KEY OR

'ACCEPT THE INPUT BY PRESSING <F9>

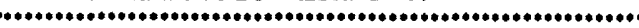

$\mathrm{n}=1:$ towinCF $=1:$ towinUNTT $=$ " Degrees $F ":$ towinUNIT1S = towinUNITs: towin $=0:$ towins $=$ -

CLS : CALL border: : LOCATE 6, 3: PRINT Type in the condenser and absorber cooling water temperature. Use Function"

LOCATE 7, 3: PRINT "key <F1> to select proper units for your entry. Press < F9> when finisbed." COLOR 15, bac: LOCATE 23, 7: PRINT "<F1>-TOGGLE UNITS <F9>-CONFIRM ENTRY

PRTUNTTii: LOCATE 19, 3: PRINT "Condenser and absorber cooling inlet temperature ":

LOCATE 19, 64: PRINT tcwinUNTS

OCATE 19, 40, 0. trapS = INKEYS: IF trap $\$=-$ GOTO 20033

IP traps = "I" GOTO 21033

IF ASC(trap\$) $=8$ THEN tcwins = ": towin = 0: LOCATE 19, 55: PRINT " ": GOTO 20033

IF trap $\$=$ "A" GOTO CHANGEUNITiii:

IF ASC(traps) $=27$ THEN

escllag $=1$

GOTO 21533

END IF

IF ASC(trap\$) < 46 OR ASC(trap\$) $>57$ OR ASC(trap\$) $=47$ GOTO 20033

tcwins = towin + traps

LOCATE 19, 55: PRINT VAL.(towin\$); : towin = VAL(towin\$): GOTO 20033

10000000000000000000000000000000000000000000000000000000000000000000000

' CONFIRM YOUR TEMPERATURE INPUT PRESS <F1> FOR CORRECT INPUT OR <F2> FOR

' INCORRECT INPUT

'

21033 CLS : CALL border: : LOCATE 12, 15: PRINT "Your chosen condenser and absorber" LOCATE 13, 15: PRINT "cooling water temperature is "; tcwin; " "; tcwinUNIIS LOCATE 23, 12: PRINT * <F1>- Correct <F2>-Incorrect ";

21133 DTCHECKS = INKEYS: IF DTCHECKS = "A" GOTO 21533

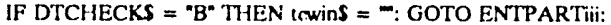
GOTO 21133

CHANGEUNTTiii:

$n=n+1:$ IP $n=3$ THEN $n=1$

ON $n$ GOTO 21233,21234

21233 towinCF $=1:$ tcwinUNTTS $=$ "Degrees $F ":$ GOTO PRTUNTTiii:

21234 towinCF $=2$ : towinUNITS $=$ " Degrees $C *$ : GOTO PRTUNITii: 


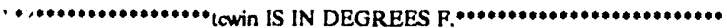

END SUB

SUB condh2oin (tcwin) STATIC

.

' THIS PROGRAM IS USED TO INPUT THE CONDENSER WATER INLET TEMPERATURE (tCwin)

BY INDIVIDUAL SCREENS

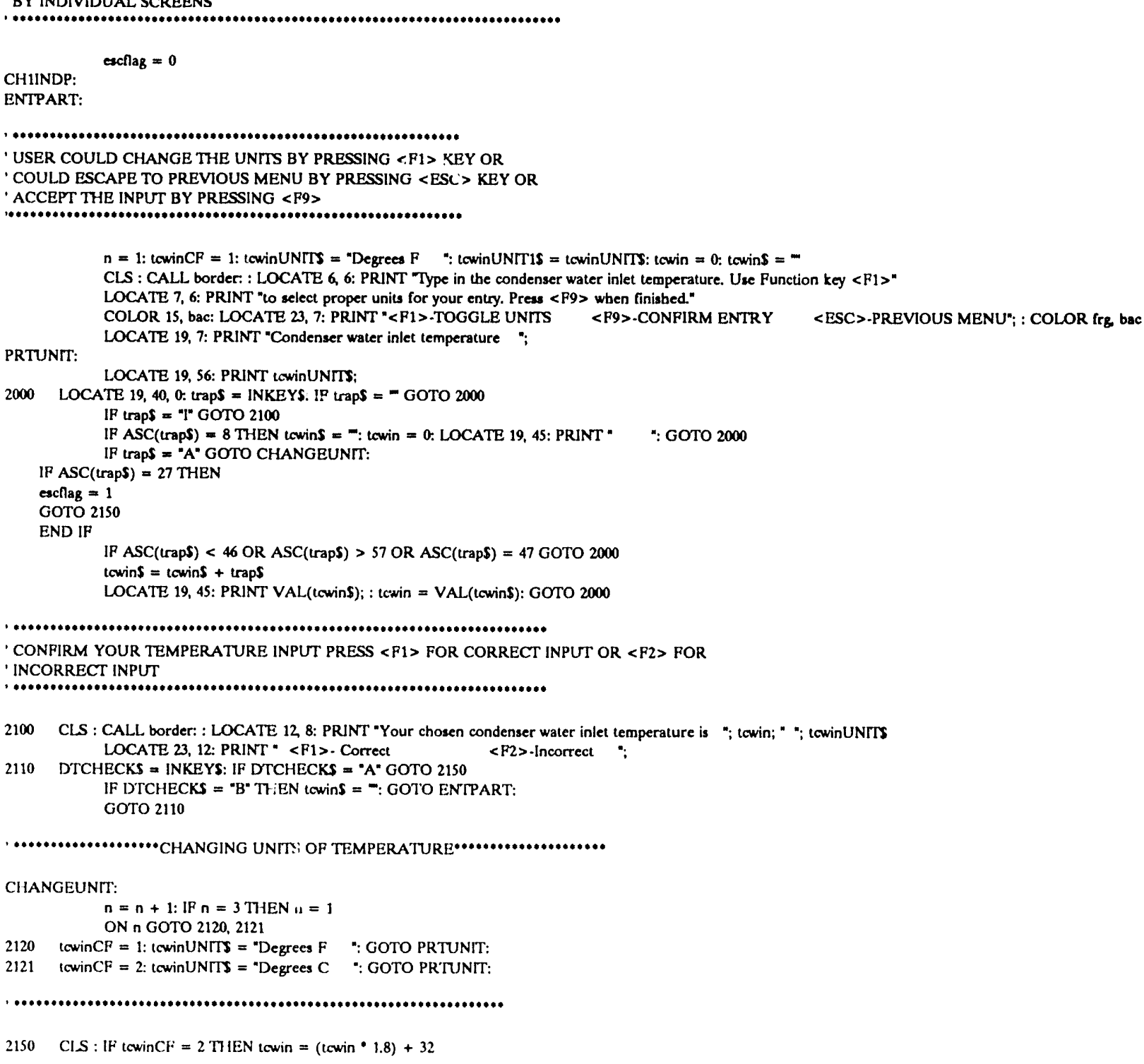

-

END SUB 


\section{MODULEII.BAS}

DECLARE SUB denalk (tn! wtl, hosoln!)

DECLARE SUB denlibr ( 4 , $m !$, thosoln!)

DECLARE SUB denh2o (tn, thoh2o!)

DECLARE SUB condabsin (towinl)

DECLARE SUB xhtcalalkHA (brt!, T!, wtout!, wt!, twapor!, wtabsout!)

DECLARE SUB xhtcalLiBrHA (hxl, TI, wtout!, wt!, bvapor!, wtabsout!)

DECLARE SUB mainchoiceii ()

DECLARE SUB tabdata2 (ESTIDS, matS, conS, qoutl, towinl, twastedesin!, twasteevapin!, tcapp!, teapp!, tdappl, taapp!, thrapp!) DECLARE SUB INPTWASTEDES (twastedesin!, twastedesinS, twastedesinUNITS, trapS, aaaa!)

DECLARE SUB wastebestevapin (twasteevapin!)

DECLARE SUB wastehesidesin (twastedesin!)

DECI ARE SUB logoTA ()

DECLARE SUB logOHA ()

DECLARE SUB hxtLiBr ( $(n, w), h \times 1 !)$

DECLARE SUB Boout Talk (PI, wt!, tmaxd)

DECLARE SUB abswtoutalk (T), P!, wtout!, wt!)

DECILARE SUB throutcalalt (hxt!, wt!, throut!)

DECLARE SUB xhtcalalk (hx!!, T, wtout!, wt!, bvapor, wtabsin)

DECLARE SUB hxalk (T1!, wt!, hx!)

DECLARE SUB prealk (Un, wt!, prat!)

DECLARE SUB hgsuper (past!, Hg!, tsat!, TI, hauperheat!)

DECLARE SUB TSATH2O (P!, T1!)

DECLARE SUB abswtoutLiBr (T!, P!, whout!, wt!)

DECLARE SUB throutcalLiBr (hxt!, wtl, throut!)

DECLARE SUB xhtcalLiBr (hrt!, T!, wtout!, wt!, hvapor, wtabsin)

DECLARE SUB preLiBr (tr!, w!! psat!)

DECLARE SUB BoostTLiBr (PI, wr!, tmax)

DECLARE SUB hgwater $(4 n, \mathrm{Hg}$ !)

DECLARE SUB bfwater (Un, b? )

DECLARE SUB preb2o (4n, P!)

DECLARE SUB TCABSIN (tcain!)

DECLARE SUB Tdesorber (tdeso!)

DECLARE SUB inptcain (tcainl, tcains, tcainUNTTs, trapS)

DECLARE SUB inptdeso (tdeso!, tdesos, tdesoUNTTS, trap\$)

DECLARE SUB wrabs (wts, wt)

DECLARE SUB deaTapp (tdapp!)

DECLARE SUB Abs'Tapp (taapp!)

DECLARE SUB HXTapp (thrappl)

DECLARE SUB inptcapp (tcapp!, tcappS, tcappUNITS, trapS)

DECLARE SUB inpteapp (leapp!, teappS, teappUNTT, trapS)

DECLARE SUB inptdapp (tdapp!, tdappS, tdappUNITS, trap\$)

DECLARE SUB inptaapp (Laapp!, taappS, taappUNTTS, trapS)

DECLARE SUB inpthrapp (thrapp!, thrappS, thrappUNIT, trapS)

DECLARE SUB condtapp (tcappl)

DECLARE SUB evaTapp (teapp!)

DECLARE SUB waterpre (tr!, hfl, Hg!, psat!, T1!)

DECLARE SUB inptowin (towin!, lowin\$, LowinUNTTS, trap\$, coc!)

DECLARE SUB INPTWASTE (twaste!, twasteS, twasteUNITS, trap\$, aa!)

DECLARE SUB wasteheatin (twaste!)

DECLARE SUB INPqout (qoutl, qouts, qoutUNITS, traps, bbb)

DECLARE SUB RUNID (ESTIDS, trap\$)

DECLARE SUB condb2oin (lowin)

DECLARE SUB qtout (qout)

DECLARE SUB tabdata (ESTIDS, matS, conS, qout!, towin!, twaste, tcapp, teapp, tdapp, taapp, thxapp, tcain, tdeso)

DECLARE SUB MAINMENU ()

DECLARE SUB TTTLESCR ()

DECLARE SUB mainchoicei ()

DECLARE SUB mixture ()

DECLARE SUB noise ()

DECLARE SUB border ()

COMMON SHARED frg, bac, escrlag

$\mathrm{frg}=14:$ bac $=1$

SUB condtapp (tcapp) STATTC

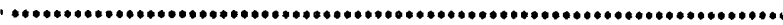

' THIS PROGRAM IS USED TO INPUT THE APPROACH TEMPERATURE IN CONDENSER (tCAPP)

' BY INDIVIDUAL SCREENS

.

CHIINDP3:

$\operatorname{esclag}=0$

ENTPART3: 


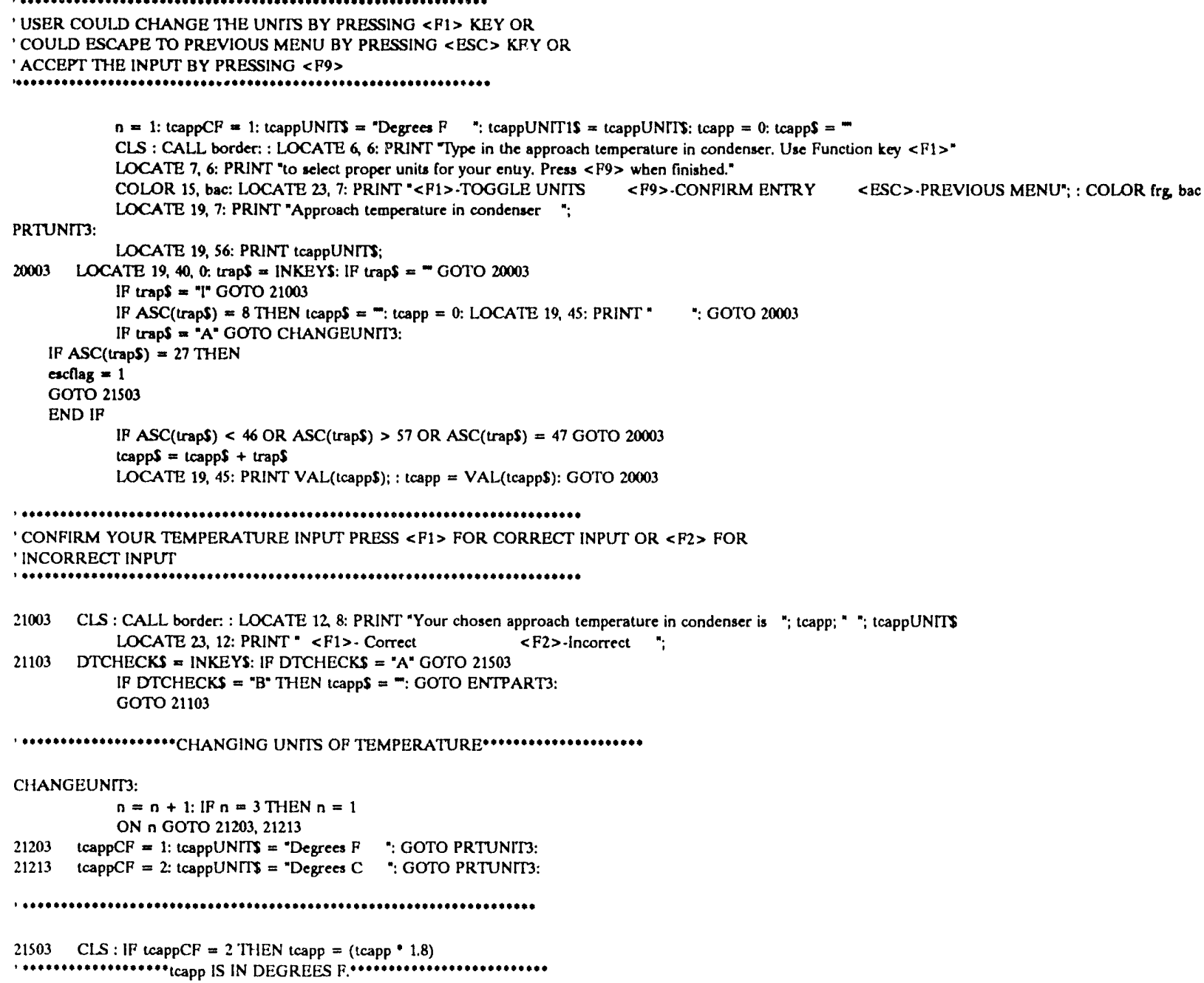

END SUB

SUB denalk ( $(f$, wh, rhosoln) STATIC

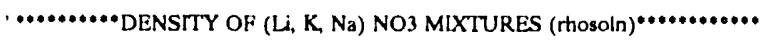

........................." to is in Degrees F

$\mathrm{a} 11=1.0980812353 \#: \mathrm{a} 21=-.00127501810157 \#$

$\mathrm{a} 12=.0024334711 \#: \mathrm{a} 22=.00001147387974 \#$

$\mathrm{a} 13=7.475 .38 \mathrm{E}-05: \mathrm{a} 23=-9.640613 \mathrm{E}-08$

$\mathrm{T}=(\mathrm{t} \cdot \mathrm{\cdot} 2) / 1.8$

rhosoln $=a 11+a 12 * w t+a 13 * w t \wedge 2+(a 21+a 22 \cdot w t+a 23 * w t \wedge 2) \cdot T$

rhosoln $=62.3719 \cdot$ thosoln

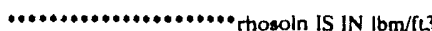

wt IS IN WT\% AND T IS IN DEGREES C..............

END SUB

SUB denh2o (tf, rhoh2o)

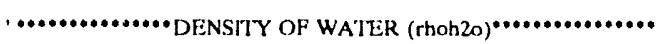

$T=\boldsymbol{L}$

$\mathrm{a} 11=62366496 \#: \mathrm{a} 21=.00568761 \#$ 


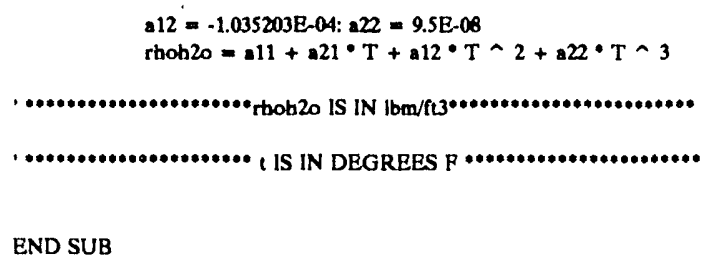

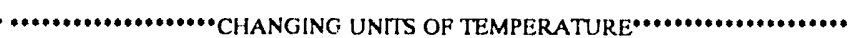

CHANGEUNTTS: 


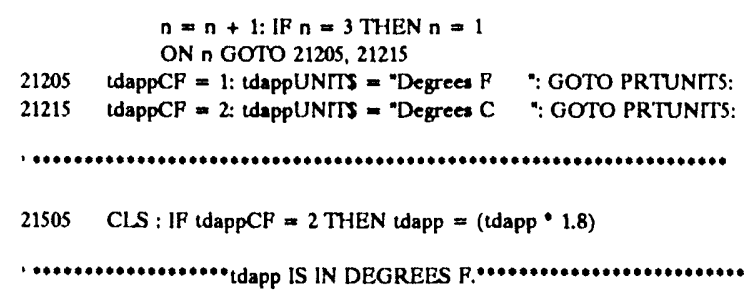

END SUB

SUB evaTapp (leapp) STATIC

' THIS PROGRAM IS USED TO INPUT THE APPROACH TEMPERATURE IN EVAPORATOR (leapP)

' BY INDIVIDUAL, SCREENS

(

CH1INDP4:

eaclag $=0$

ENTPART4:

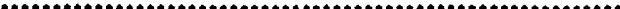

, USER COULD CHANGE THE UNTTS BY PRESSING $\angle F_{1}>$ KEY OR

' COULD ESCAPE TO PREVIOUS MENU BY PRESSING <ESC > KEY OR

ACCEPT THE INPUT BY PRESSING <F9>

(..........................................................

$n=1:$ teappCF $=1:$ teappUNITS $=$ "Degrees $F \quad ":$ teappUNIT1S $=$ teappUNITS: teapp $=0:$ teapp $S=-$

CLS : CALL border: : LOCATE 6, 6: PRINT "Type in the approach temperature in evaporator. Use Function key <F1 >"

LOCATE 7, 6: PRINT "to select proper units for your entry. Press <P9> when finished."

COLOR 15, bac: LOCATE 23, 7: PRINT "<F1>-TOGGLE UNITS <F9>-CONFIRM ENTRY <ESC>-PREVIOUS MENU"; : COLOR frg bac

PRTUNIT4: LOCATE 19, 7: PRINT "Approach temperature in evaporator ";

LOCATE 19, 56: PRINT teappUNITS;

20004 LOCATE 19, 40, 0: traps = INKEYS: IF trapS = - GOTO 20004

IF traps $=$ "I" GOTO 21004

IF ASC(trapS) $=8$ THEN teappS $=$ ": teapp $=0$ : LOCATE 19, 45: PRINT " $\quad$ ": GOTO 20004

IF trapS = "A" GOTO CHANGEUNIT:

ASC(trapS) $=27$ THEN

$\operatorname{escllag}=1$

GOTO 21504

END IF

IF ASC(trapS) < 46 OR ASC(trap\$) $>57$ OR ASC(trap\$) $=47$ GOTO 20004

teappS $=$ teappS + trapS

LOCATE 19, 45: PRINT VAL_(teapp\$); : teapp = VAL(teapp\$); GOTO 20004

.

' CONFIRM YOUR TEMPERATURE INPUT PRESS $<$ F1 $>$ FOR CORRECT INPUT OR $<F 2>$ FOR

- INCORRECT INPUTI

21004 CLS : CALL border: : LOCATE 12, 8: PRINT "Your chosen approach temperature in evaporator is ": teapp; " "; teappUNITS LOCATE 23, 12: PRINT * $\angle F 1>$ - Correct $<$ F2 $>$-Incorrect

21104 DTCHECKS = INKEYS: IF DTCHECKS = "A" GOTO 21504

IF DTCHECKS = "B" THEN teappS $=-$ : GOTO ENTPART4:

GOTO 21104

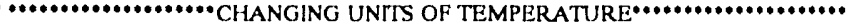

CHANGEUNRT 4:

$n=n+1:$ IF $n=3$ THEN $n=1$

ON $n$ GOTO 21204,21214

$21204 \quad$ teappCF $=1:$ teappUNTTS $=$ "Degrees $\mathrm{F} \quad \because:$ GOTO PR'TUNIT 4

21214 teappCF $=2$ : teappUNTT $=$ "Degrees C ": GOTO PRTUNTT4:

21504 CLS : IF teappCF $=2$ THEN teapp $=($ teapp $\bullet 1.8)$

END SUB

SUB hfwater (U, hn 


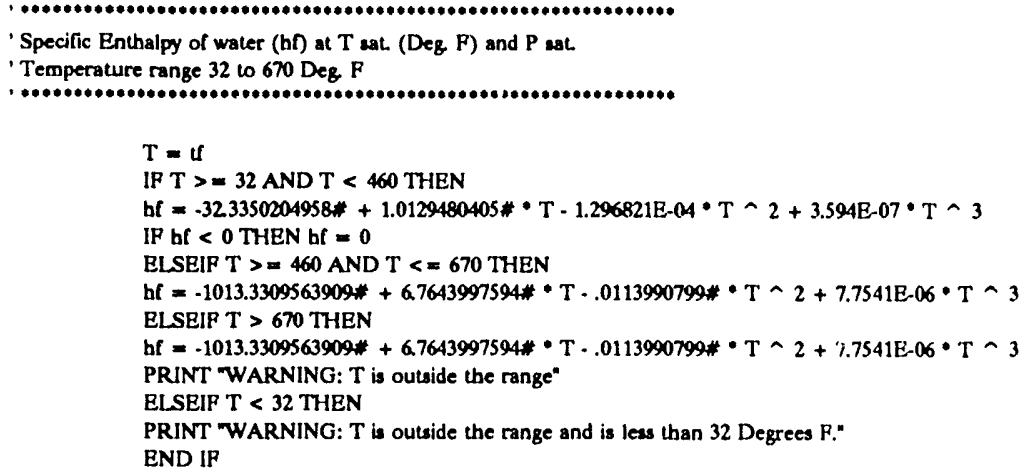

END SUB

SUB hgwater $\left(\mathrm{tf}, \mathrm{H}_{\mathrm{g}}\right.$ )

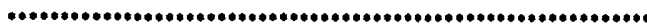

' Specific Enthalpy of Steam $\left(\mathrm{H}_{\mathrm{g}}\right)$ at $\mathrm{T}$ sat. (Deg. F) and P sat.

' Temperature range 32 to 670 Deg. F

-

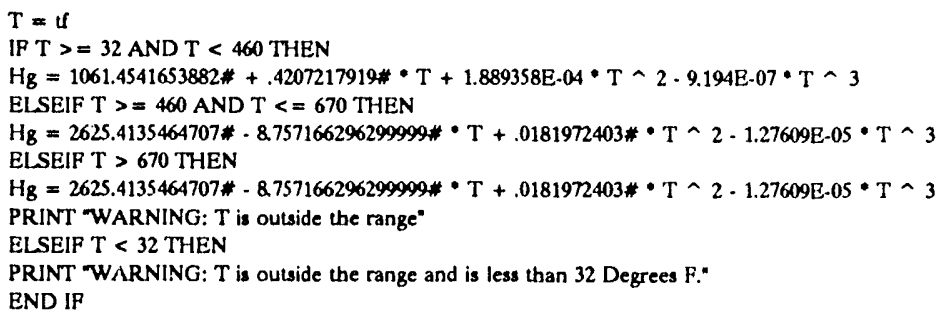

END SUB

SUB hxtalk (T1, wh hx)

' Specific Enthalpy of (Li, K, Na) NO3 Mixtures (hxt)

' CORRELATION BETWEEN 50 WT\% TO 94.1 WT\%

IF OUTSIDE THE RANGE OF WT\%, THIS PROGRAM CALCULATES THE VALUE

' USING THE CORRELATION WITH A WARNING

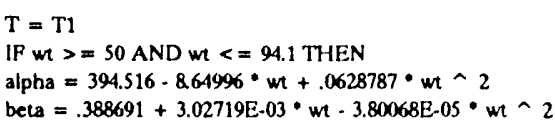


ELSE

PRINT WARNING: $w$ is outside the range $C p$ and $I X X$ could be inaccurate"

alpha $=394.516 \cdot 864996^{\circ} w t+.0628787 \cdot w t \wedge 2$

beta $=.388691+3.02719 \mathrm{E}-03 \cdot w t-3.80068 \mathrm{E}-05 \cdot w t \wedge 2$

END IP

hxt $=$ alpha + beta $\cdot T$

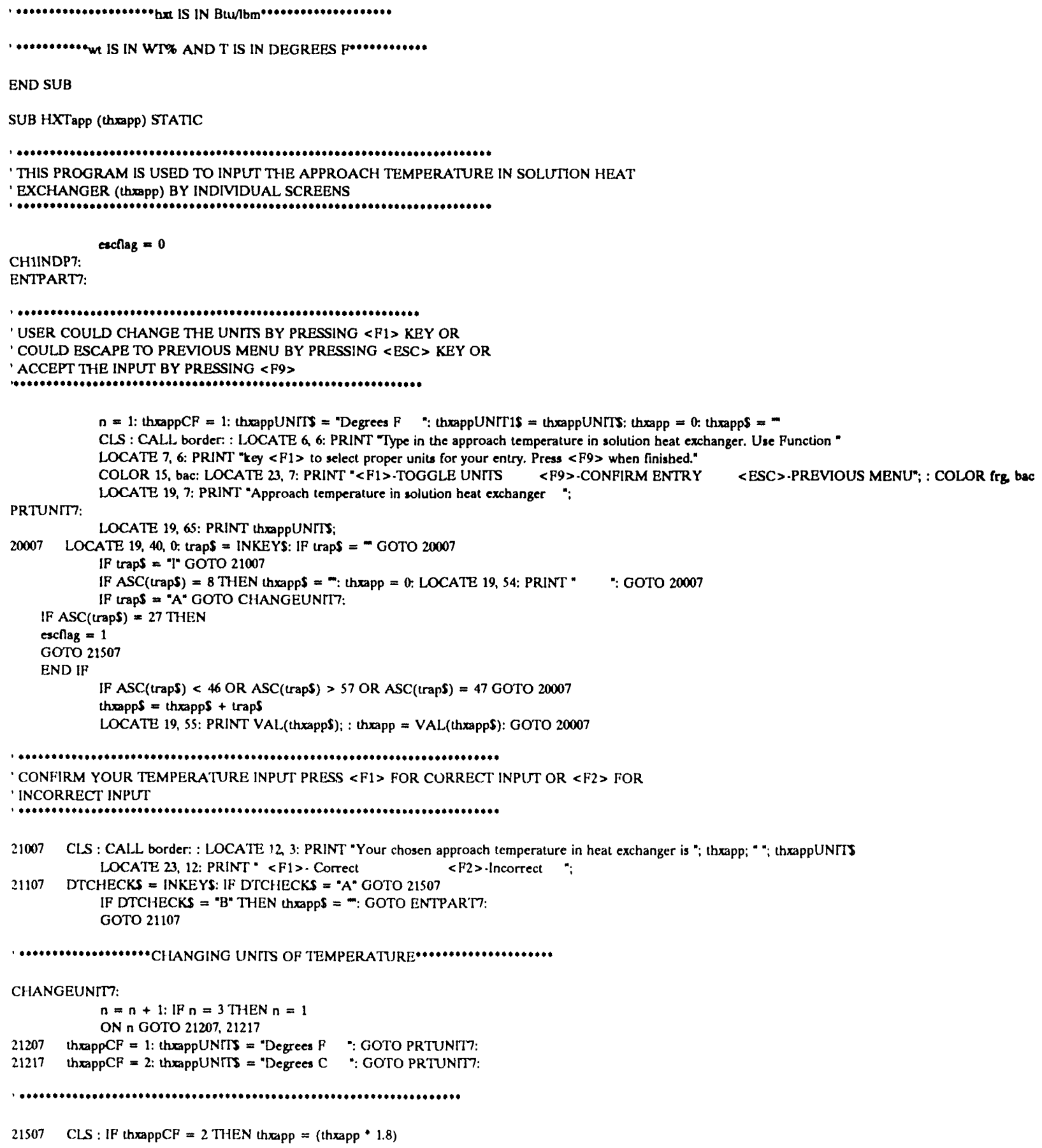




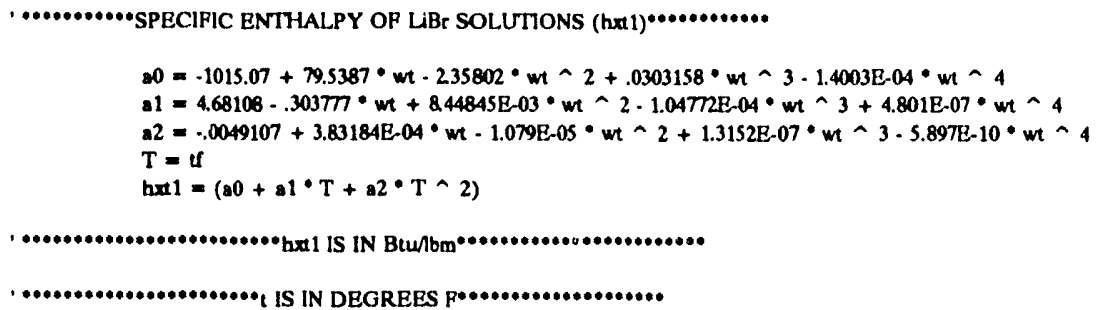

END IF CHANGEU:

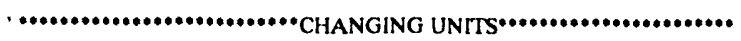

LOCATE 6, 35: COLOR bac frg $n=n+1: \operatorname{IP}_{n}=5$ THEN $n=1$

ON n GOTO 26, 27, 28, 29

26 qoutCP $=1$ : qoutUNITS $=$ " Btu/hr ": GOTO 25

27 qoutCF $=1 / 1055:$ qoutUNITS $=* \mathrm{~J} / \mathrm{hr} \quad$ ": GOTO 25

28 qoutCP $=1000000 !:$ qoutUNTTS $={ }^{*} \mathrm{MM}$ Btu/hr $":$ GOTO 25

29 qoutCF $=341232$; qoutUNTTS $=$ " $\mathrm{kW}$ ": GOTO 25

DATAF:

qout $=$ qout $\bullet$ qoutCF

LOCATE $6,(3+b b b+1)$ : COLOR frg, bac: PRINT SPACES(8)

LOCATE $6,(3+b b b+1)$ : PRINT qouts

LOCATE $6,(3+$ bbb + 12): PRINT qoutUNITS

END SUB

SUB inplaapp (taapp, taappS, taappUNITS, trap\$) STATTC



' THIS PROGRAM IS USED TO INPUT APPROACH TEMPERATURE IN ABSORBER (LaAPP)

' IN TABULAR FORMAT

LOCATE 11, 38: COLOR bac, frg: PRINT SPACES(8)

LOCATE 11, 38: PRINT taappS

LOCATE 11, 51: COLOR frg bac 


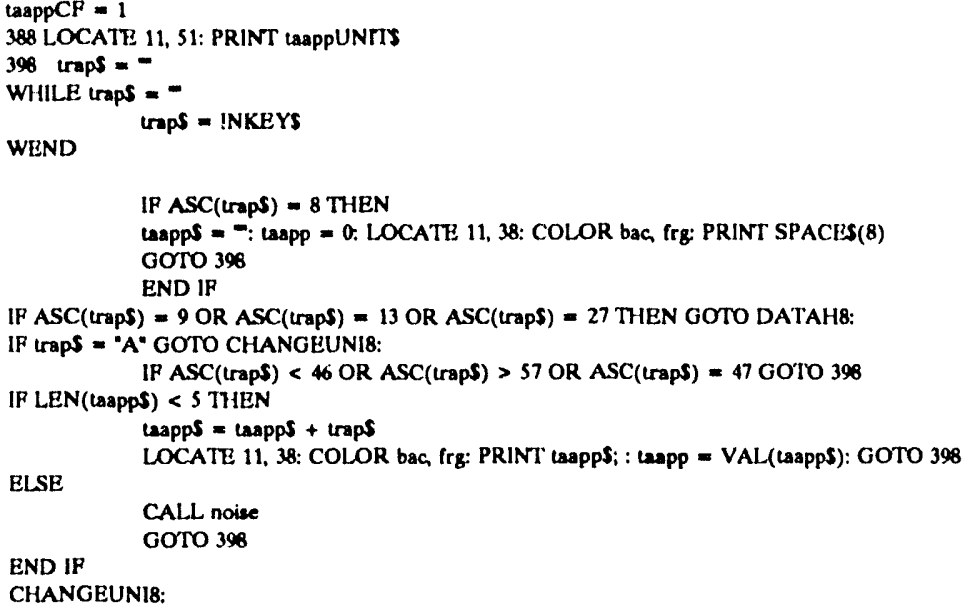

END IF

CHIANGBUNI99:

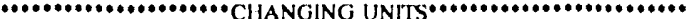

LOCATE 13, 66: COLOR bac, frg 


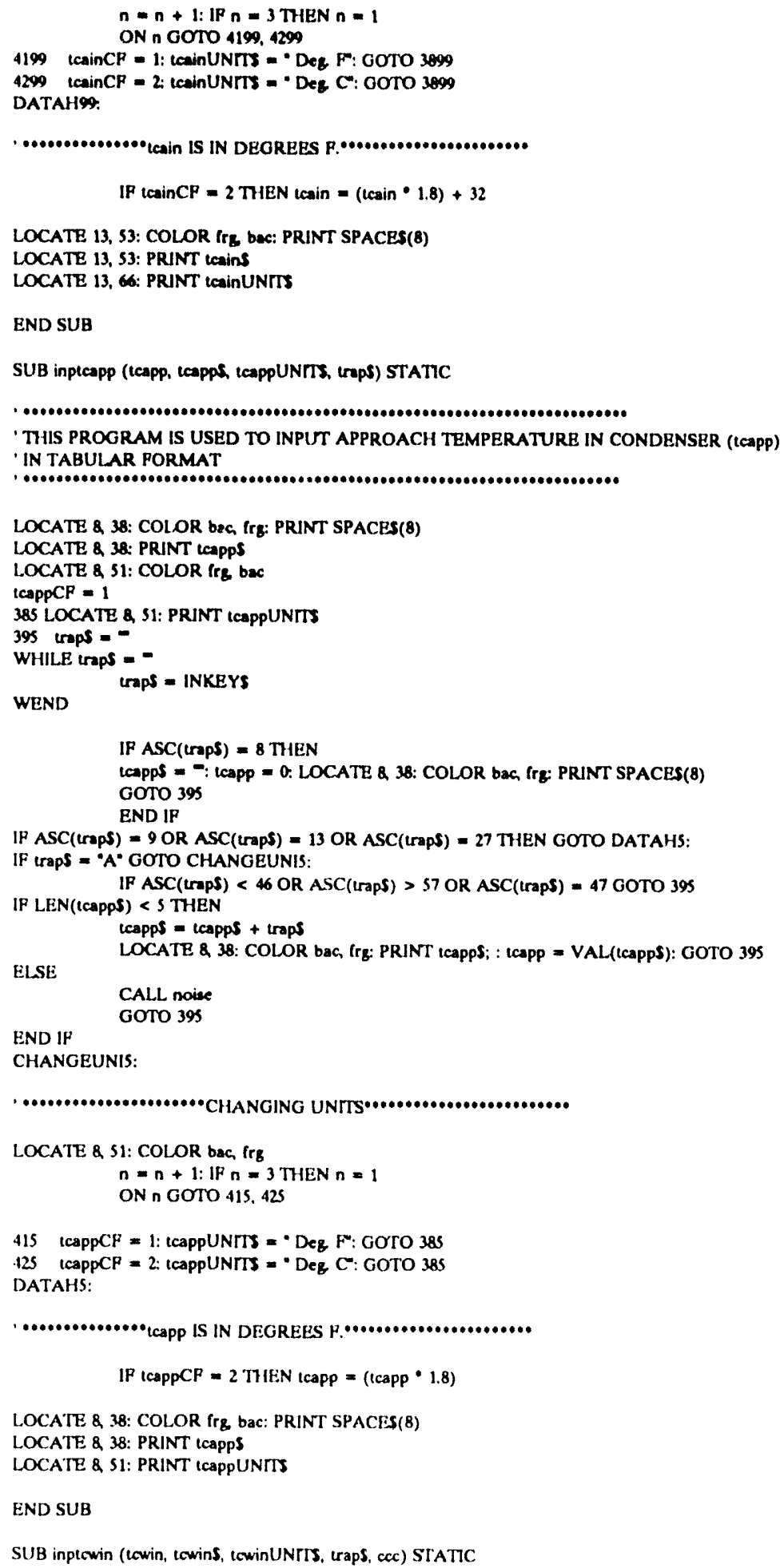




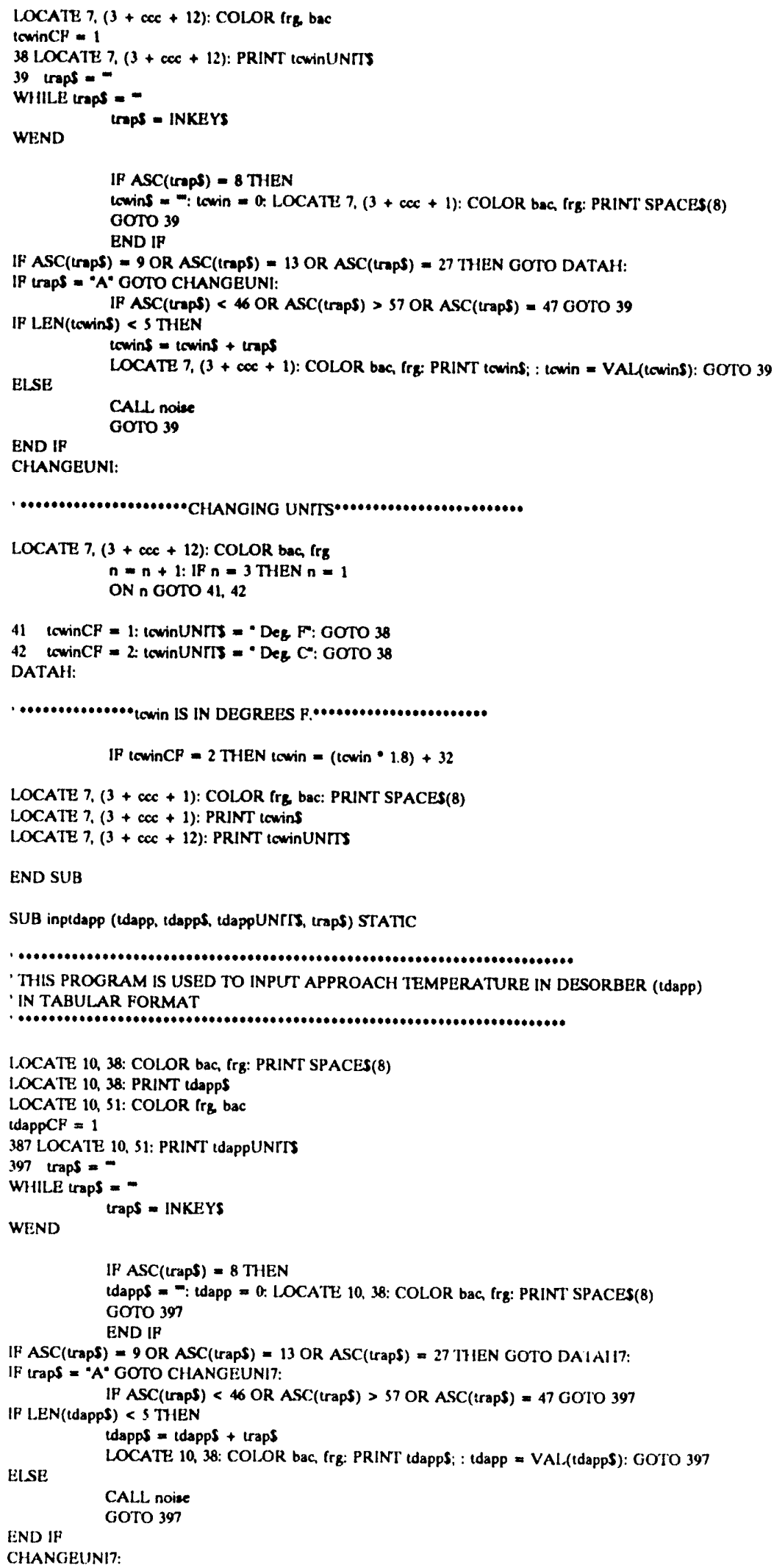




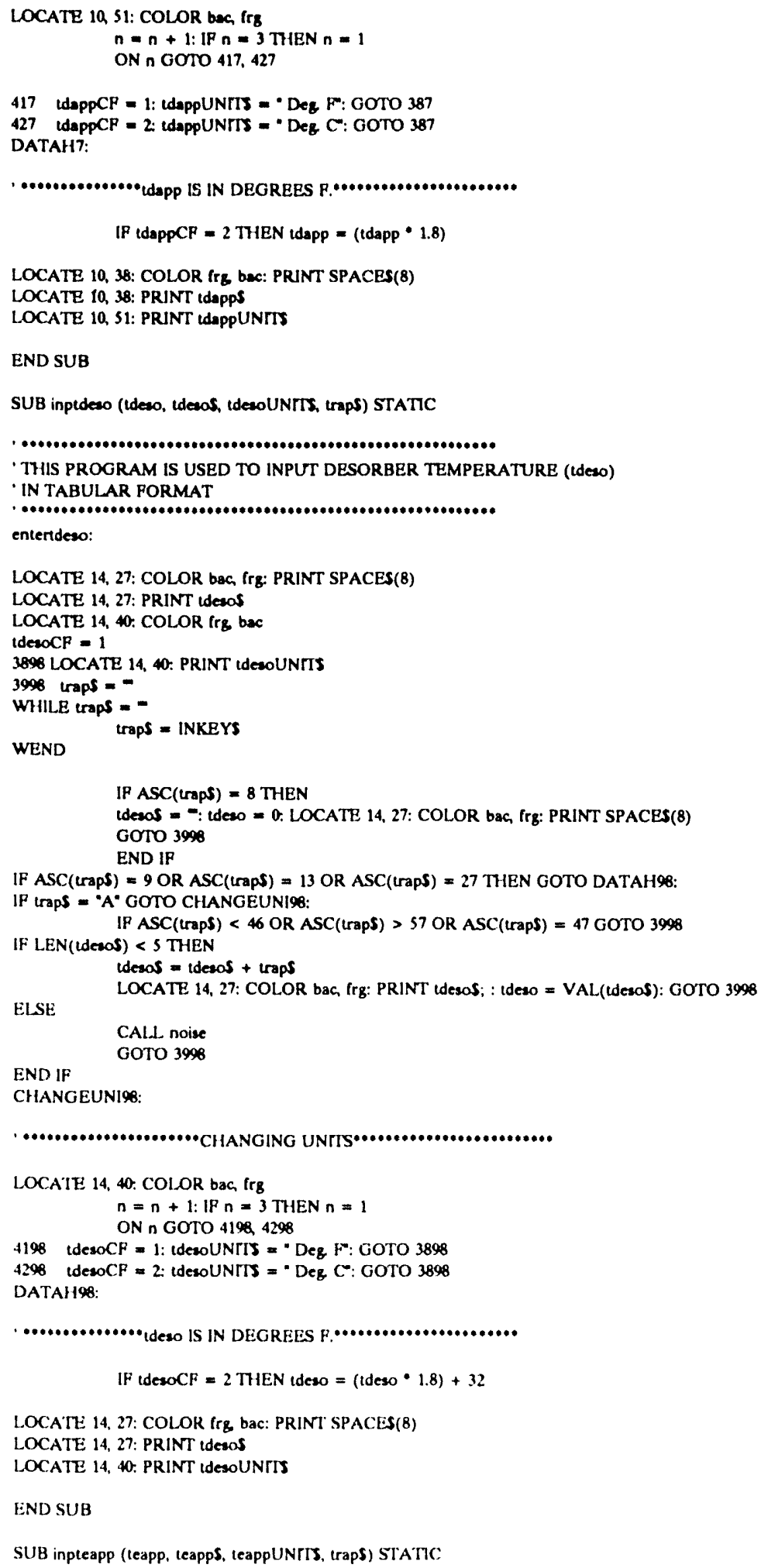




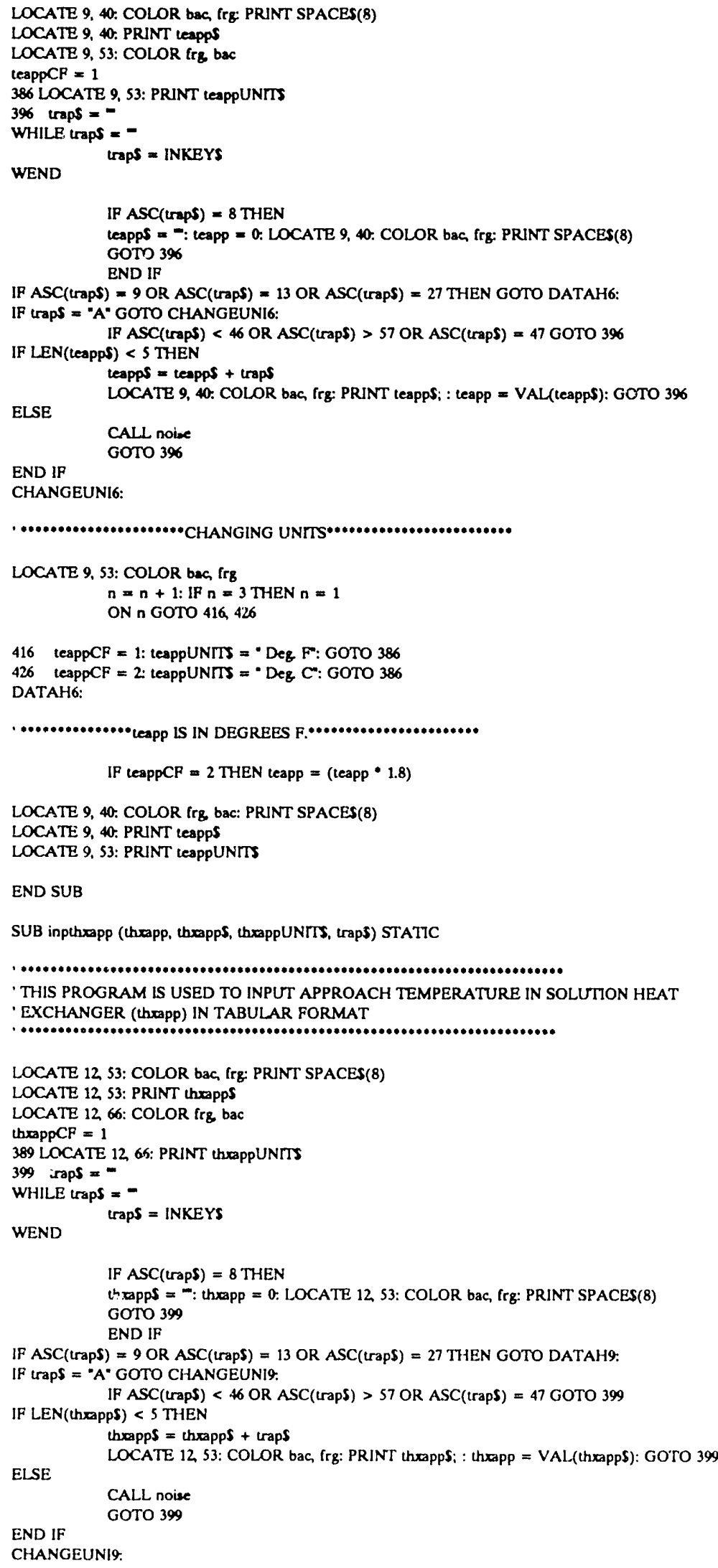




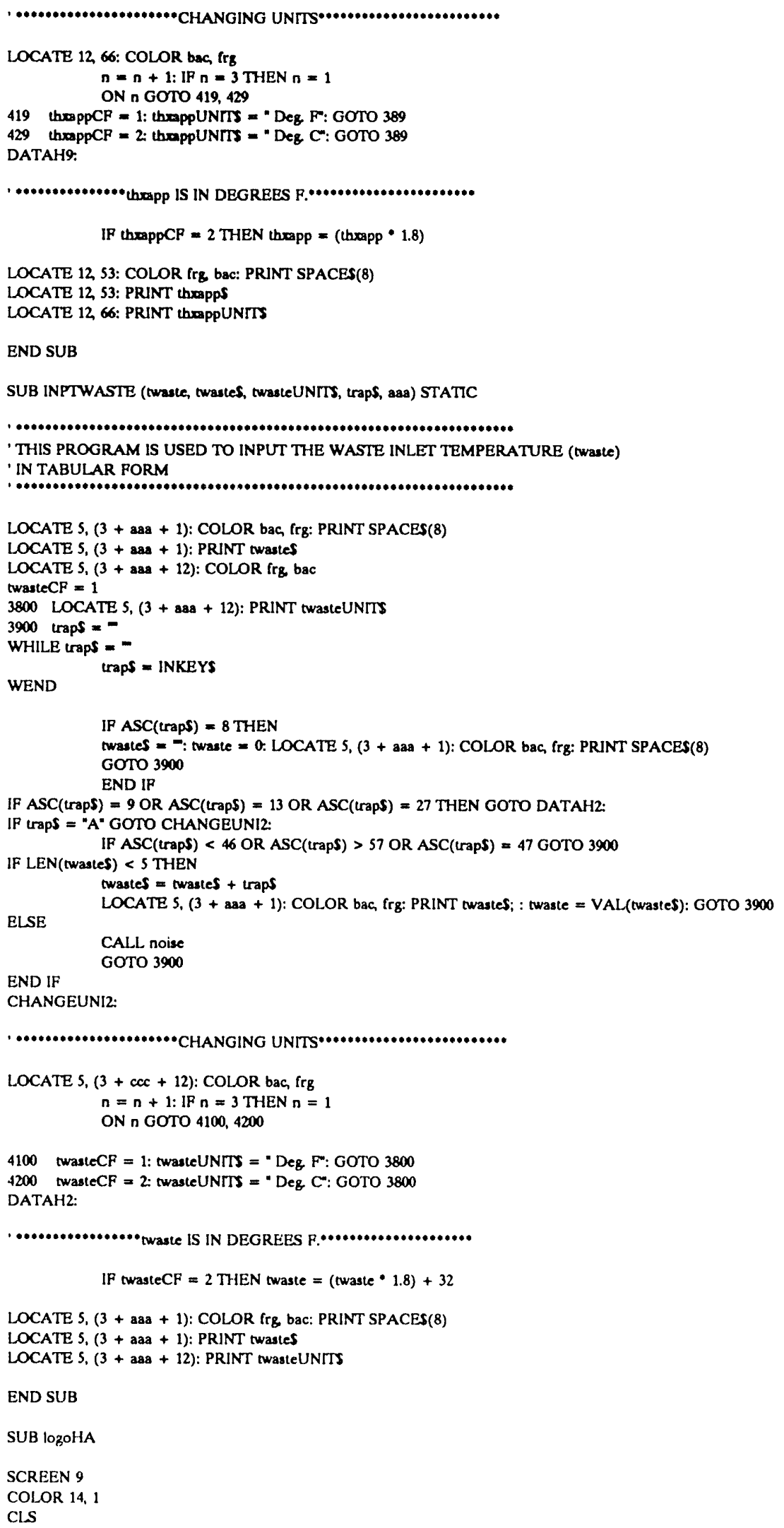




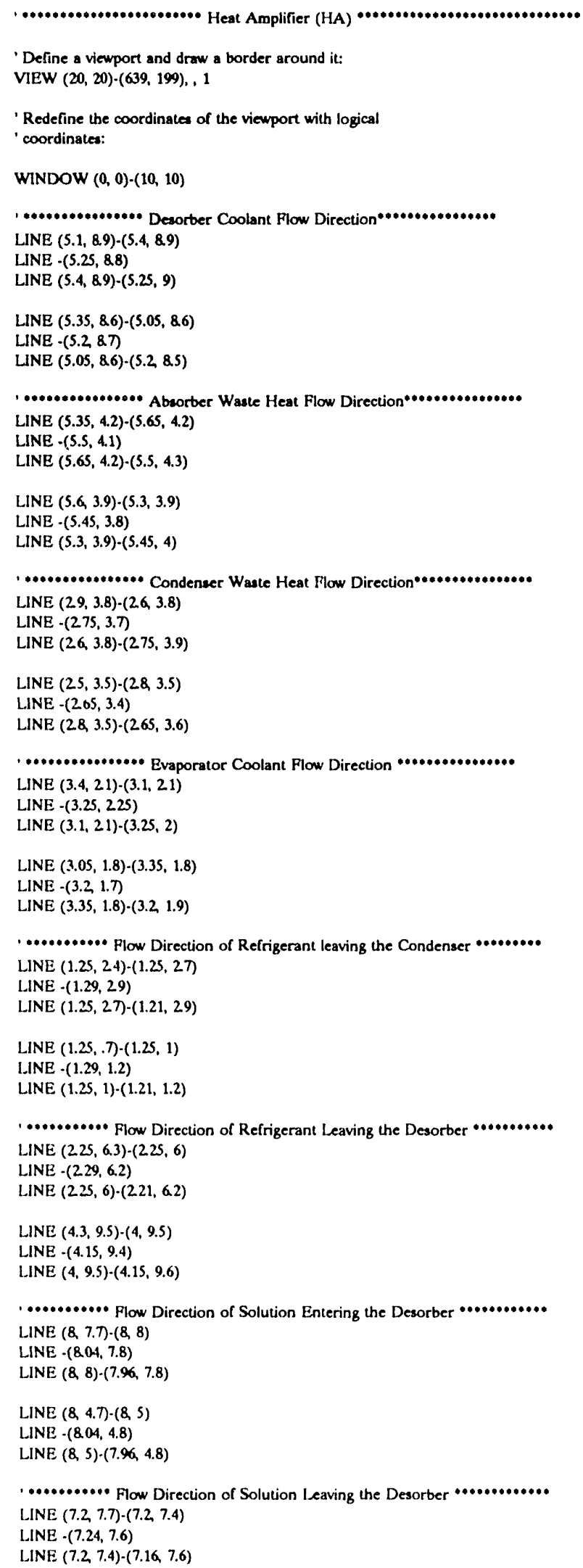




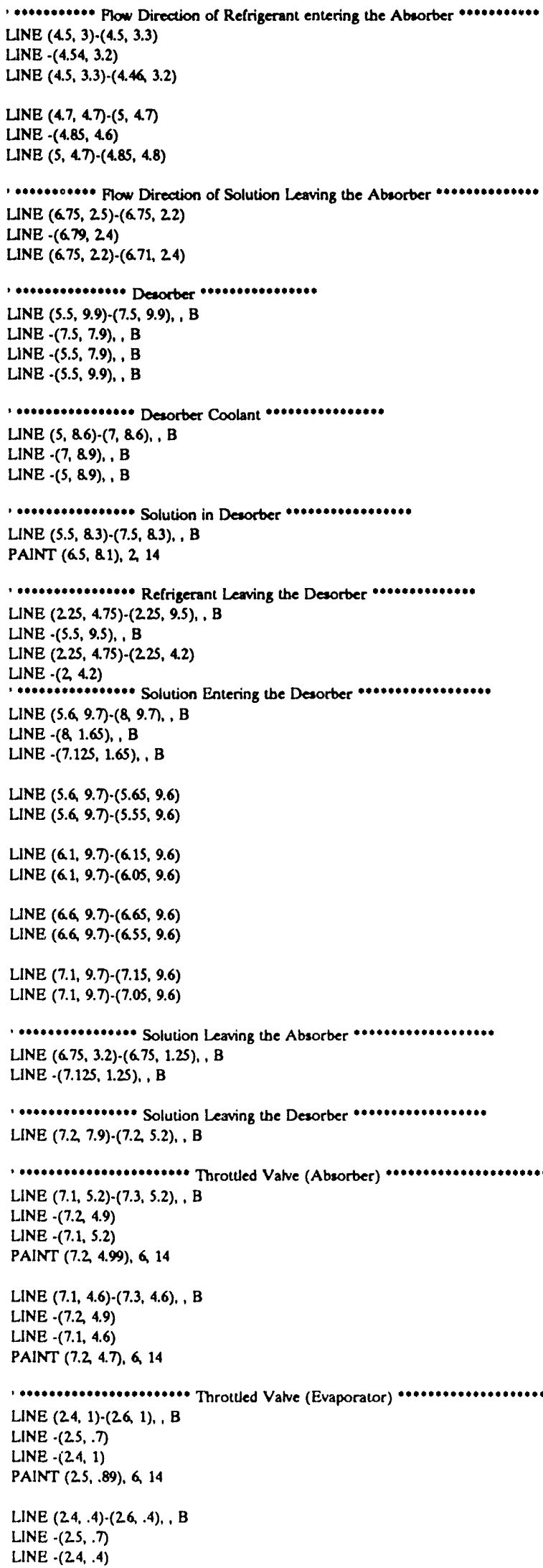




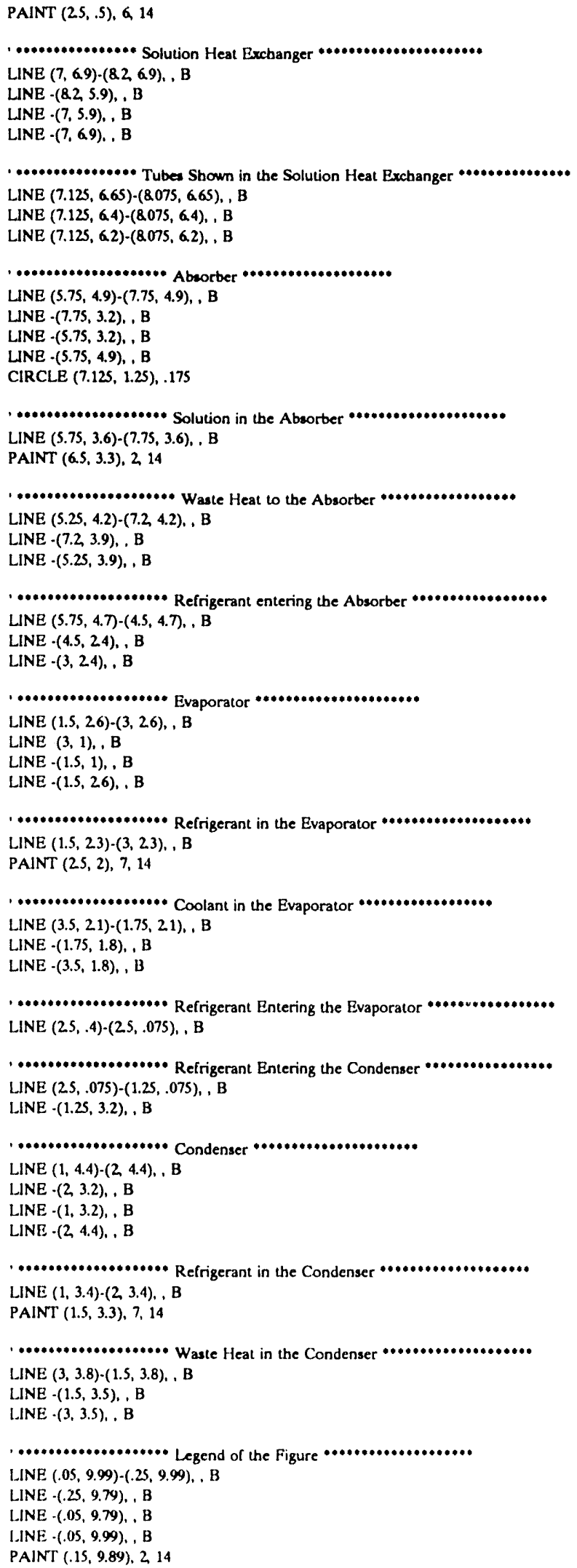




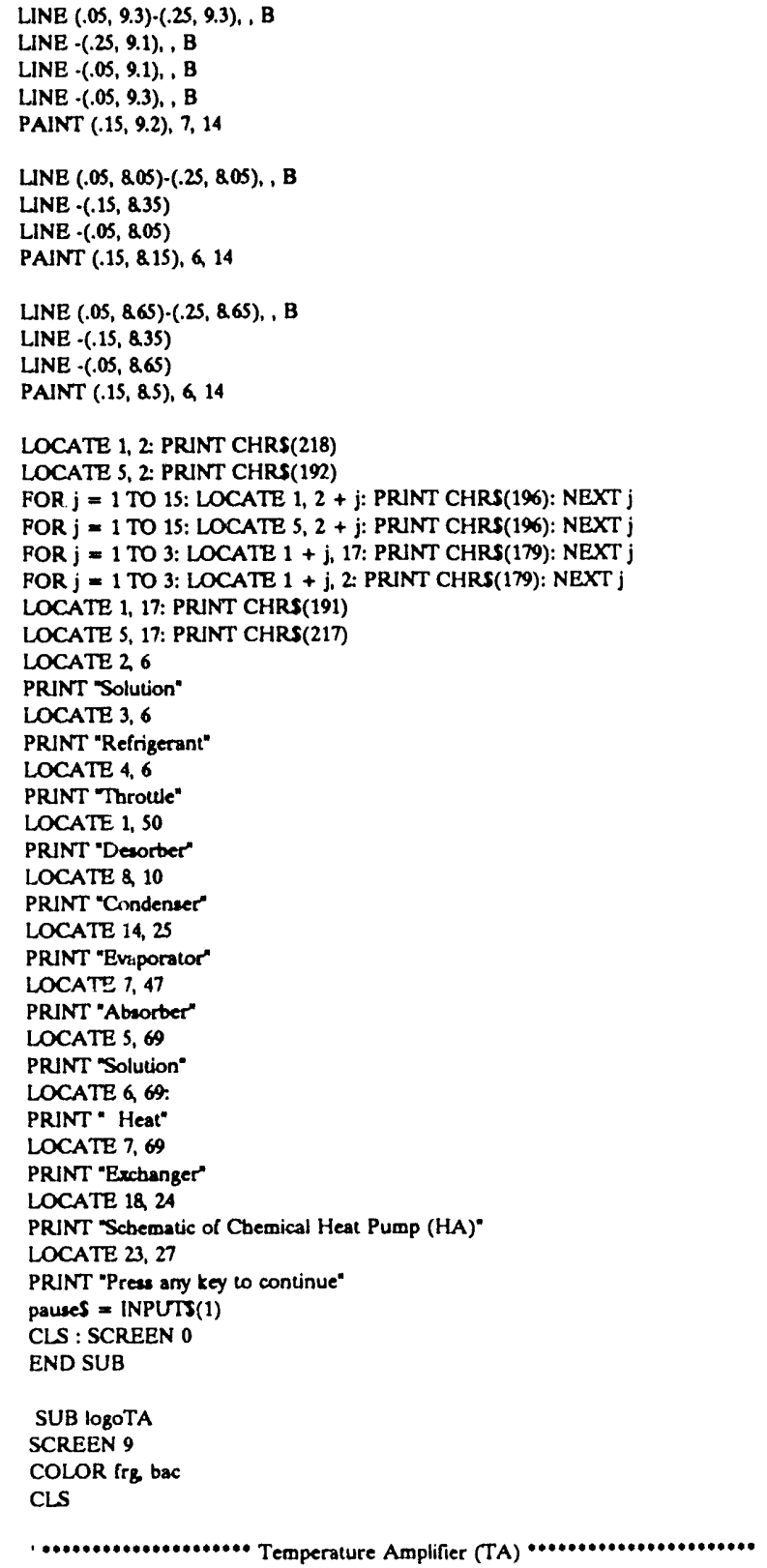

WINDOW $(0,0)-(10,10)$

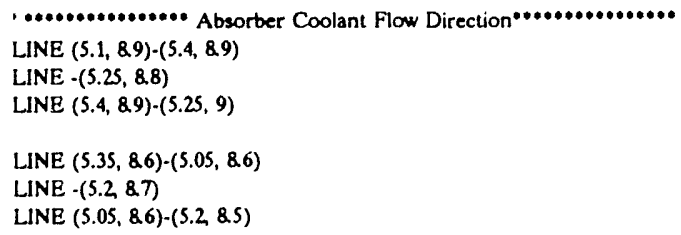


LINE - $(5.5,4.1)$

LINE (5.65, 4.2)-(5.5, 4.3)

LINE (5.6, 3.9)-(5.3, 3.9)

LINE $\cdot(5.45,3.8)$

LINE $(5.3,3.9)-(5.45,4)$

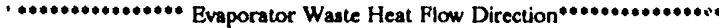

LINE $(29,3.8) \cdot(26,3.8)$

LINE - $(275,3.7)$

LINE $(26,3.8) \cdot(2.75,3.9)$

LINE $(2.5,3.5)-(2.8,3.5)$

LINE - $(265,3.4)$

LNE (2., 3.5)-(2.65, 3.6)

[

LINE $(3.4,21)-(3.1,21)$

LINE - $(3.25,225)$

LINE $(3.1,21)-(3.25,2)$

LINE $(3.05,1.8)-(3.35,1.8)$

LNE $-(3.2,1.7)$

LINE $(3.35,1.8)-(3.2,1.9)$

........... Flow Direction of Refrigerant Leaving the Condenser *.........

LINE $(25,1.35)-(2.5,1.05)$

LINE - $(254,1.25)$

LINE $(25,1.05) \cdot(246,1.25)$

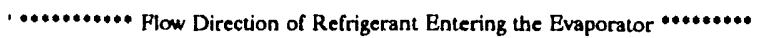

LINE $(1.25,26)-(1.25,29)$

LINE $\cdot(1.29,27)$

LINE $(1.25,2.9)-(1.21,27)$

LINE $(1.25, .7)-(1.25,1)$

LINE $-(1.29, .8)$

LINE $(1.25,1)-(1.21, .8)$

....*.*... Flow Direction of Refrigerant Entering the Absorber *...........

LINE $(2.25,6) \cdot(2.25,6.3)$

LINE - $(229,6.1)$

LINE $(2.25,6.3) \cdot(2.21,6.1)$

LINE $(4,9.5) \cdot(4.3,9.5)$

LINE - $(4.15,9.4)$

LINE $(4.3,9.5) \cdot(4.15,9.6)$

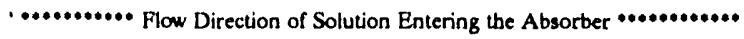
LINE $(8,7.7) \cdot(8,8)$

LINE $\cdot(8.04,7.8)$

LINE $(8,8)-(7.96,7.8)$

LINE (8, 4.7)-(8, 5$)$

LINE - $(8.04,4.8)$

LINE (\&, 5)- $(7.96,4.8)$

.

LINE $(7.2,7.7) \cdot(7.2,7.4)$

LINE - $(7.24,7.6)$

LINE (7.2, 7.4)-(7.16, 7.6)

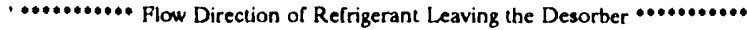

LINE $(4.5,3.3) \cdot(4.5,3)$

LINE $\cdot(4.54,3.2)$

LINE $(4.5,3)-(4.46,3.2)$

LINE $(5,4.7)-(4.7,4.7)$

LINE - $(4.85,4.6)$

LINE $(4.7,4.7)-(4.85,4.8)$

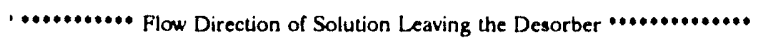

LINE $(6.75,25) \cdot(6.75,22)$

LINE - $(6,79,24)$

LINE $(6.75,2.2) \cdot(6.71,24)$

.

LINE $(5.5,9.9) \cdot(7.5,9.9)$, B

LINE - $(7.5,7.9)_{1}, \mathrm{~B}$ 


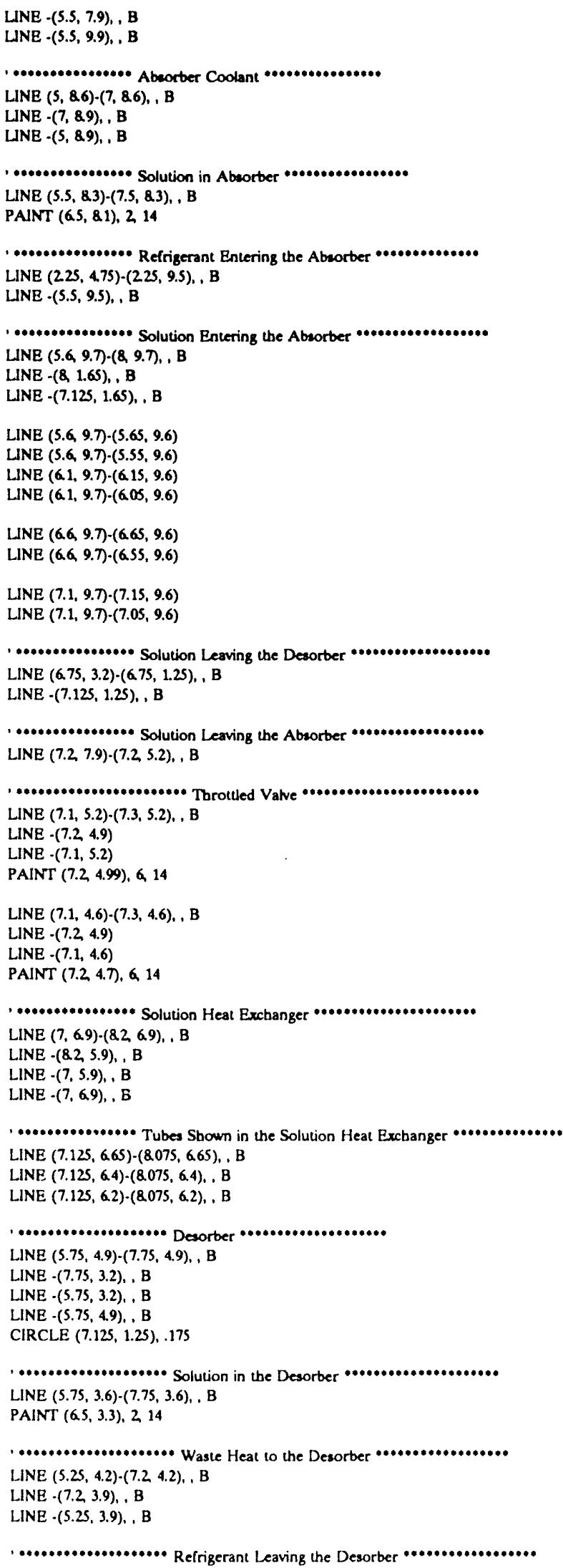




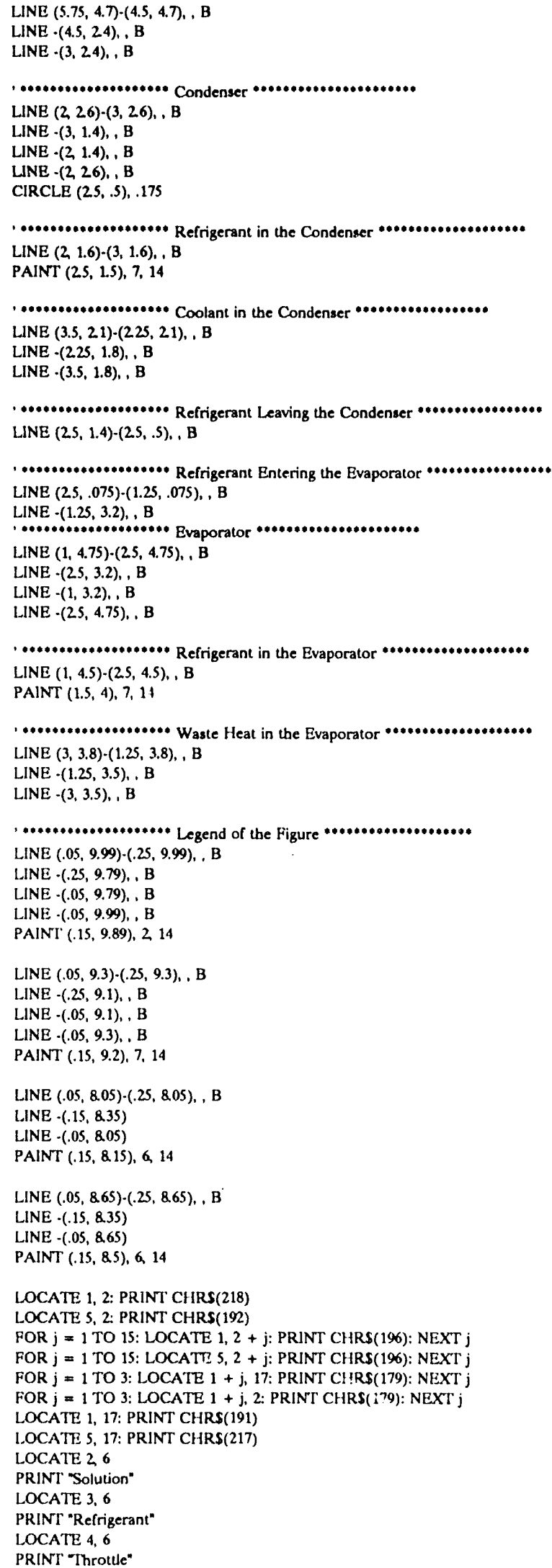




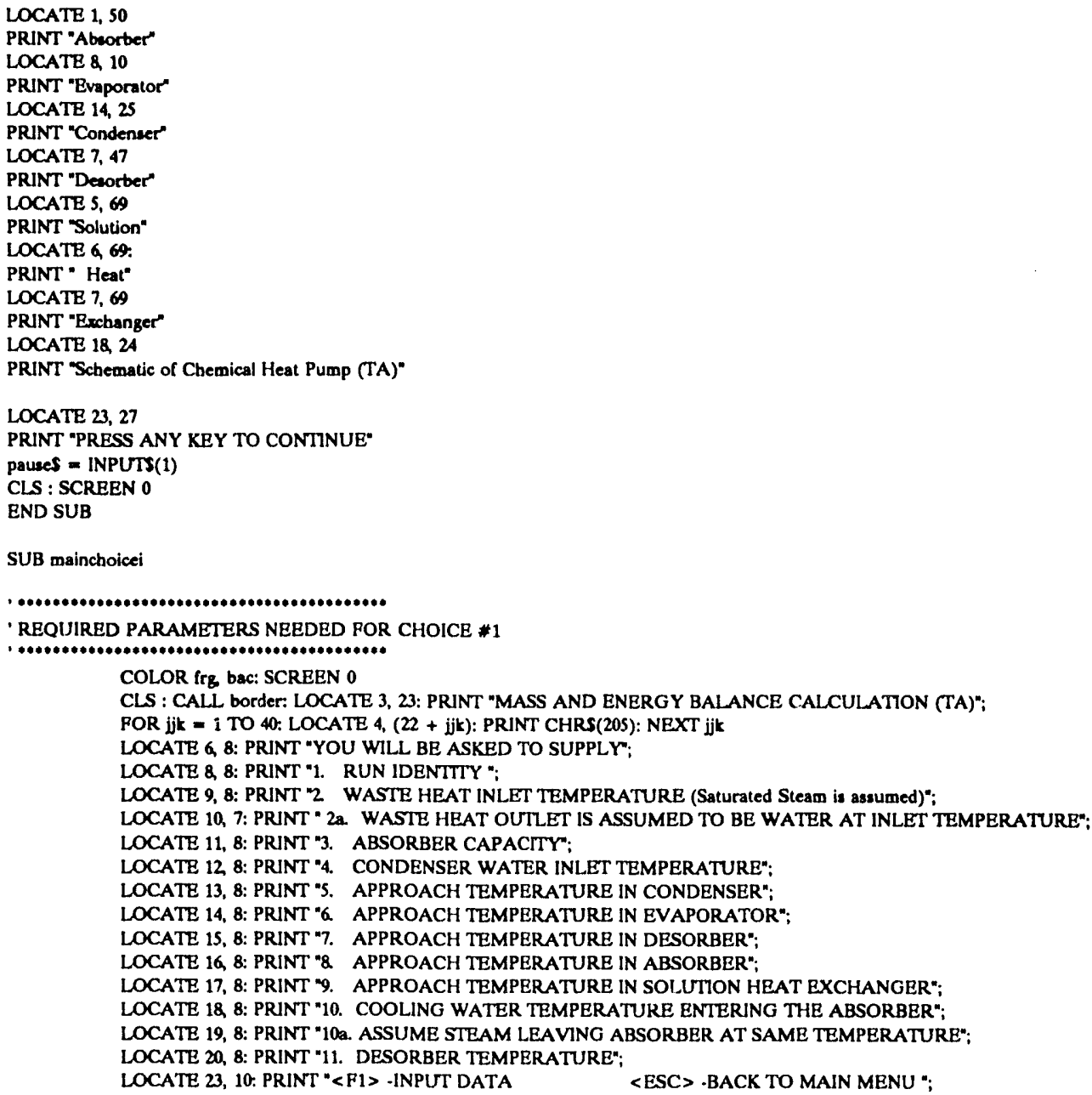

$<$ ESC > -BACK TO MAIN MENU ";

END SUB

SUB mainchoiceii

' REQUIRED PARAMETERS NEEDED FOR CHOICE \# 1

-

COLOR frg bac: SCREEN 0

CLS : CALL border: LOCATE 3, 23: PRINT "MASS AND ENERGY BALANCE CALCULATION (HA)";

POR $\mathrm{jkk}=1$ TO 40: LOCATE 4, $(22+\mathrm{jjk})$ : PRINT CHRS(205): NEXT jik

LOCATE 6, 8: PRINT "YOU WILL BE ASKED TO SUPPLY"

LOCATE \& 8: PRINT "1. RUN IDENTTTY ":

LOCATE 9, 8: PRINT "2 WASTE HEAT INLET TEMPERATURE TO THE EVAPORATOR";

LOCATE 10, 8: PRINT "2a. EVAPORATOR WASTE HEAT IS ASSUMED TO BE SATURATED STEAM":

LOCATE 11, 8: PRINT "3. ABSORBER CAPACTTY";

LOCATE 12, 8: PRINT "4. COOLING WATER TEMPERATURE ENTERING THE ABSORBER \& CONDENSER":

LOCATE 13, 8: PRINT "4a. COOLING WATER IS ASSUMED SATURATED AND USED BY BOTH UNITS";

LOCATE 14, 8: PRINT "5. APPROACH TEMPERATURE IN CONDENSER";

LOCATE 15, 8: PRINT "6. APPROACH TRMPERATURE IN EVAPORATOR"

LOCATE 16, 8: PRINT "7. APPROACH TEMPERATURE IN DESORBER";

LOCATE 17, 8: PRINT "8. APPROACH TEMPERATURE IN ABSORBER";

LOCATE 18 8: PRINT "9. APPROACH TEMPERATURE IN SOLUTION HEAT EXCHANGER":

'LOCATE 19, 8: PRINT "10. WASTE HEAT INLET TEMPERATURE TO THE DESORBER";

'LOCATE 20, 8: PRINT "10a. DESORBER WASTE HEAT IS ASSUMED TO BE SATURATED STEAM";

LOCATE 23, 10. PRINT "<FI> -INPUT DATA CESC> -BACK TO MAIN MENU ";

END SUB

SUB MAINMENU 


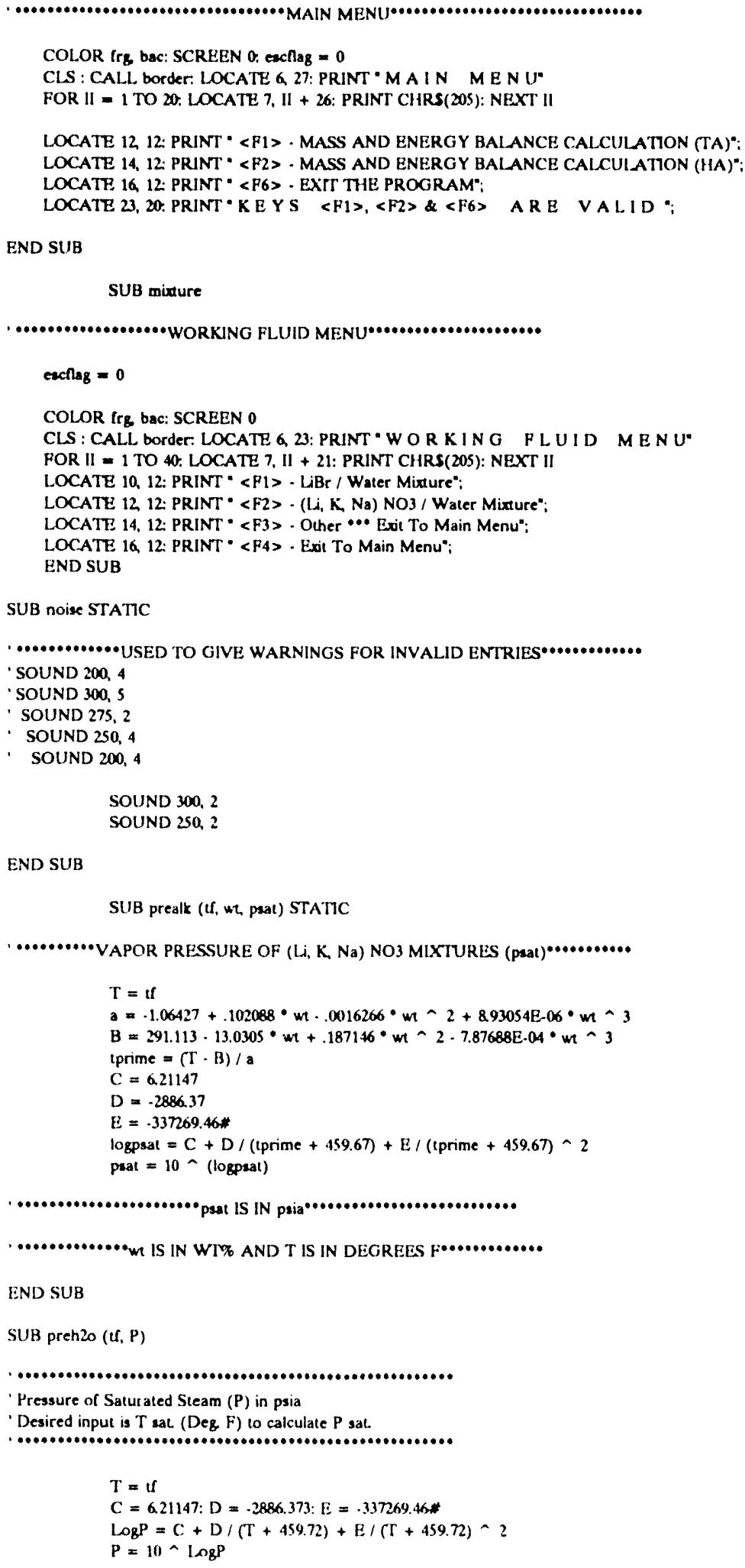

END SUB

SUB prel.jBr (U, wh, psat) STATTC 


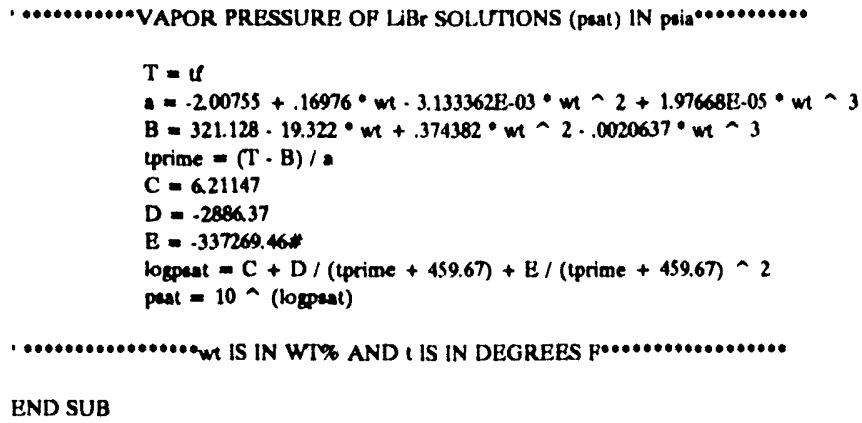

END SUB

\section{MODULIII.BAS}

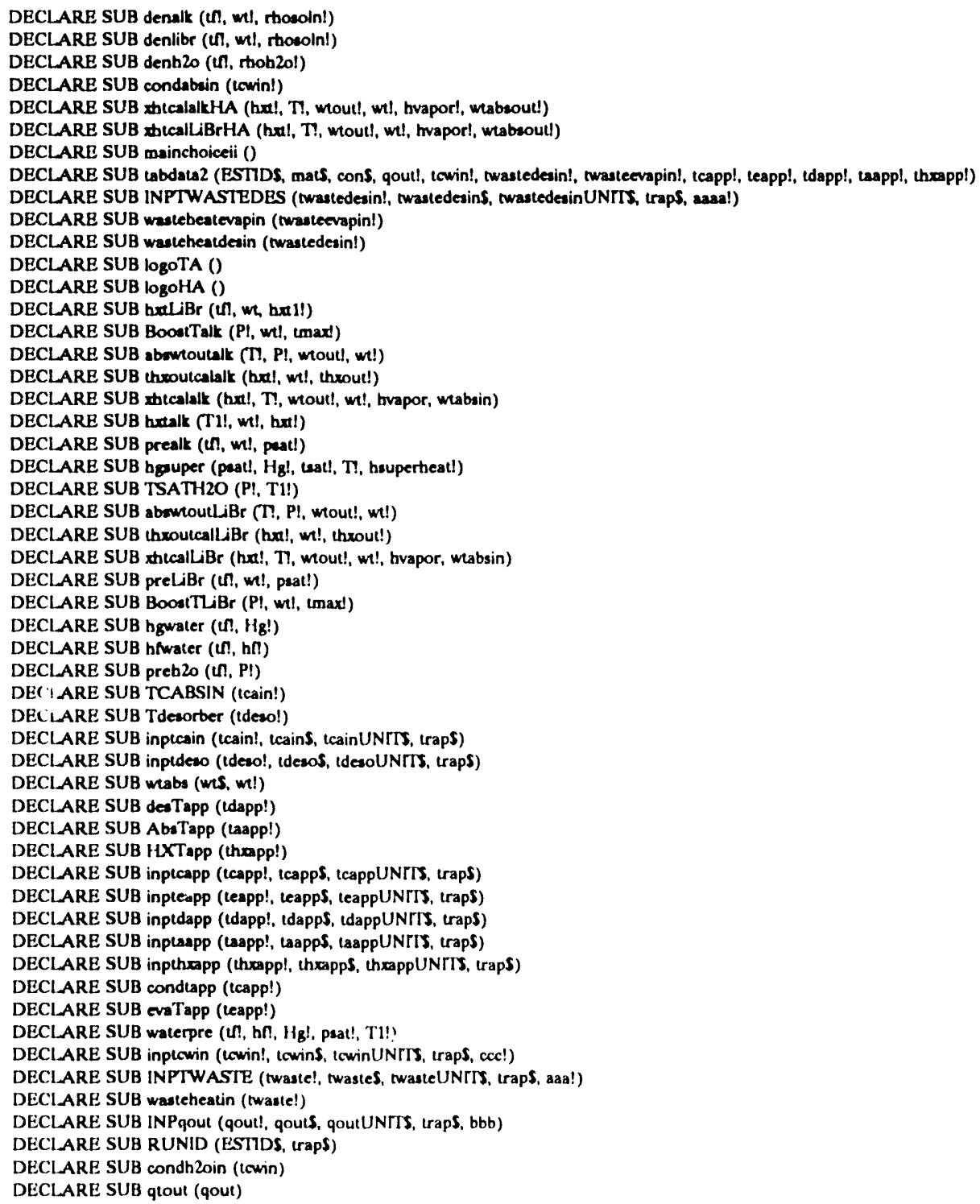




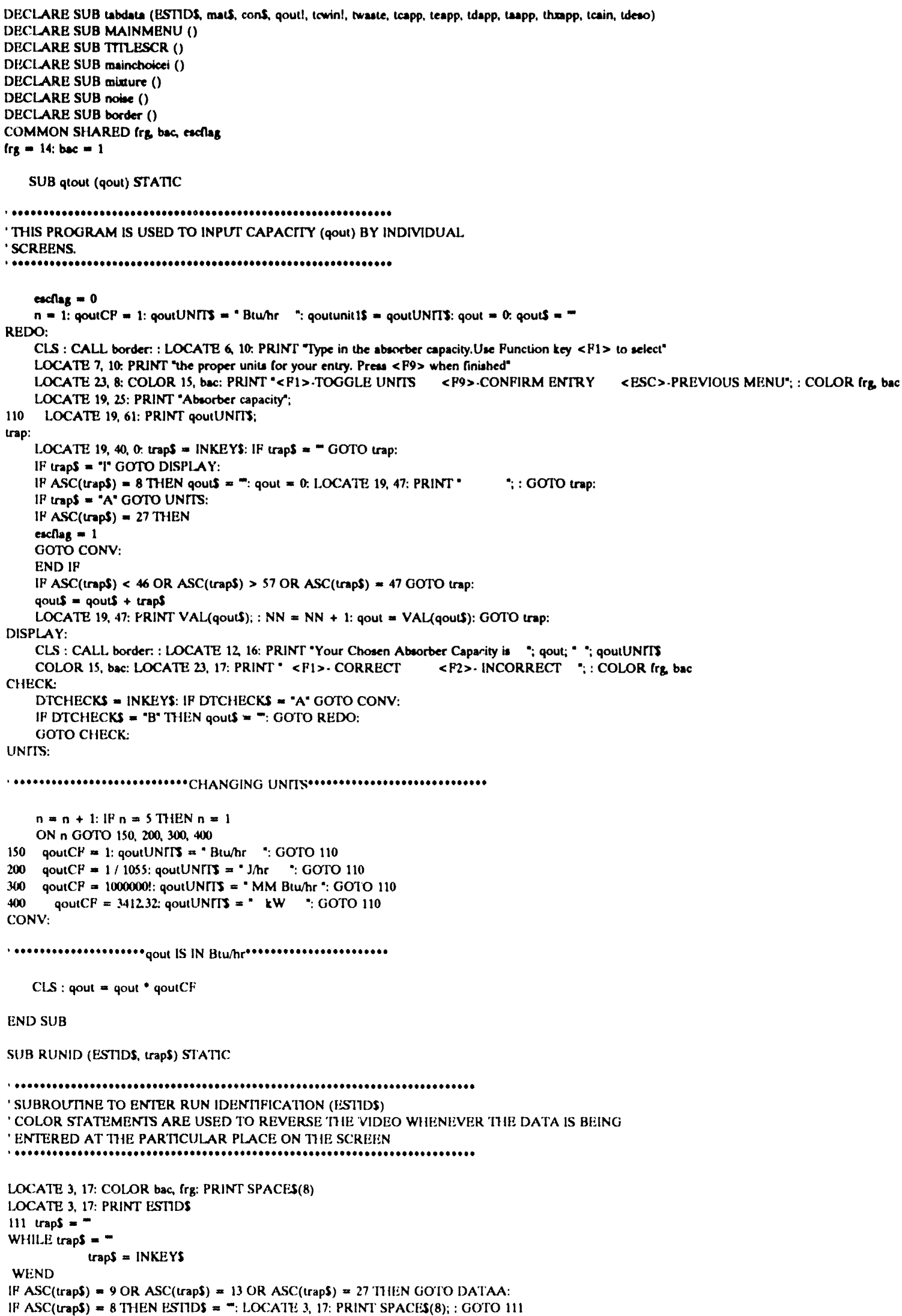

SUB qtout (qout) STATIC

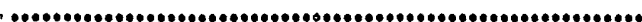

' THIS PROGRAM IS USED TO INPUT CAPACITY (qOUI) BY INDIVIDUAL

' SCREENS.

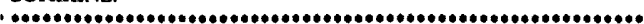

eacnag $=0$ REDO:

$n=1:$ qoutCP $=1:$ qoutUNITS $=$ " Btuhr $\quad$ ": qoutunit1s = qoutUNIIS: qout $=0$ q qouts = -

CLS : CALL border: : LOCATE 6, 10. PRINT "Type in the absorber capacity. Use Function key <F1 > to select"

LOCATE 7, 10. PRINT "the proper unils for your entry. Press $<$ F9 $>$ when finished"

LOCATE 23, 8: COLOR 15, bac: PRINT "<P1>.TOGGLE UNITS <P9>-CONFIRM ENTRY <ESC>-PREVIOUS MENU": : COLOR frg, bac

LOCATE 19, 25: PRINT "Absorber capacity";

110 LOCATE 19, 61: PRINT qoutUNITS:

trap:

LOCATE 19, 40, 0. traps = INKEYS: IF traps = - GOTO trap:

IF (rapS = "I" GOTO DISPLAY:

IP ASC(traps) $=8$ THEN qouts $=-"$ qout $=0$. LOCATE 19, 47: PRINT " $\quad$ : : GOTO trap:

IP traps = "A" GOTO UNITS:

IF ASC(Laps) $=27$ THEN

exhag $=1$

GOTO CONV:

END IF

IP ASC(traps) < 46 OR ASC(trapS) > 57 OR ASC(traps) $=47$ GOTO trap:

qouts $=$ qouts + traps

LOCATE 19, 47: FRINT VAL(qout\$); : NN = NN + 1: qout = VAL(qoul\$): GOTO trap:

DISPLAY:

CLS : CALL border: : LOCATE 12 16: PRINT "Your Chosen Absorber Caparity is "; qout; " "; qoutUNITS

COLOR 15, bac: LOCATE 23, 17: PRINT * <P1>. CORRECT <P2>. INCORRECT ": : COLOR frg bac

CHECK:

DTCHECKS = INKEYS: IP DTCHECKS $=$ "A" GOTTO CONV

IF DTCHECKS $=$ "B" THEN qoutS $=-$ : GOTO REDO

UNTIS:

GOTO CHECK:

.

$n=n+1: I F n=5$ THEN $n=$

ON n GOTO 150, 200, 300, 400

150 qoutCF $=1:$ qoutUNrTs $="$ Btuhr $"$ GOTO 110

200 qoutCF $=1 / 1055:$ qoutUNITS $=" \mathrm{~J} / \mathrm{hr} \quad ":$ GOTO 110

30 qoutCP $=1000000 !:$ qoutUNTIS $=" \mathrm{MM} \mathrm{Btu/hr} ":$ GOTO 110

400 qoutCF $=141232$ qoutUNTIS $={ }^{\circ} \mathrm{kW} ":$ GOTO 110

CONV:

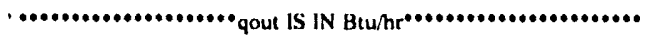

CLS : qout $=$ qout ${ }^{\bullet}$ qoutCF

END SUB

SUB RUNID (ESTIDS, trapS) STATIC:

1000000000000000000000000000000000000000000000000000000000000000000000000

' SUBROUTINE TO ENIER RUN IDENITFICATION (ESTIDS)

' COLOR STATEMENTS ARE USED TO REVERSE TIIE VIDEO WHENEVER TIIE DATA IS BEING

' ENTERED AT TTHE PARTTCULAR PLACE ON THE SCREEN

LOCATE 3, 17: COLOR bac, frg: PRINT SPACES(8)

LOCATE 3, 17: PRINT ESTIDS

111 traps $=-$

WHILE traps $=-$

traps $=$ INKEYS

WEND

If ASC(trapS) $=9$ OR ASC(trap\$) $=13$ OR ASC(trapS) $=27$ ITIEN GOTO DATAA:

IP ASC(trapS) $=8$ THEN ESIIDS $=-:$ LOCATU 3, 17: PRINT SPACES(8); : GOTO 111 


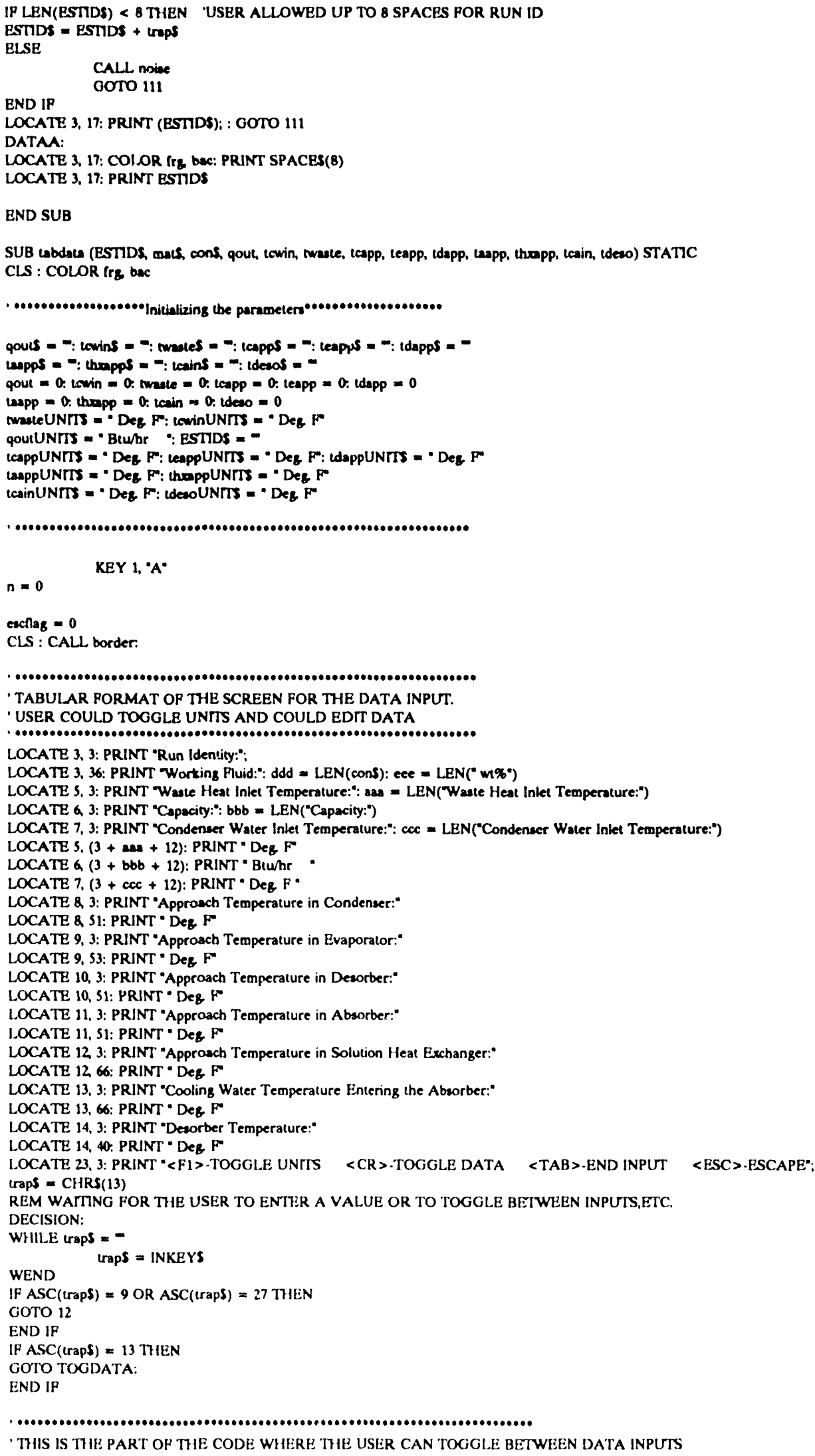

- THIS IS THIE PART OF THIE CODE WHERE THIE USER CAN TOGGLE BETWEEN DATA INPUTS 


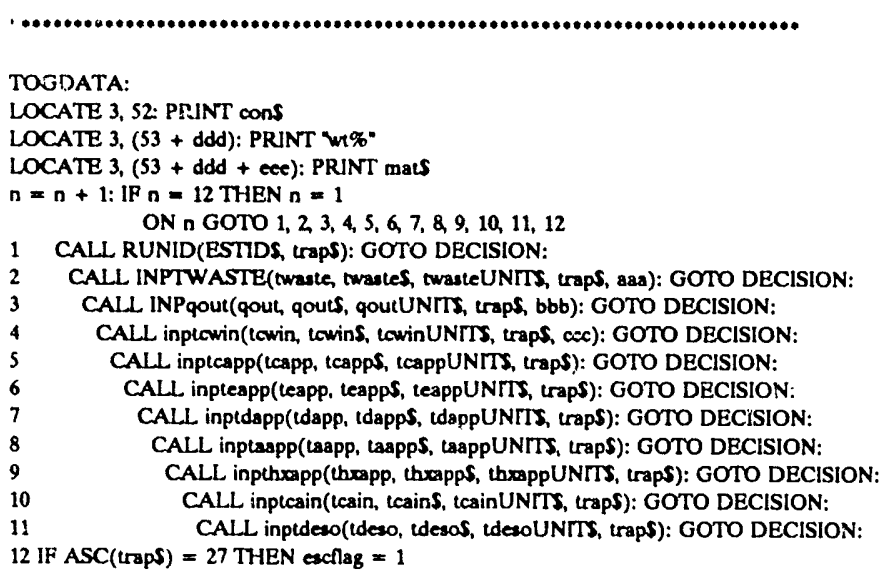

END SUB

SUB tabdata2 (ESTIDS, matS, conS, qout, towin, twastedesin, twasteevapin, tcapp, teapp, tdapp, taapp, thrapp)

CLS : COLOR frg, bac

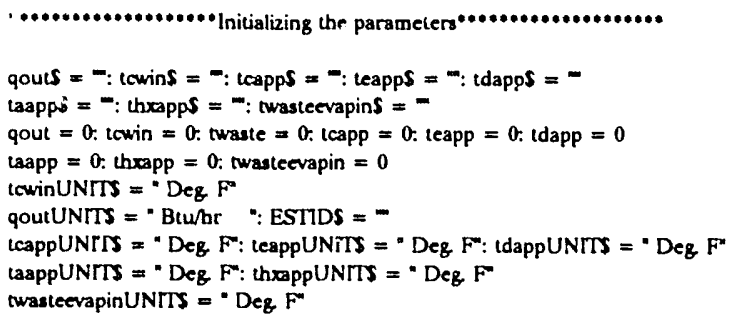

LOCATE 3, 3: P'RINT "Run Identity:";

LOCATE 3, 36: PRINT Working Fiuid:": ddd = LEN(conS): cee = LEN(" wt\%")

LOCATE 5, 3: PRINT "Waste Hea' ,et Temperature (evaporator):": aaa = LEN("Waste Heat Inlet Temperature (evapurator):")

LOCATE 6, 3: PRINT "Absorber Capacity:": bbb = LEN("Absorber Capacity:")

LOCATE 7, 3: PRINT "Cooling Water Temperature (absorber \& condenser):"; cce = LEN("Cooling Water Temperature (absorber \& condenser):")

LOCATE $S_{1}(3+$ aaa +12$)$ : PRINT " Deg $F^{m}$

LOCATE á $(3+b b b+12):$ PRINT - Btuhr -

LOCATE 7, $(3+$ ccc + 12): PRINT- Deg F"

LOCATE \& 3: PRINT *Approach Temperature in Condenser:"

LOCATE \& 51: PRINT " Deg F"

LOCATE 9, 3: PRINT "Approach Temperature in Evaporator:"

LOCATE 9, S3: PRINT - Deq. F"

LOCATE 10, 3: PRINT "Approach Temperature in Desorber:"

LOCATE 10, 51: PRINT * Deg. F"

LOCATE 11, 3: PRINT "Approach Temperature in Absorber:"

LOCATE 11, S1: PRINT " Deg. F"

LOCATE 12 3: PRINT "Approach Temperature in Solution Heat Exchanger:"

LOCATE 12, 66: PRINT * Deg. F*

LOCATE 23, 3: PRINT * $<1>$-TOGGLE UNITS <CR>-TOGGLE DATA <TAB>-ENDINPUT <ESC>-ESCAPE*;

trapS $=$ CHRS(13)

REM WATTING FOR THE USER TO ENTER A VALUE OR TO TOGGLE BEIWEEN INPUIS,EIC.

DECISIONii:

WHILE traps =-

$$
\text { traps = INKEYS }
$$




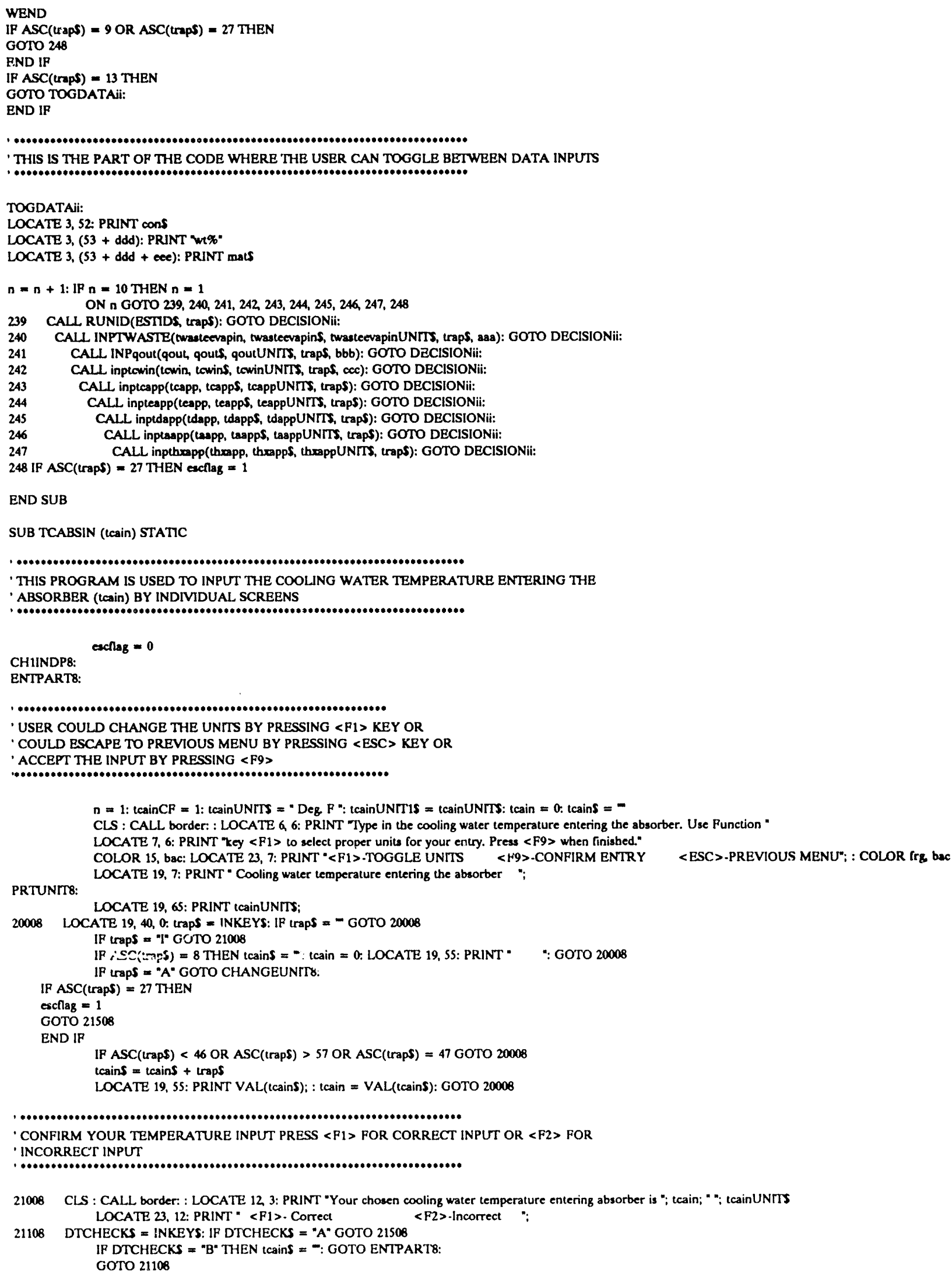




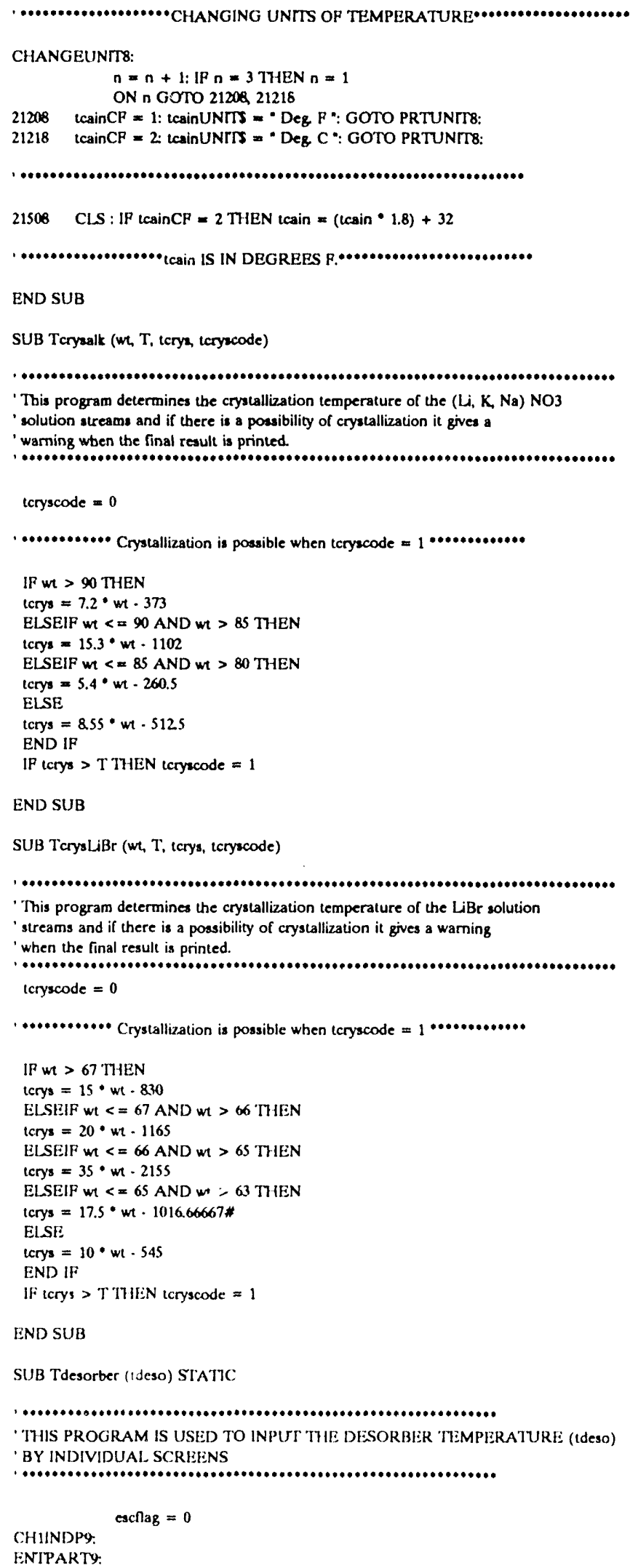




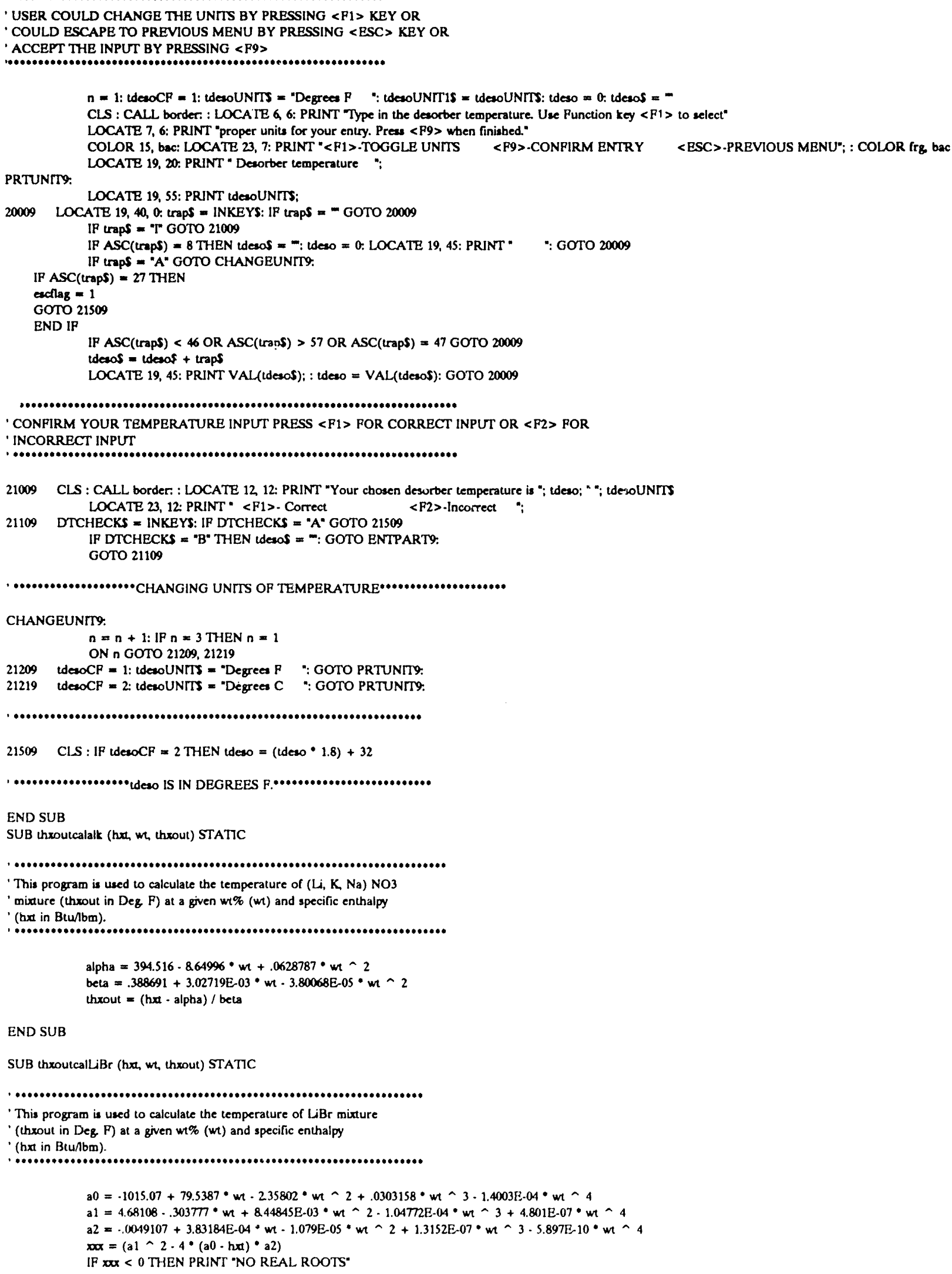

END SUB

SUB throutcalliBr (hx, wh, thxout) STATIC

'This program is used to calculate the temperature of $\mathrm{LBBr}$ mixture

' (throut in Deg. P) at a given wt\% (wt) and specific enthalpy

' (hxt in Btu/bm). 


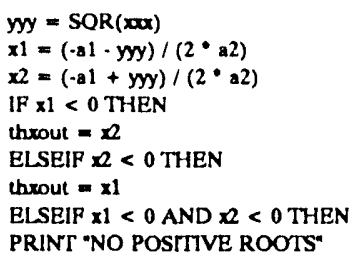

END SUB

SUB TTLRSCR

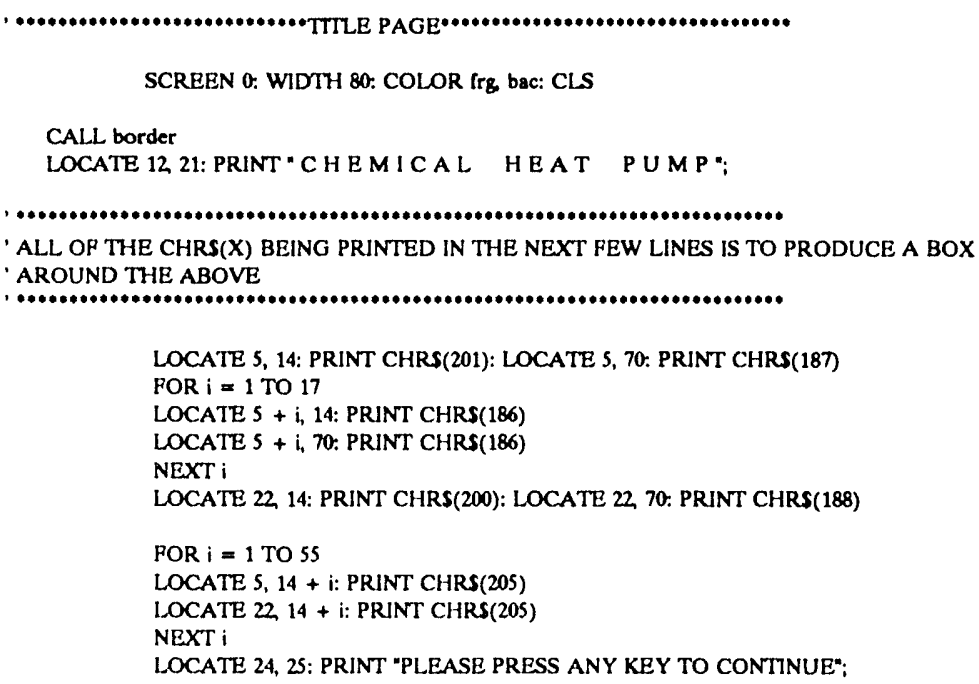


LOCATE 19, 56: PRINT twasteevapinUNITY:

20002

LOCATE 19, 40, 0. trapS = INKEYS: IF trapS = - GOTO 20002

IF traps = "I" GOOTO 21002

IP ASC(trapS) $=8$ THEN twatteevapinS $=-$ : twasteevapin = 0: LOCATE 19, 47: PRINT " ": GOTO 20002 IF traps = "A" GOTO CHANGEUNITZi:

eacliag $=1$

GOTO 21502

END IP

IF ASC(traps) < 46 OR ASC(traps) > 57 OR ASC(trapS) $=47$ GOTO 20002

twasteevapin $\$=$ twasteevapinS + traps

LOCATE 19, 47: PRINT VAL(twasteevapinS); : twasteevapin = VAL(twasteevapin\$): GOTO 20002

21002 CLS : CALL, border: : LOCATE 12, 3: PRINT "Your chosen evaporator waste heat inlet temperature is "; twasteevapin; " "; twasteevapinUNIT LOCATE 23, 12: PRINT " <F1>- Correct

21102 DTCHECKS = INKEYS: IF DTCHECKS $=$ "A" GOTO 21502 IF DTCHECKS = "B" THEN twasteevapin $\$=-$ : GOTO ENTPART2i:

CHANGEUNIT2i: GOTO 21102

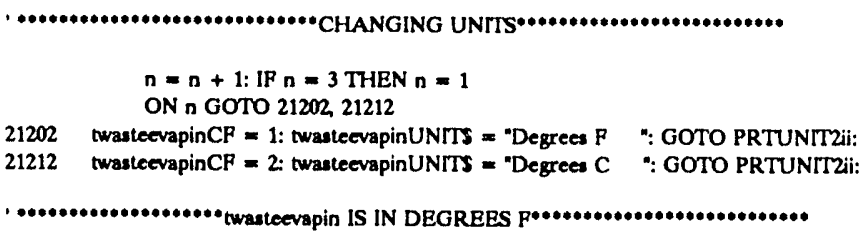

SUB wasteheatin (twaste) STATIC

-

' THIS PROGRAM IS USED TO INPUT WASTE INLET TEMPERATURE (twaste) BY INDIVIDUAL SCREENS

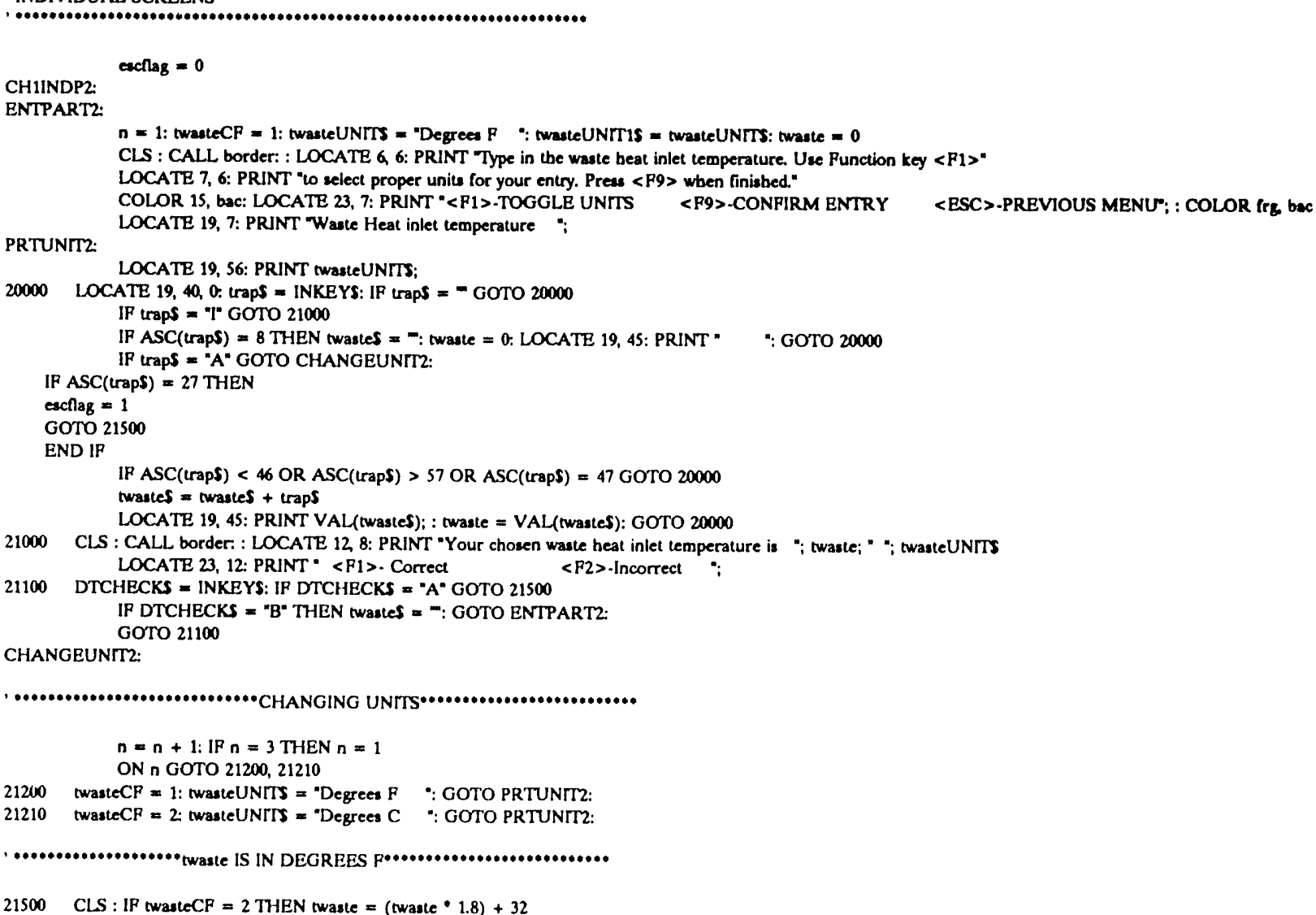




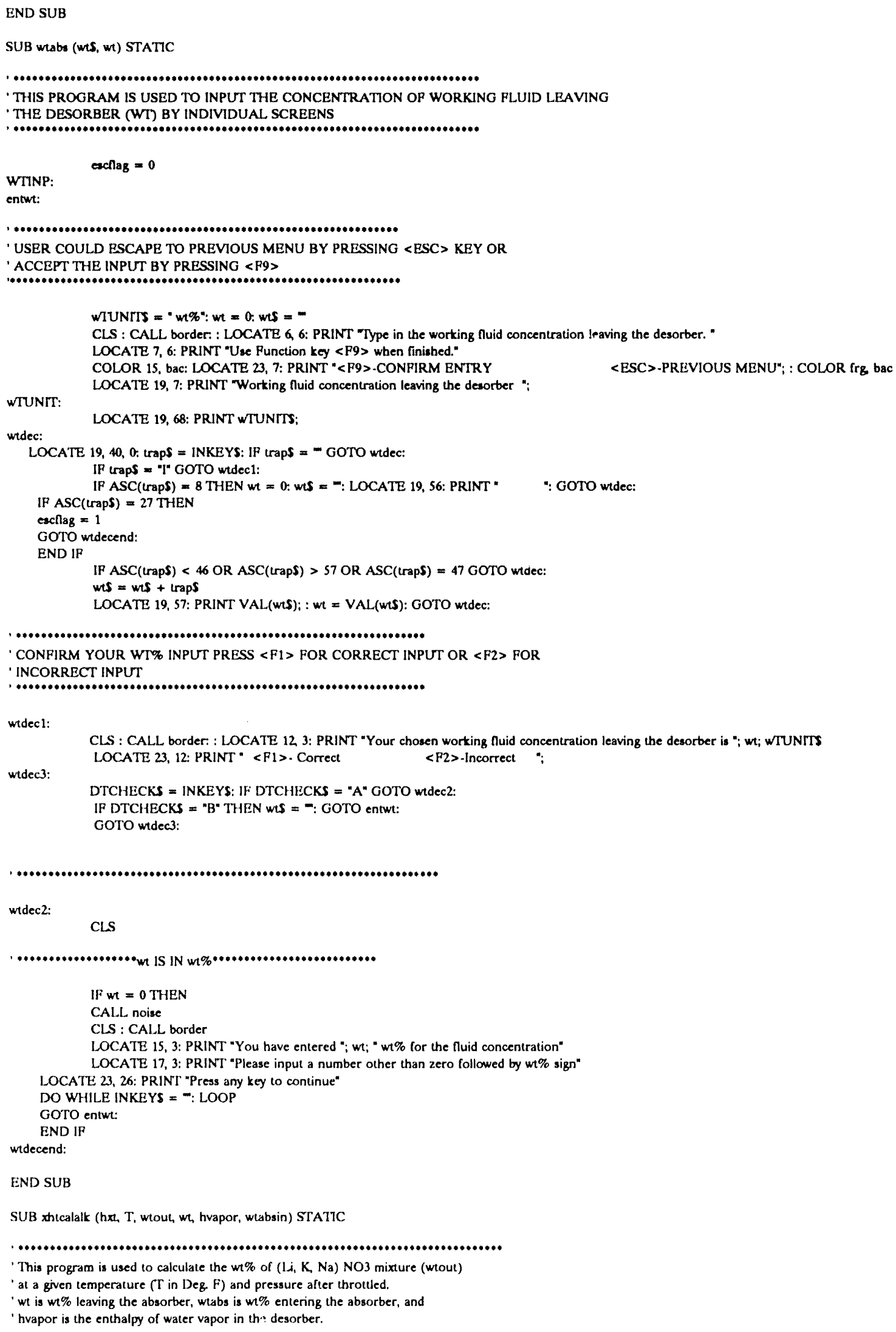

widec $2:$

CLS

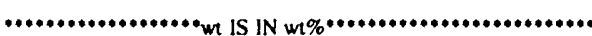

IF $w t=0$ THEN

CALL noise

CLS : CALL border

LOCATE 15, 3: PRINT "You have entered "; wt: "wt\% for the fluid concentration"

LOCATE 17, 3: PRINT "Please input a number other than zero followed by wt\% sign" LOCATE 23, 26: PRINT "Press any key to continue"

DO WHILE INKEYS $=-$ : LOOP

GOTO entwt:

END IF

wtdecend:

END SUB

SUB xhicalalk (hxt, T, wtout, wh, hvapor, wtabsin) STA77C

'This program is used to calculate the wt\% of $(\mathrm{L}, \mathrm{K}, \mathrm{Na}) \mathrm{NO3}$ mixture (wtout)

at a given temperature ( $T$ in Deg. $F$ ) and pressure after throtuled.

' wt is wt\% leaving the absorber, wtabs is wt\% entering the absorber, and

' hvapor is the enthalpy of water vapor in th'" desorber. 


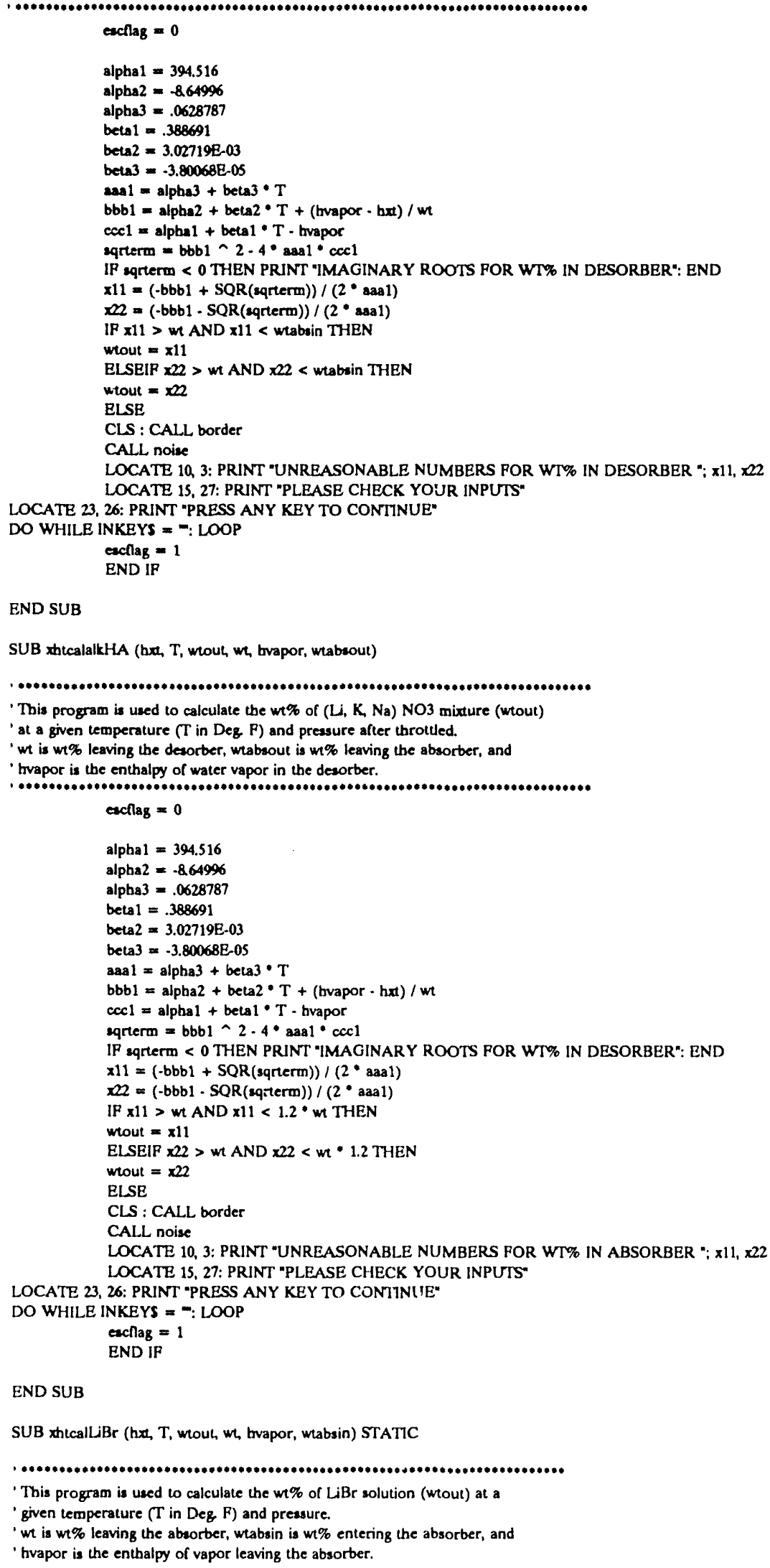

END SUB

SUB xhtcalLiBr (hxt, T, wrouh, wh, bvapor, wtabsin) STATTC

- This program is used to calculate the wt\% of LiBr solution (wtout) at a given temperature ( $T$ in Deg, $F$ ) and pressure.

' $w$ tis wr\% leaving the absorber, wtabsin is wt\% entering the absorber, and

' hvapor is the enthalpy of vapor leaving the absorber. 


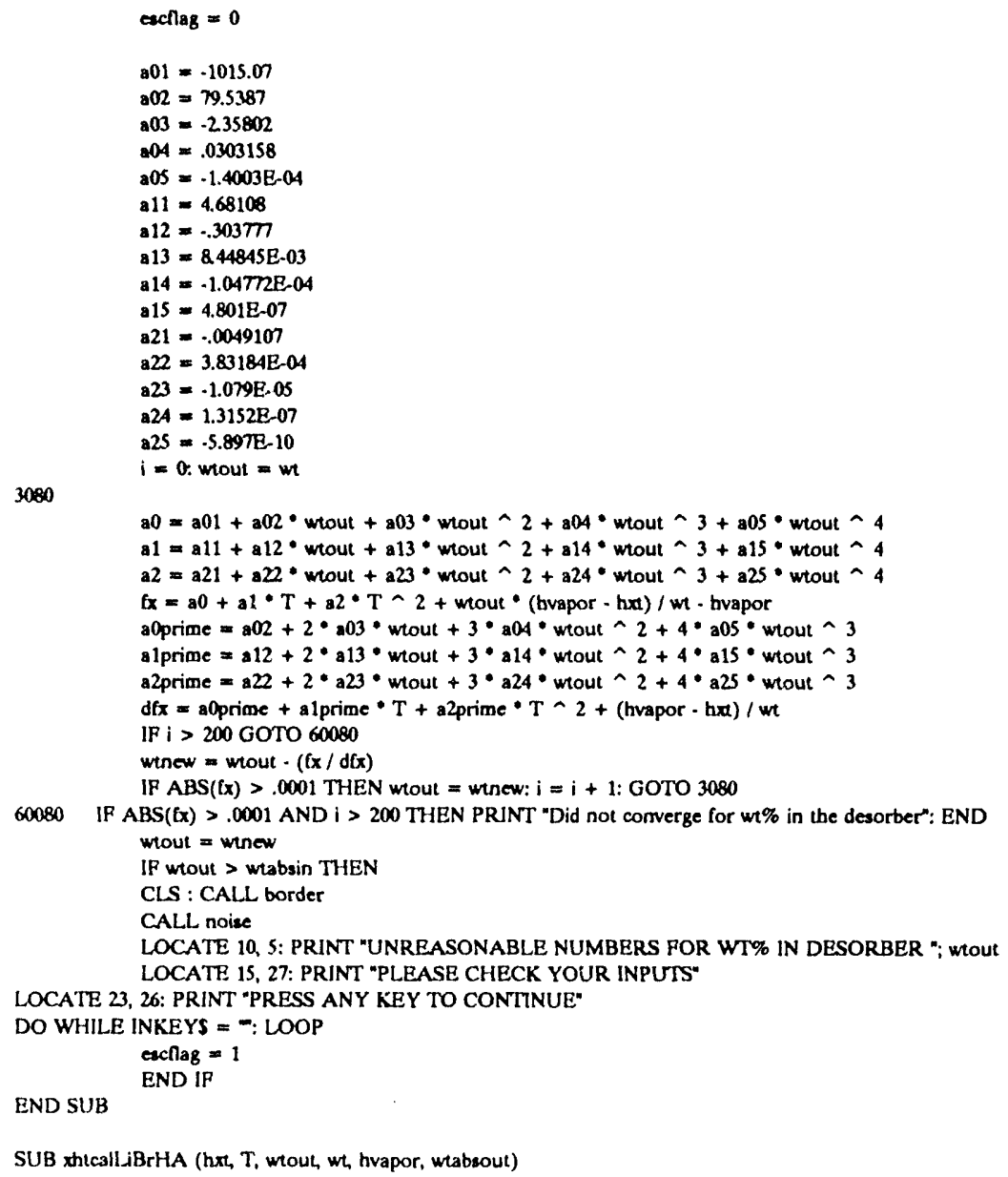

$\mathrm{a} 0=\mathrm{a} 01+\mathrm{a} 02 \cdot$ whout $+\mathrm{a} 03 \cdot$ whout $\wedge 2+\mathrm{a} 04 \cdot$ whout $\wedge 3+\mathrm{a} 05 \cdot$ wtout $\wedge 4$ $\mathrm{a} 1=\mathrm{a} 11+\mathrm{a} 12 \cdot$ wout $+\mathrm{a} 13^{\circ}$ wtout $\wedge 2+\mathrm{a} 14 \cdot$ wtout $\wedge 3+\mathrm{a} 15 \cdot$ wtout $\wedge$ ค $\mathrm{a} 2=\mathrm{a} 21+\mathrm{a} 22^{*}$ whout $+\mathrm{a} 23^{\circ}$ whout $\wedge 2+\mathrm{a} 24^{\circ}$ wtout $\wedge 3+\mathrm{a} 25^{\circ}$ wtout $\wedge$

$\mathrm{fx}=\mathrm{a} 0+\mathrm{al} \cdot \mathrm{T}+\mathrm{a} 2 \cdot \mathrm{T} \wedge 2+$ wtout ${ }^{\circ}$ (bvapor $-\mathrm{hxt}$ ) / $\mathrm{wt}$ - bvapor

aOprime $=\mathrm{a} 02+2 \bullet \mathrm{a} 03 *$ whout $+3^{\bullet} \mathrm{a}_{04}{ }^{*}$ wtout $\wedge 2+4^{\bullet} \mathrm{a} 05^{\bullet}$ whout $\wedge 3$

alprime $=\mathrm{a} 12+2 * \mathrm{a} 13^{*}$ whout $+3^{*}$ a14 ${ }^{*}$ mout $\wedge 2+4 * \mathrm{a} 15^{\bullet}$ ' whout $\wedge 3$

a2prime $=\mathrm{a} 22+2{ }^{*} \mathrm{a} 23 \cdot$ wtout $+3 \cdot \mathrm{a} 24 \cdot$ wtout $\wedge 2+4 \cdot \mathrm{a} 25 \cdot$ wtout $\wedge 3$

$\mathrm{dfx}=\mathrm{s}$ oprime + alprime ${ }^{\circ} \mathrm{T}+\mathrm{a}$ prime ${ }^{\circ} \mathrm{T} \wedge 2+($ hvapor $\cdot \mathrm{hxt}) / \mathrm{wt}$

IF $\mathrm{i}>200$ GOTO 60080

winew m wrout - $(f x / d f x)$

If $\mathrm{ABS}(\mathrm{t} x)>.0001$ THEN wtout $=$ wtnew: $i=i+1$ : GOTO 3080

60080 IF ABS $(\hat{x})>.0001$ AND $\mathrm{i}>200$ THEN PRINT "Did not converge for wt\% in the desorber": END

wrout $=$ wtnew

IF wtout $>$ wtabsin THEN

CLS : CALL border

CALL noise

LOCATE 10, 5: PRINT "UNREASONABLE NUMBERS FOR WT\% IN DESORBER "; wtout LOCATE 15, 27: PRINT "PLEASE CHECK YOUR INPUTS"

LOCATE 23, 26: PRINT "PRESS ANY KEY TO CONTTNUE"

DO WHILE INKEY $=-$ : LOOP

eacnag $=1$

END SUB

END IF

SUB xhtcalliBrHA (hxt, T, whout, wh, hvapor, wtabsout)

- This program is used to calculate the wt\% of $\mathrm{LBBr}$ solution (wtout) at a given temperature ( $\Gamma$ in Deq. $F$ ) and pressure.

wt is wt\% leaving the desorber, wtabsout is wt\% leaving the absorber, and

hvapor is the enthalpy of vapor leaving the absorber.

$$
\text { esclag }=0
$$

$\mathrm{a} 01=-1015.07$

$\mathrm{a} 02=79.5387$

$\mathrm{a} 03=-2.35802$

$\mathrm{a} 04=.0303158$

$\mathrm{a} 05=-1.4003 \mathrm{E}-04$

$\mathrm{a} 11=4.68108$

a12 $=. .30377$

a13 $=8.44845 \mathrm{E}-03$

a14 $=-1.04772 \mathrm{E}-04$

a $15=4.801 \mathrm{E}-07$

a21 $=.0049107$

$\mathrm{a} 22=3.83184 \mathrm{E}-04$

$\mathrm{a} 23=-1.079 \mathrm{E}-05$

$\mathbf{a} 24=1.3152 \mathrm{E}-07$

$\mathrm{a} 25=-5.897 \mathrm{E}-10$

30833

$\mathrm{i}=0$. wtout $=\mathrm{wt}$

$\mathrm{a} 0=\mathrm{a} 01+\mathrm{a} 02 \cdot$ wtout $+\mathrm{a} 03 \cdot$ wtout $\wedge 2+\mathrm{a} 04 \cdot$ wtout $\sim 3+\mathrm{a} 05 \cdot$ whout $\sim 4$ $\mathrm{a} 1=\mathrm{a} 11+\mathrm{a} 12 \cdot$ whout $+\mathrm{a} 13^{\circ}$ wtout $\wedge 2+\mathrm{a} 14 \cdot$ wtout $\wedge 3+\mathrm{a} 15 \cdot$ wtout $\wedge 4$ $\mathrm{a} 2=\mathrm{a} 21+\mathrm{a} 22^{\circ}$ wtout $+\mathrm{a} 23^{\circ}$ wtout $\wedge 2+\mathrm{a} 24^{\circ}$ wtout $\wedge 3+\mathrm{a} 25^{\circ}$ wtout $\wedge$

$f x=a 0+a 1 \cdot T+a 2 \cdot T \wedge 2+$ whout $\cdot$ (hvapor $\cdot h x t) / w t \cdot$ hvapor

apprime $=\mathrm{a} 02+2 \cdot \mathrm{a} 03 \cdot$ whout $+3 \cdot \mathrm{a} 04 \cdot$ whout $\wedge 2+4 \cdot \mathrm{a} 05 \cdot$ whout $\wedge 3$

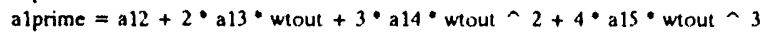

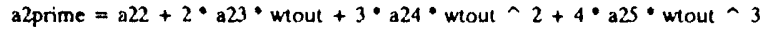


$d f x=a$ oprime + alprime $\cdot T+a 2 p r i m e \cdot T \wedge 2+($ bvapor $\cdot h x) / w t$

IF $\mathrm{i}>200$ GOTO 60033

whew = wout $-(6 x / d f x)$

IF ABS $((x)>.0001$ THEN whout $=$ whew: $i=i+1:$ GOTO 30633

60033 IP ABS( $(x)>.0001$ AND $i>200$ THEN PRINT "Did not converge for w\% in the desorter": END

wtout $=$ whew

If whout $>1.2^{*}$ w OR wtout < wtabsout THEN

CLS : CALL border

CALL noise

LOCATE 10, 5: PRINT "UNREASONABLE NUMBERS FOR WT\% IN ABSORBER "; whou

LOCATE 15, 27: PRINT "PLEASE CHECK YOUR INPUTS"

LOCATE 23, 26: PRINT "PRESS ANY KEY TO CONTINUE"

DO WHILE INKEYS = -: LOOP

escllag $=1$

END IP

END SUB 
Appendix B

Samples of Input and Output 


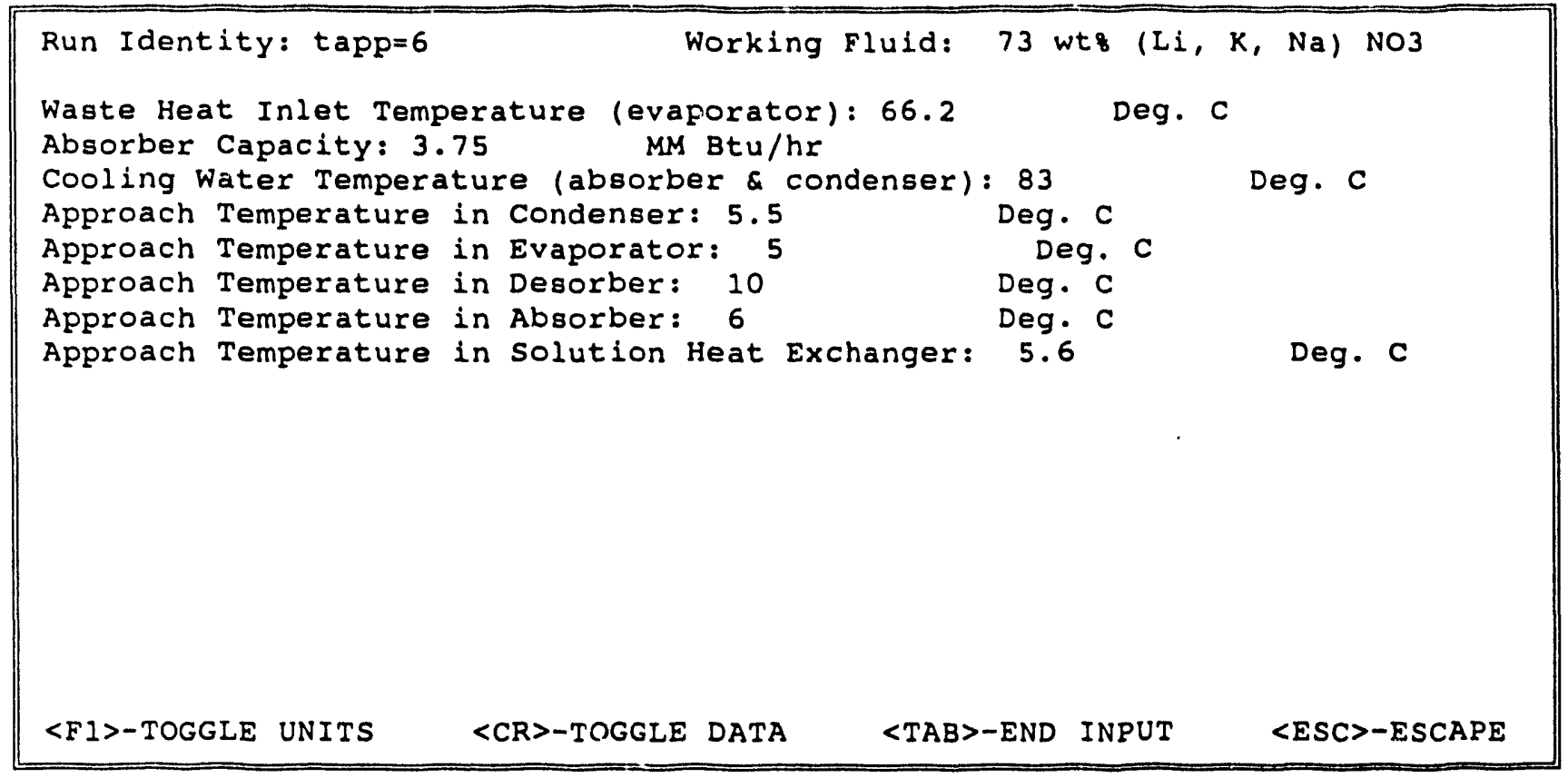

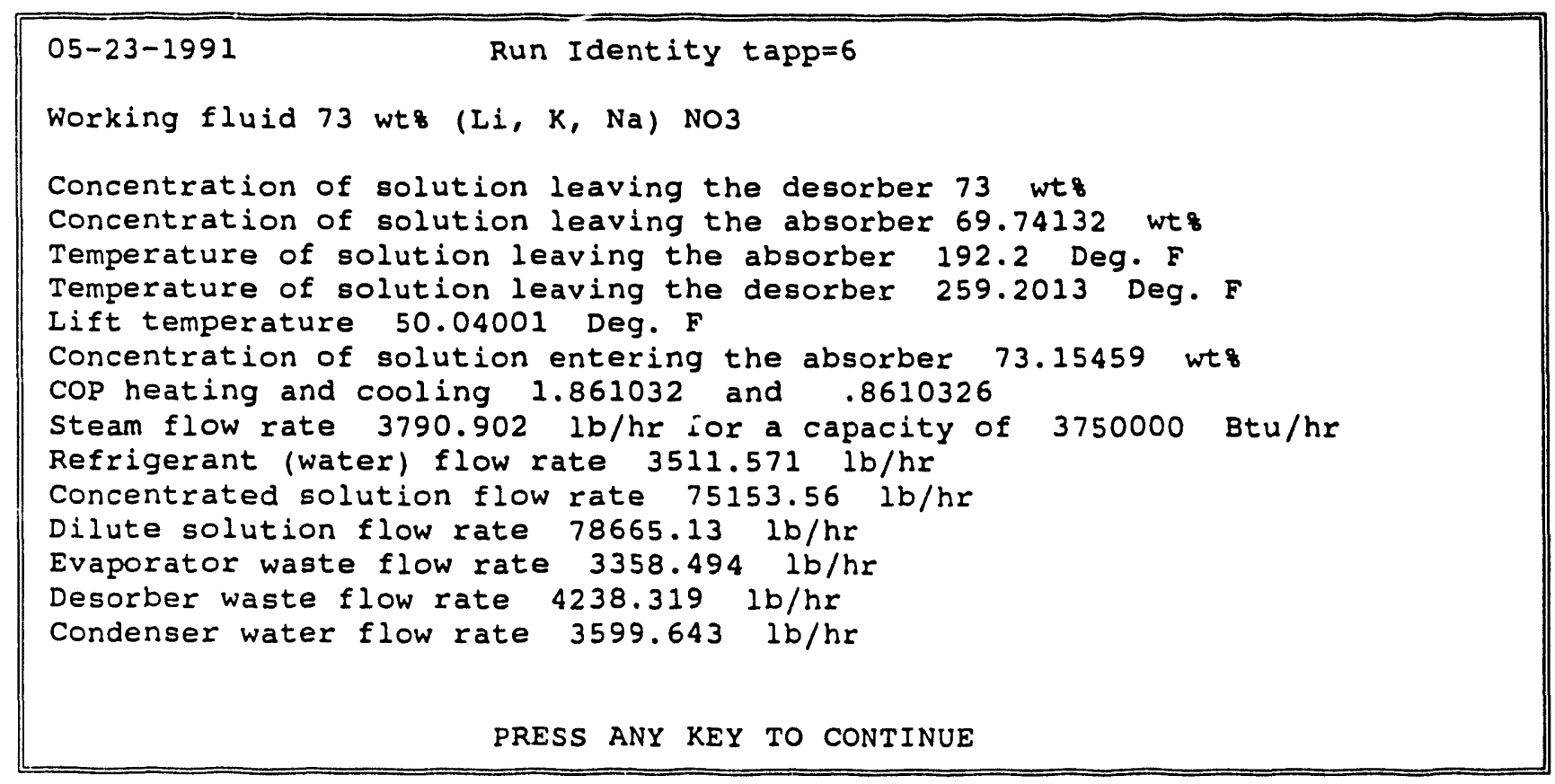




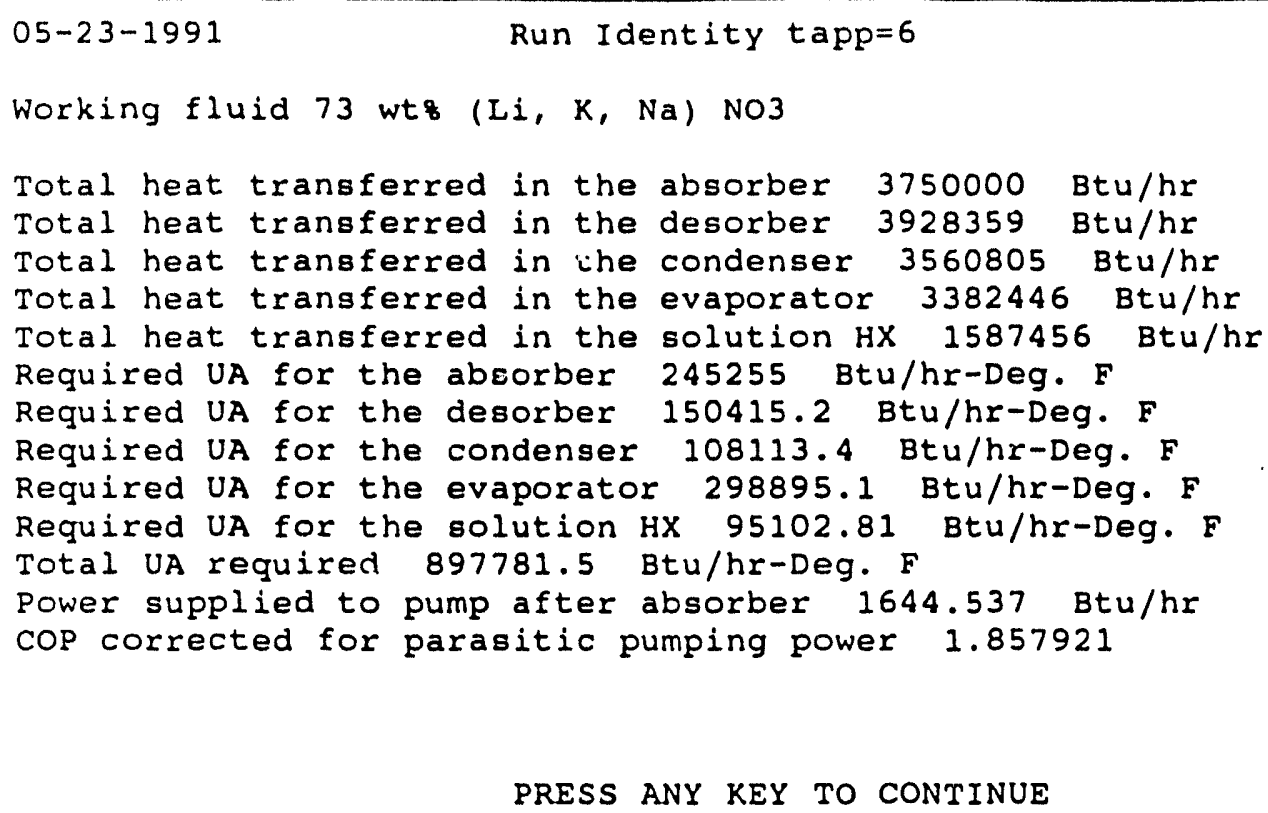

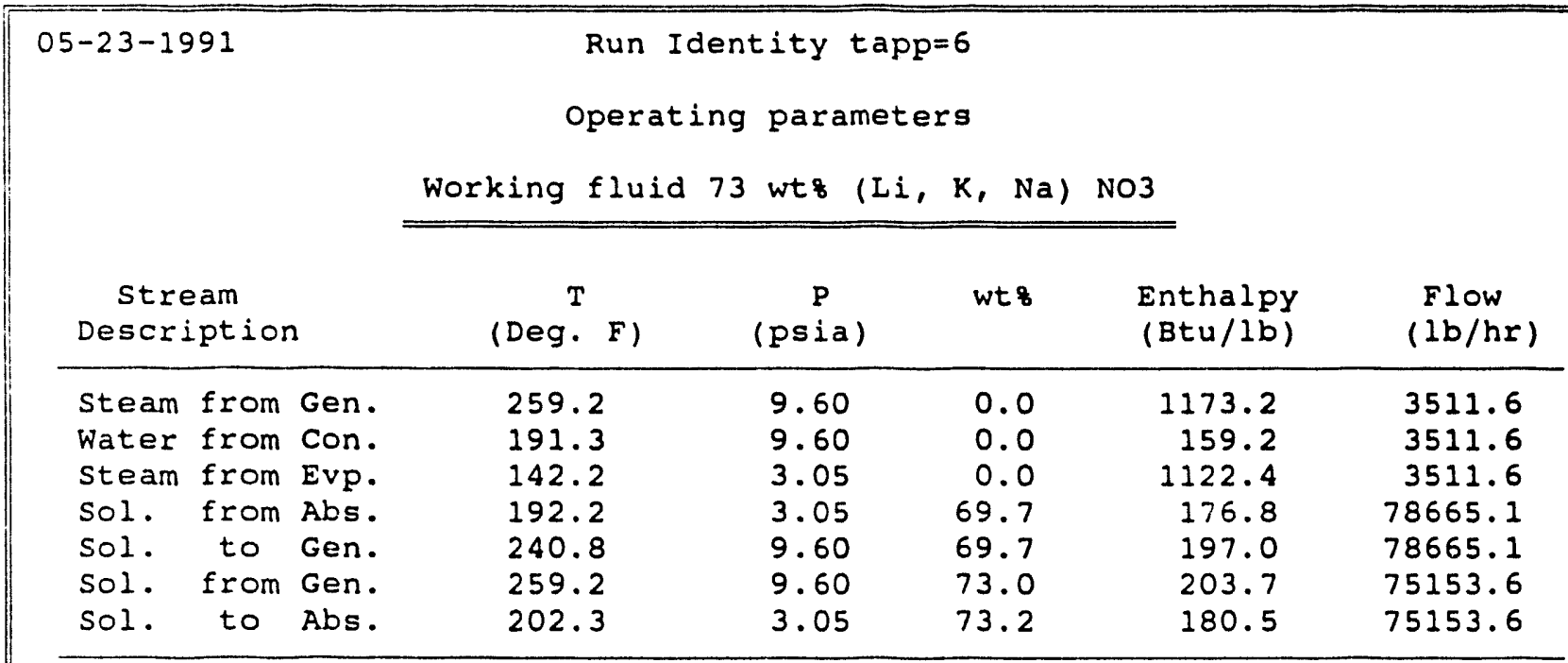




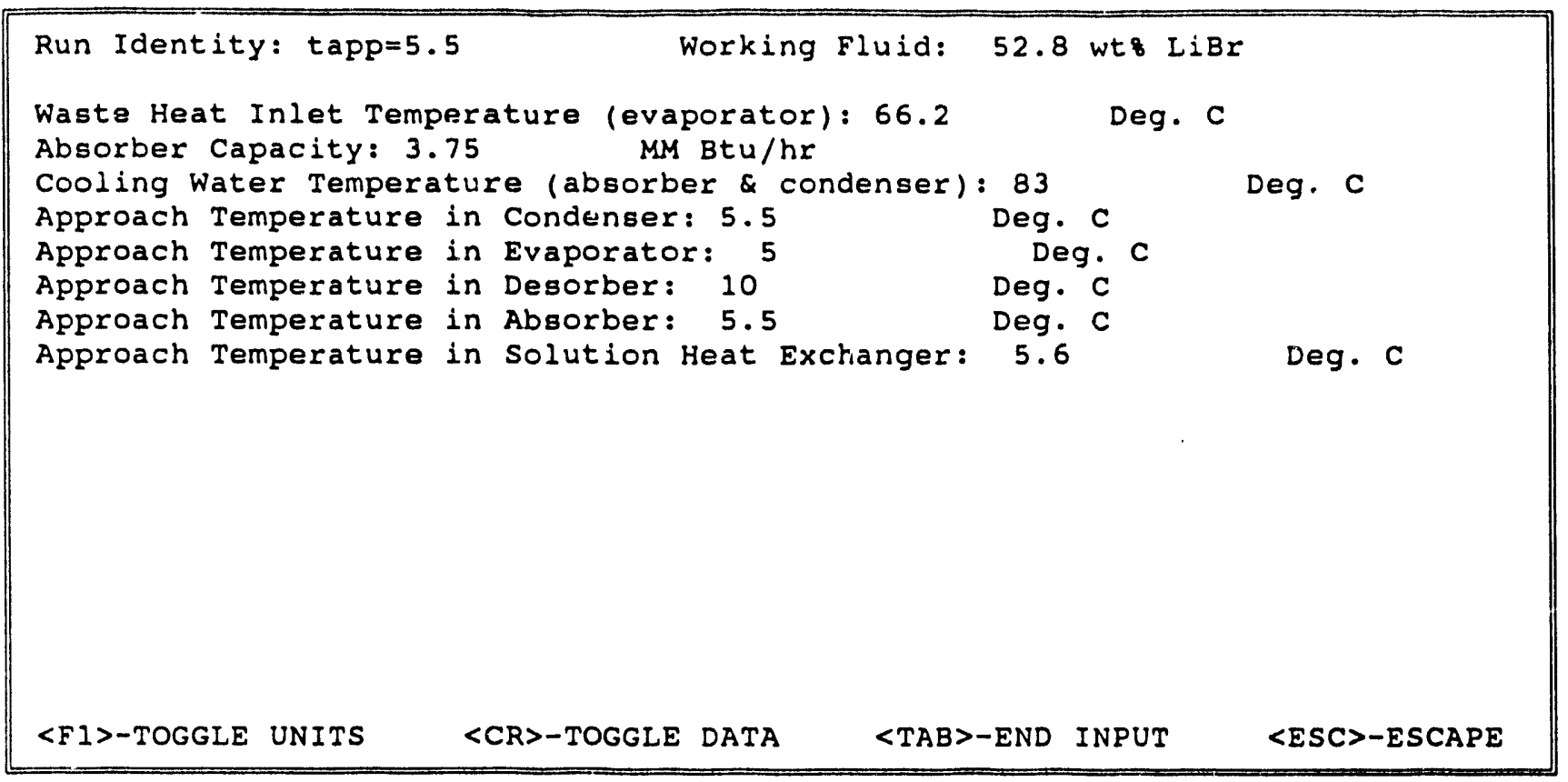

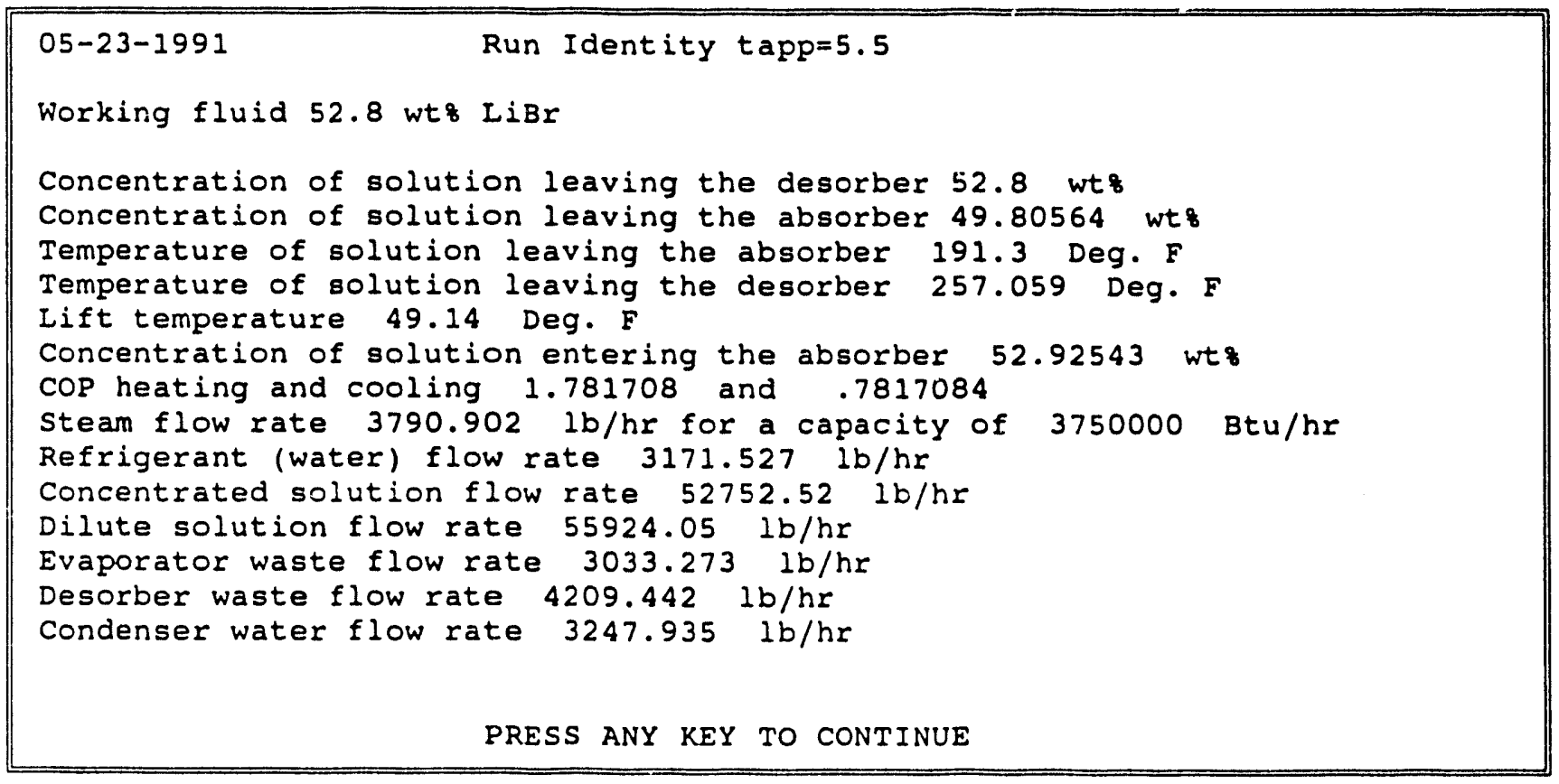




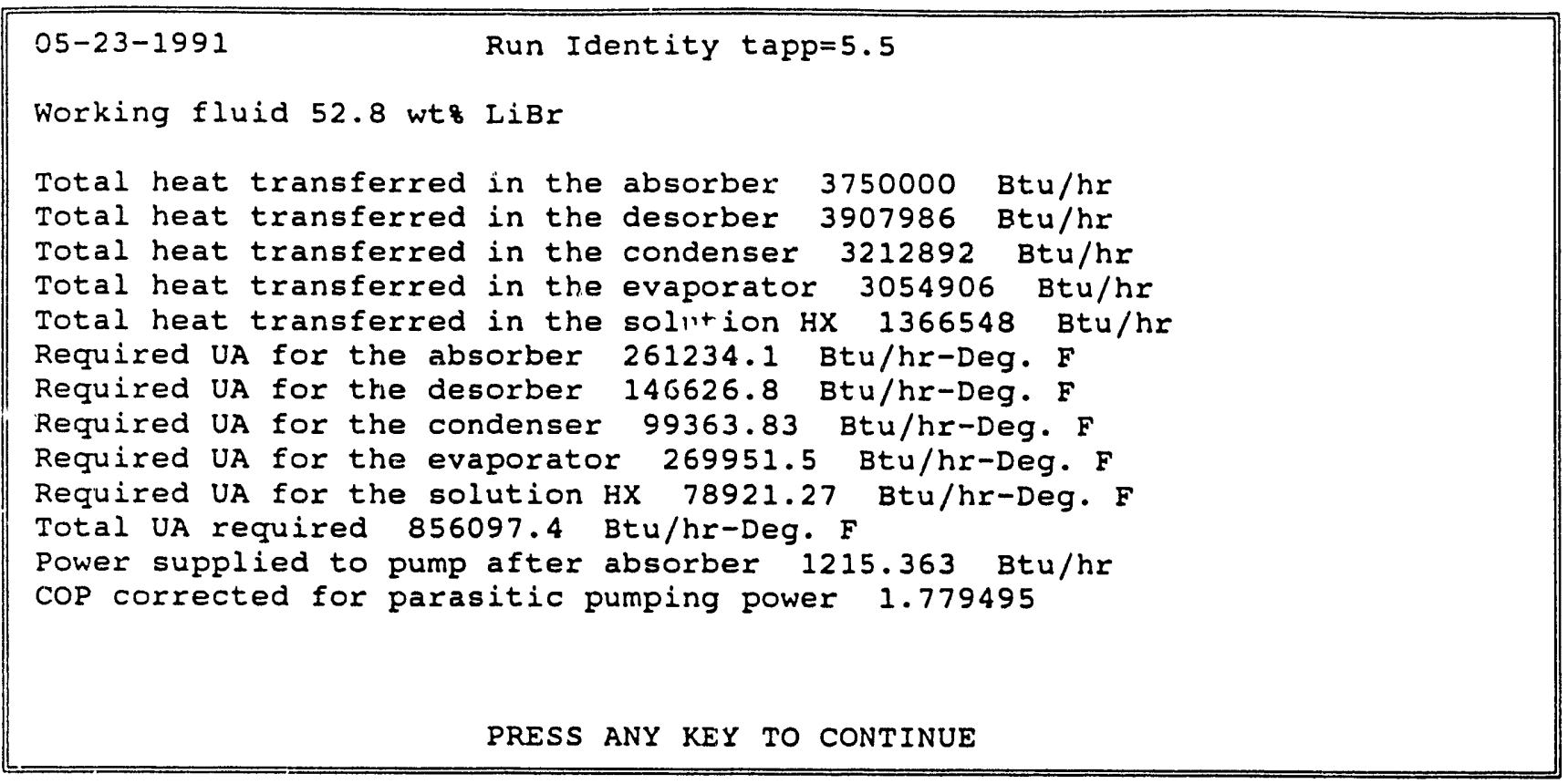

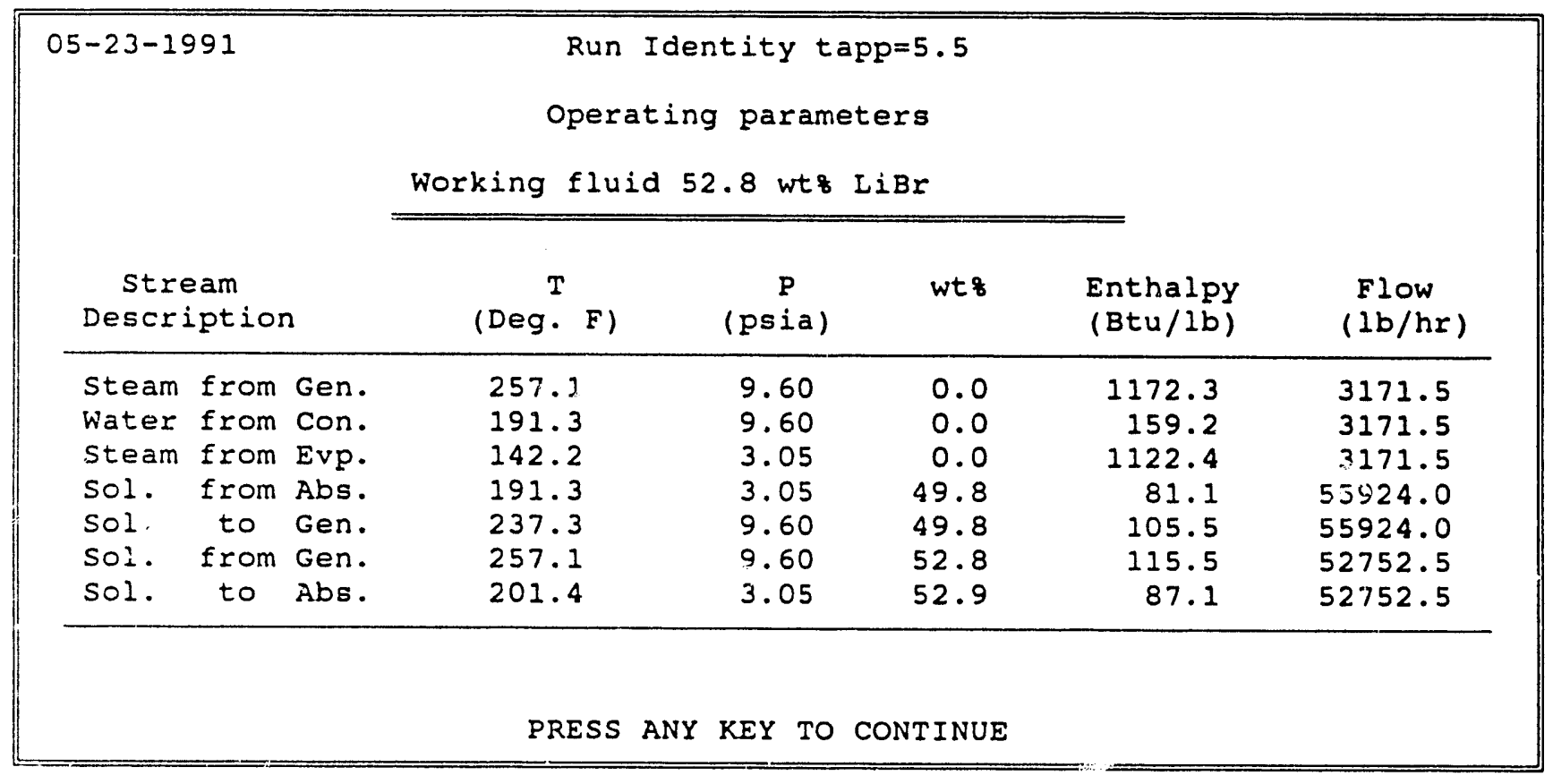




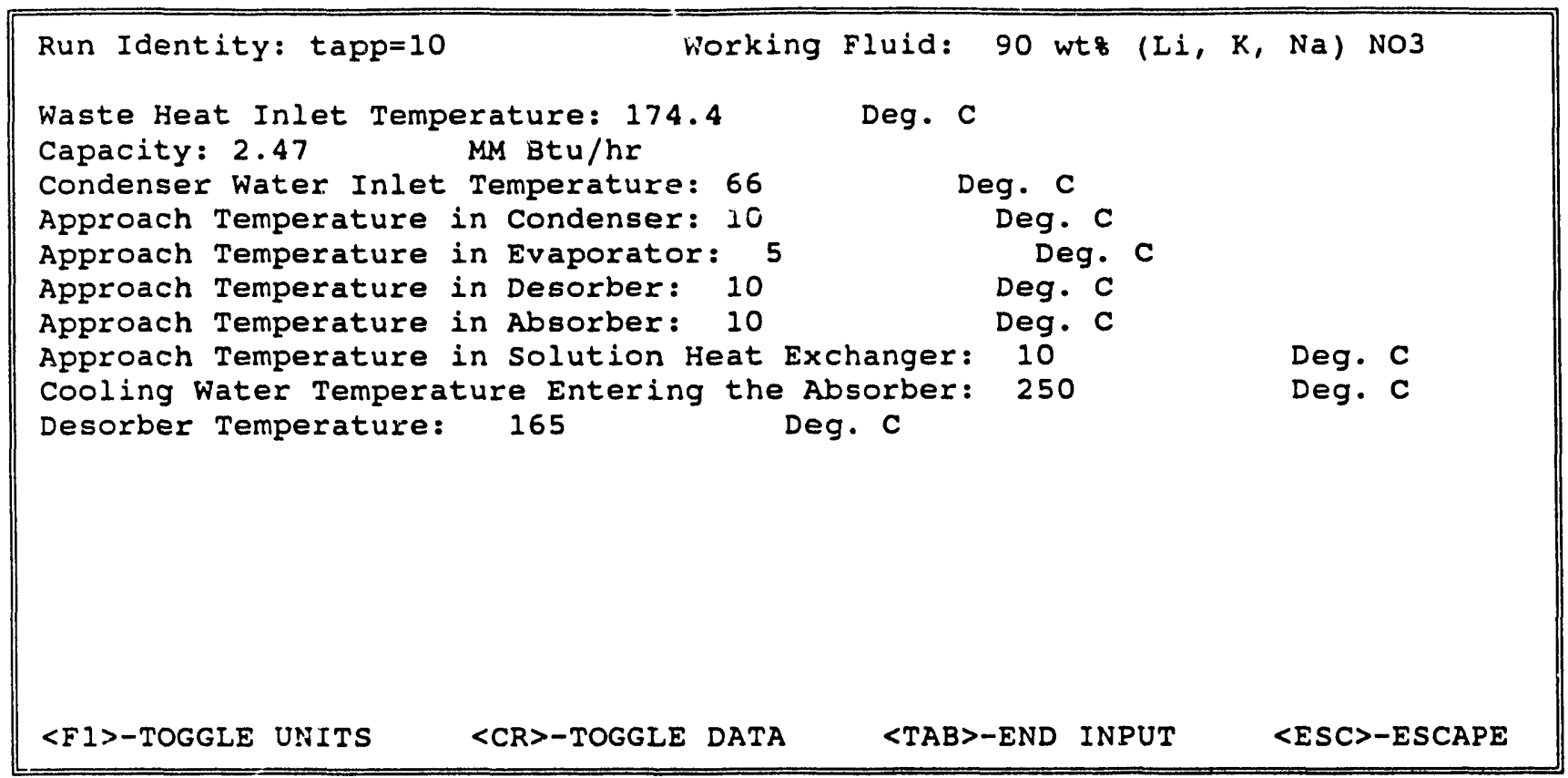

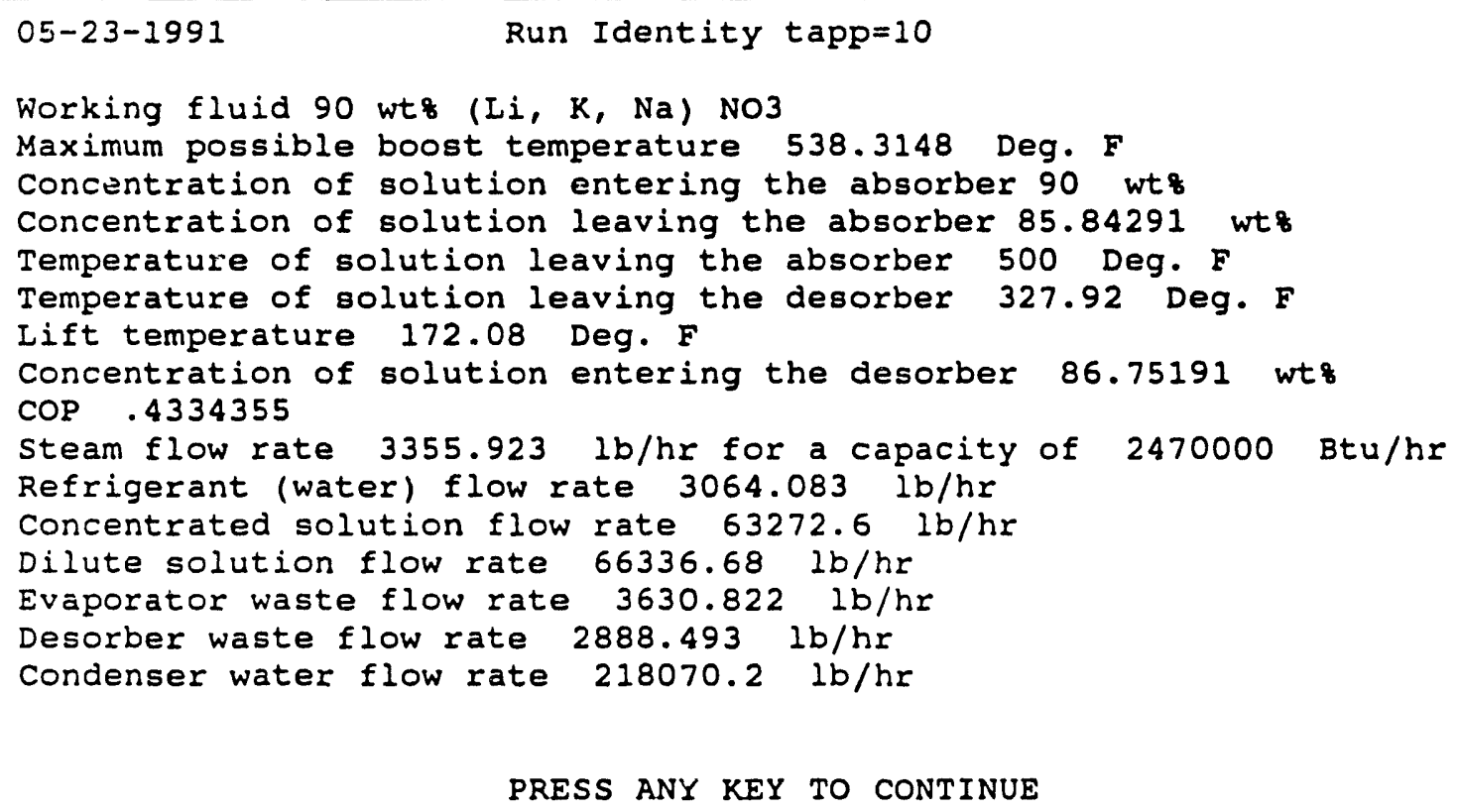




\begin{tabular}{|c|}
\hline 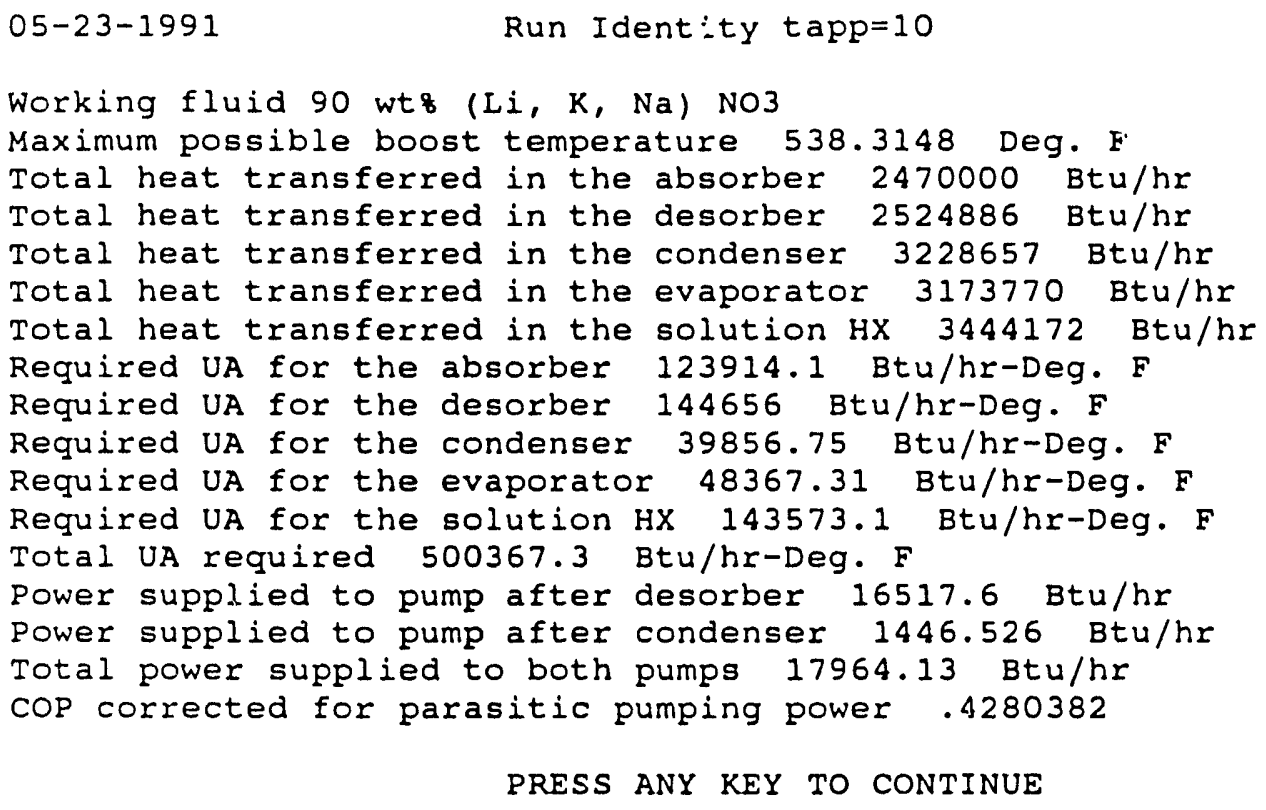 \\
\hline
\end{tabular}

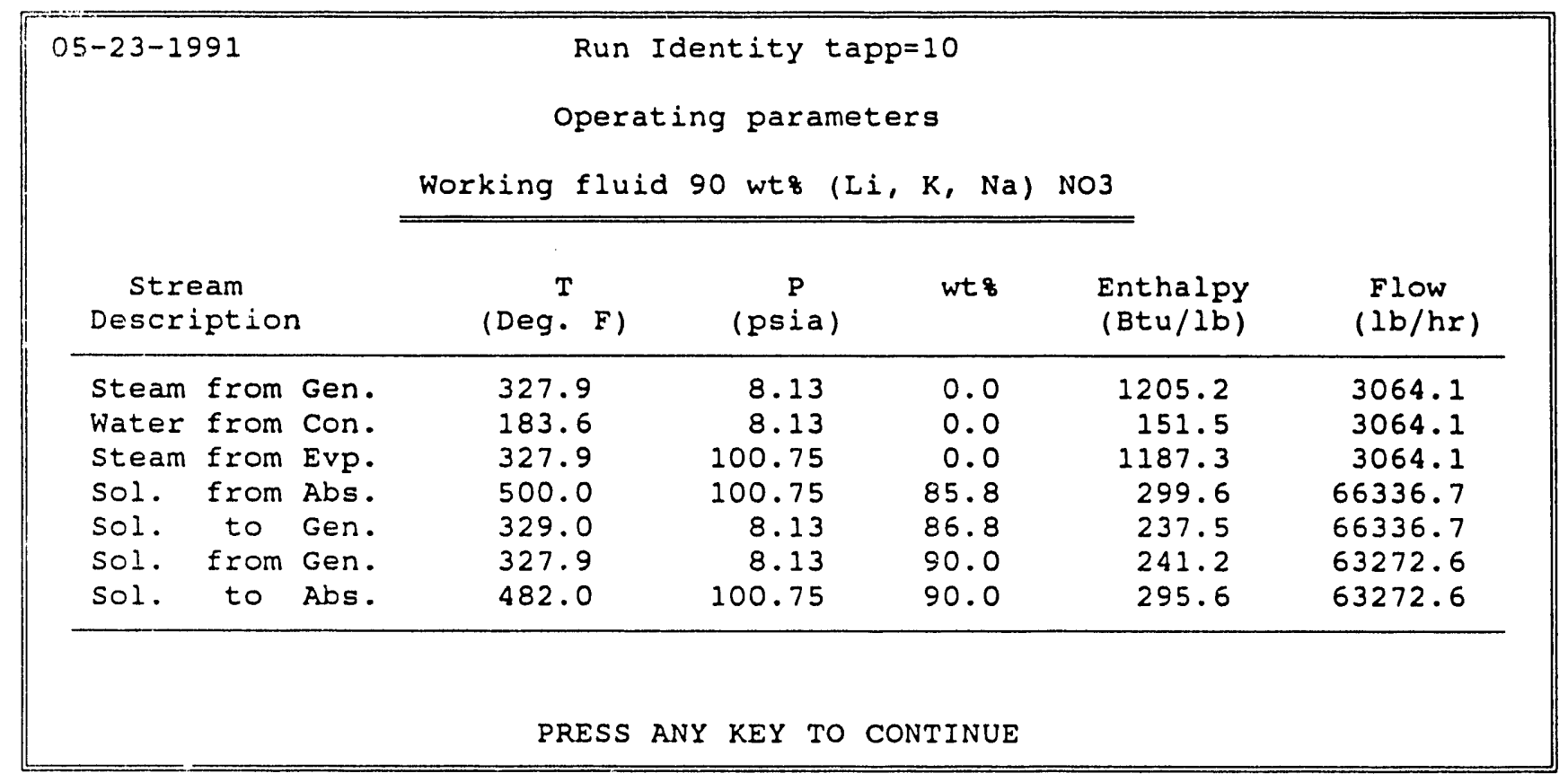




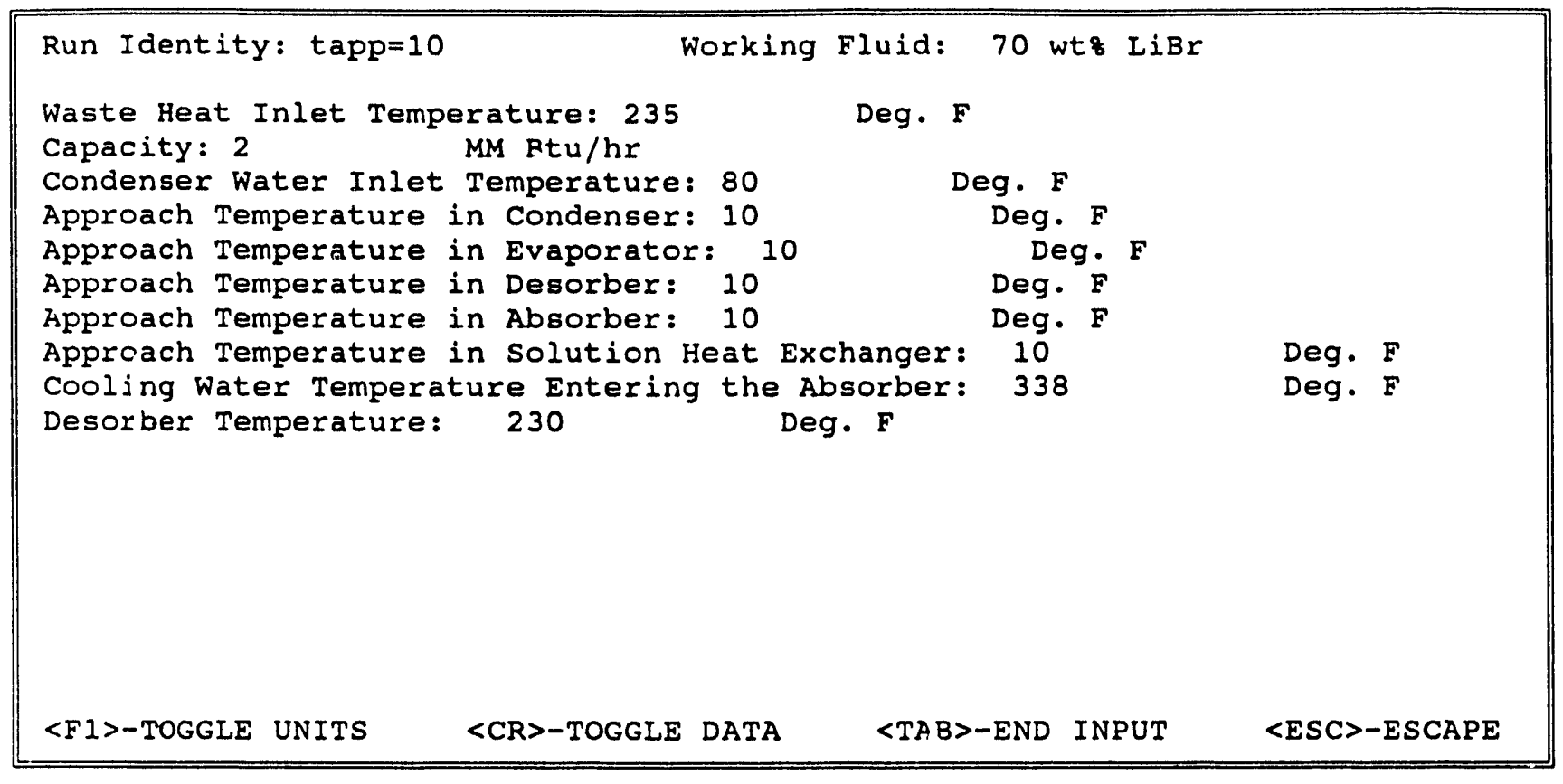

\begin{tabular}{|c|}
\hline 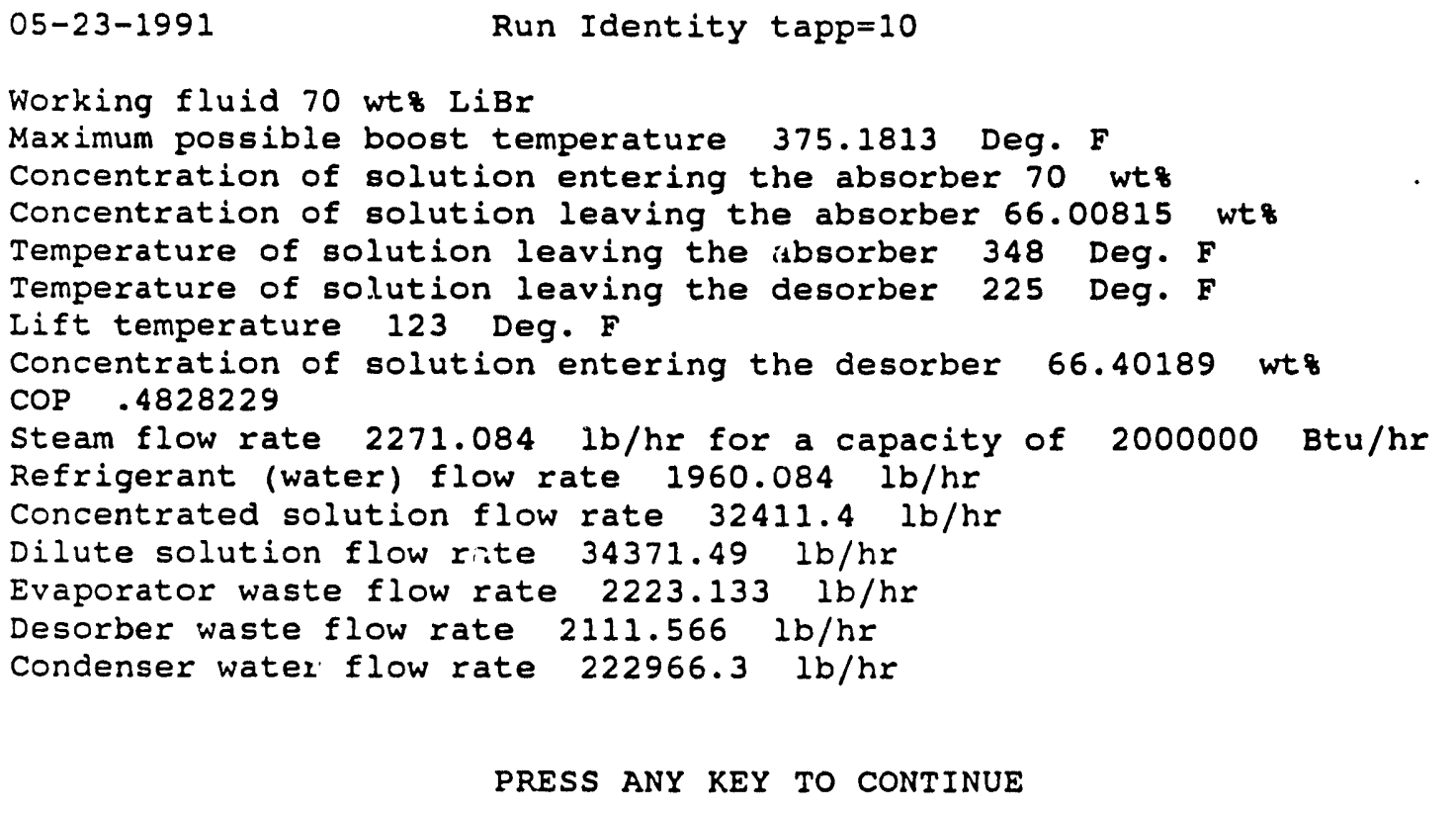 \\
\hline
\end{tabular}




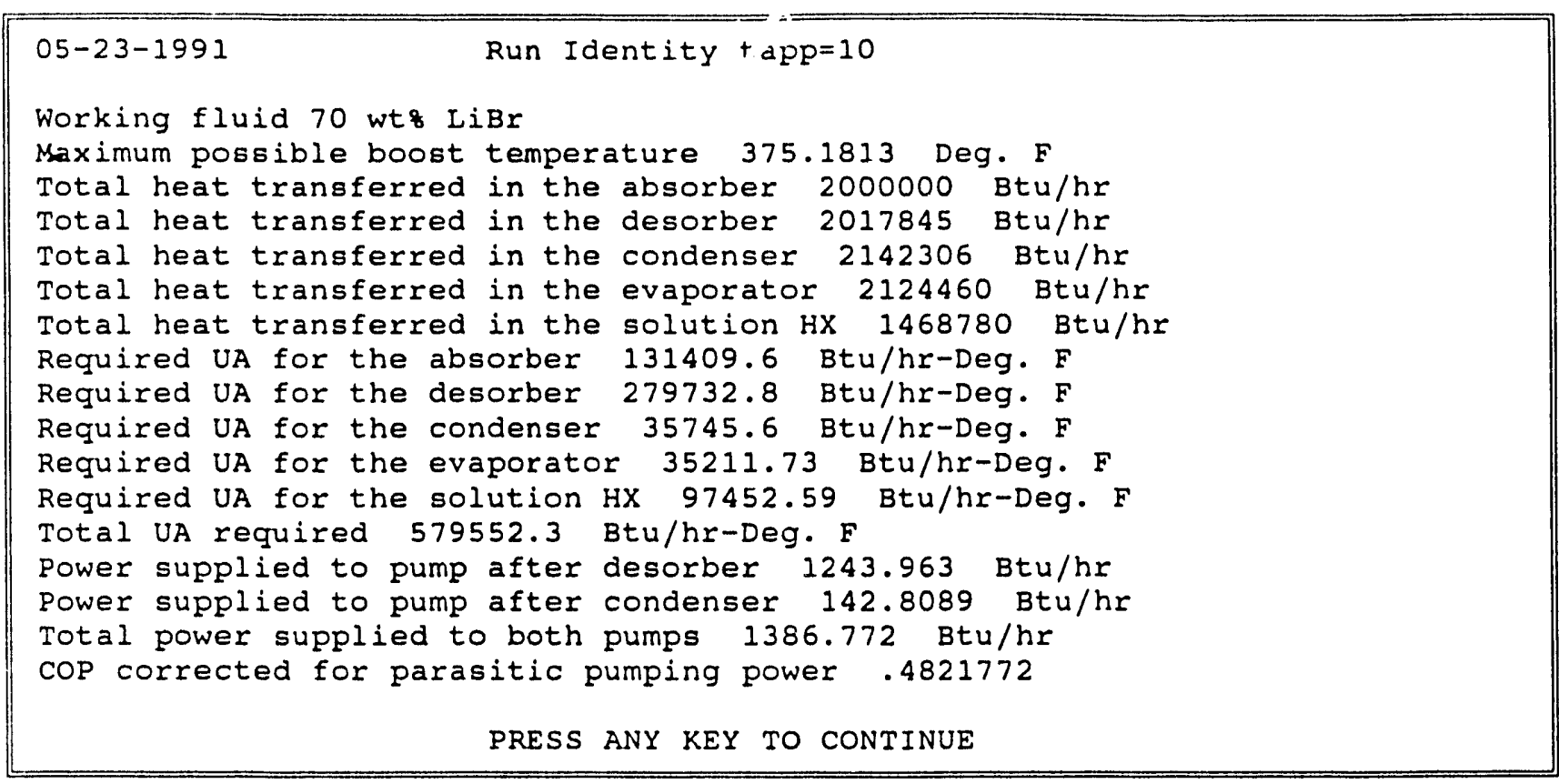

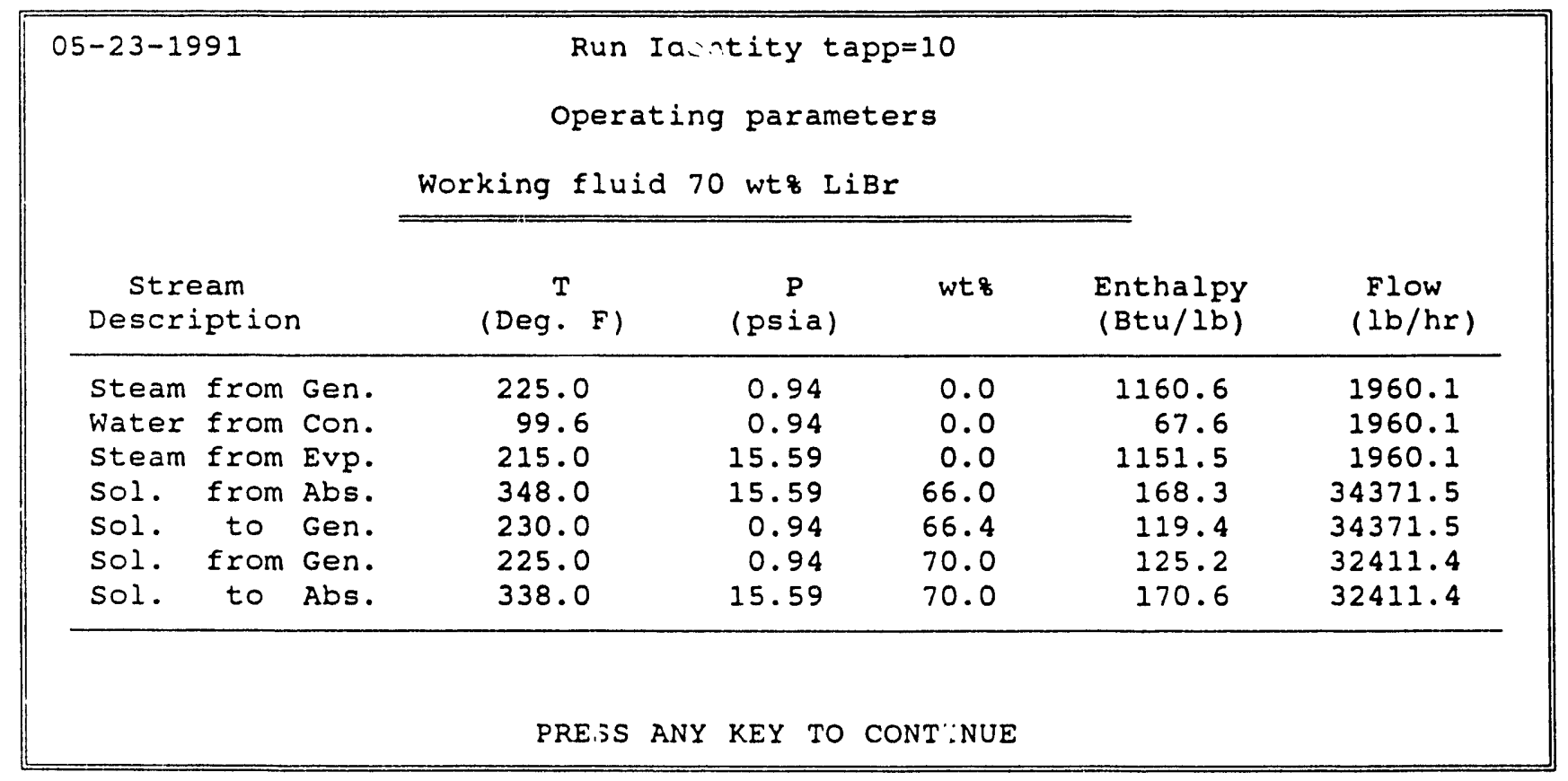


ORNL/TM-11923

\section{INTERNAL DISTRIBUTION}

$\begin{aligned} 1-5 . & \text { A. Zaltash } \\ 5-10 . & \text { M. R. Ally } \\ 11 . & \text { P. S. Gillis } \\ 12 . & \text { R. S. Carlsmith } \\ 13 . & \text { G. E. Courville } \\ 14 . & \text { V. D. Baxter } \\ 15 . & \text { F. A. Creswick } \\ 16 . & \text { R. C. DeVault } \\ 17 . & \text { P. D. Fairchild } \\ 18 . & \text { M. A. Kuliasha } \\ 19 . & \text { V. C. Mei } \\ 20-25 . & \text { R. R. Parks }\end{aligned}$

26. M. R. Patterson

27. D. E. Reichle

28. R. H. Reiner

29. R. B. Shelton

30. J. N. Stone

31. T. J. Wilbanks

32-36. Energy Conservation Dist.

37. ORNL Patent Office

38-39. Central Research Library

40. Document Reference Section

41-42. Laboratory Records

43. Laboratory Records - RC

\section{EXTERNAL DISTRIBUTION}

44. W. Bierman, 45 Foxcroft Drive, Fayetteville, NY 13066

45. B. G. Buchanan, Computer Science Department, University of Pittsburgh, 206 Mineral Industries Bldg, Pittsburgh, PA 15260

46. J. M. Calm, Electric Power Research Institute, 3412 Hillview Avenue, P. O. Box 10412, Palo Alto, CA 94303

47. J. G. Carbonell, Associate Professor of Computer Science, Carnegie-Mellon University, Pittsburgh, PA 15213

48. G. Douglas Carver, TVA, 703 Power Building, Chattanooga, TN 37402

49. R. N. Chappell, Program Manager, Energy Conservation Branch, Energy and Technology Division, DOE Idaho Operations Office, 785 DOE Place, Idaho Falls, ID 83402

50. J. J. Cuttica, Vice President of Research \& Development, Gas Research Institute, 8600 W. Bryn Mawr Avenue, Chicago, IL 60631

51. D. C. Erickson, Energy Concepts Company, 627 Ridgely Avenue, Annapolis, MD 21401

52. R. J. Fiskum, Program Manager, Energy Conservation Equipment Branch, CE-422, Room 5H-048, Department of Energy, 1000 Independence Avenue SW, Washington, DC 20585

53. Joel Gilbert, Dames and Moore, Inc., 7101 Wisconsin Avenue, Suite 700, Bethesda, MD 20814

54. S. M. Gillis, Professor, Public Policy and Economics, Duke University, 4875 Duke Station, Durham, NC 27706

55. G. Grossman, Technion Institute of Technology, Faculty of Mechanical Engineering, Haifa Israel

56. W. T. Hanna, Battelle Columbus Laboratories, 505 King Avenue, Columbus, OH 43201 
57. A. Hirsch, Vice President, Environmental Sciences and Director, Washington Operations, 5129 Leesburg Pk, Suite 414, Falls Church, VA 22041

58. F. R. Kalhammer, Vice President, Electric Power Research Institute, P.O. Box 10412, Palo Alto, CA 94303

59. Alan Karp, Electric Power Research Institute, Energy Management and Utilization Division, P.O. Box 10412, Palo Alto, CA 94303

60. R. E. Kasperson, Professor of Government anc' Geography, Graduate School of Geography, Clark University, Worcester, MA 01610

61. M. Lessen, Consulting Engineer, 12 Country Club Drive, Rochester, NY 14618

62. R. Macriss, Institute of Gas Technology, 3424 South State Street, Chicago, IL 60616

63. L. A. McNeely, 7310 Steinmeier Drive, Indianapolis, IN 46250

64. D. K. Miller, Borg-Warner Air Conditioning, Inc., P.O. Box 1592, York PA 17405

65. J. I. Mills, EG\&G Idaho, Inc., P. O. Box 1625-WCB, Idaho Falls, ID 83415

66. D. E. Morrison, 333 Oxford Road, East Lansing, MI 48823

67. Ralph Nader, Post Office Box 19367, Washington, D.C. 20036

68. H. Perez-Blanco, 314 Mechanical Engineering Bldg., Penn State, University Park, PA 16802

69. B. A. Phillips, Phillips Engineering Company, 721 Pleasant Street, St. Joseph, MI 49085

70. R. Radermacher, University of Maryland, Mechanical Engineering Department, College Park, MD 20742

71. R. C. Reimann, 5504 Ortloff Road, LaFayette, NY 13084

72. S. L. Richlen, Department of Energy, CE-221, 5F-034/FORSTL, Department of Energy, 1000 Independence Avenue SW, Washington, DC 20585

73. U. Rockenfeller, Rocky Research Company, P.O. Box 1086 Boulder City, NV 89005

74. J. D. Ryan, Building Equipment Division, Department of Energy, CE-422, 5H048/FORS, 1000 Independence Avenue SW, Washington, DC 20585

75. D. S. Severson, Gas Research Institute, 8800 West Bryn Mawr Avenue, Chicago, IL 60631

76. S. V. Shelton, Georgia Institute of Technology, Department of Mechanical Engineering, Atlanta, GA 30332

77. J. J. Tuzson, Gas Research Institute, 8800 West Bryn Mawr Avenue, Chicago, IL 60631

78. M. Wahlig, Lawrence Berkeley Laboratory, University of California, Berkeley, CA 94720

79. M. Williams, Professor, Department of Economics, Northern Illinois University, Dekalb, IL 60115

89. Office of the Assistant Manager for Energy Research and Development, Department of Energy, Oak Ridge Operations, Oak Ridge, TN 37831

90-99. OSTI, U. S. Department of Energy, P.O. Box 62, Oak Ridge TN 37831 

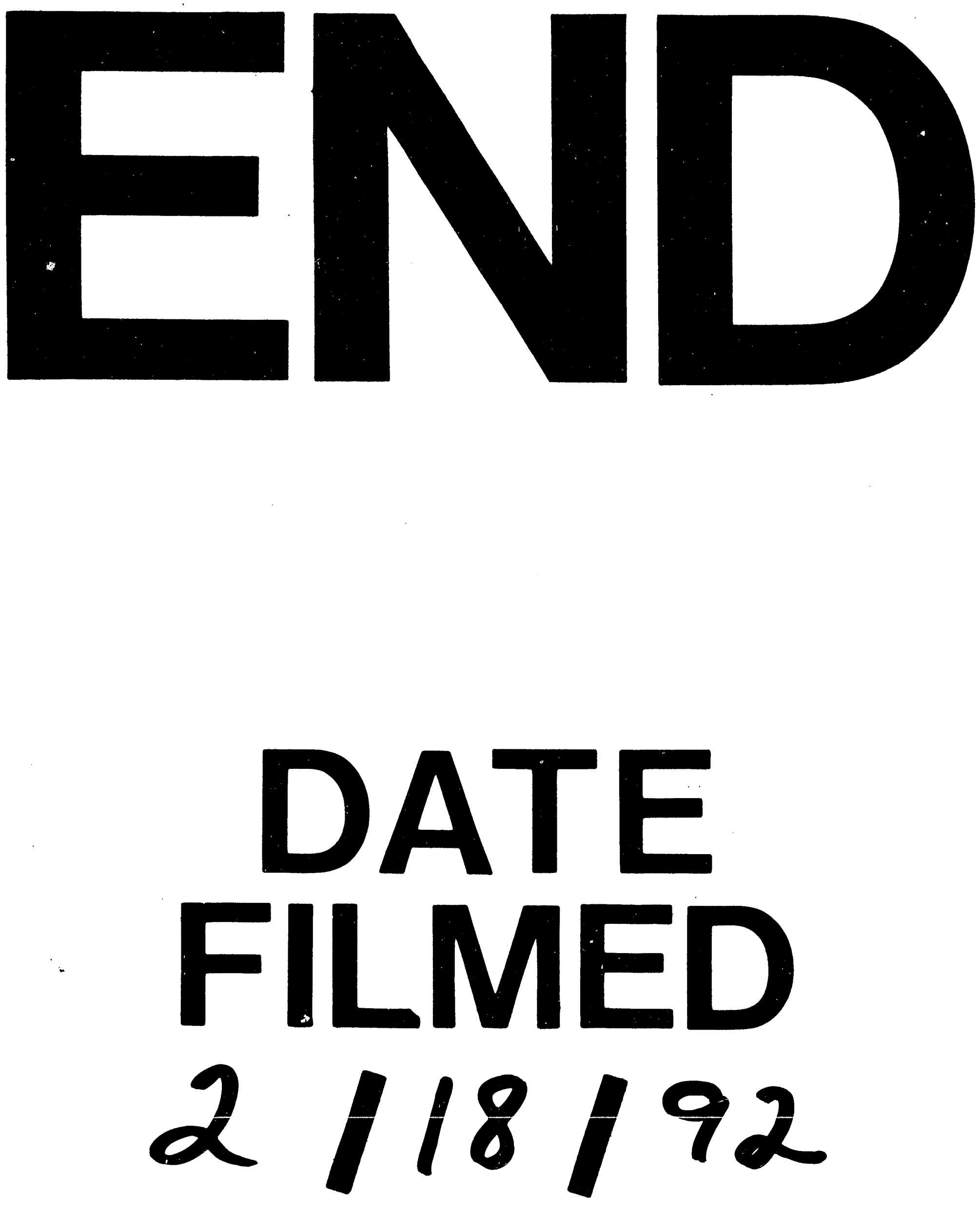
